\title{
The Study of the Forward-Voltage to Junction-Temperature Coefficient Degradation in Light-Emitting Diodes
}

\author{
A Thesis \\ presented to \\ the Faculty of California Polytechnic State University, \\ San Luis Obispo
}

\author{
In Partial Fulfillment \\ of the Requirements for the Degree \\ Master of Science in Industrial Engineering
}

By

Christopher Grasberger

June 2010 
(C) 2010

Christopher Grasberger

ALL RIGHTS RESERVED 


\section{COMMITTEE MEMBERSHIP}

TITLE:

The Study of the Forward-Voltage to Junction-

Temperature Coefficient Degradation in LightEmitting Diodes

AUTHOR

Christopher Grasberger

DATE SUBMITTED:

June 2010

COMMITTEE CHAIR:

Dr. Jianbiao (John) Pan

Associate Professor

Dept. of Industrial and Manufacturing Engineering

COMMITTEE MEMBER: Dr. David Braun

Professor

Dept. of Electrical Engineering

COMMITTEE MEMBER: Dr. Lizabeth Schlemer

Associate Professor

Dept. of Industrial and Manufacturing Engineering 


\begin{abstract}
The Study of the Forward-Voltage to Junction-Temperature Coefficient Degradation in Light-Emitting Diodes

Christopher Grasberger
\end{abstract}

Light-emitting diodes (LEDs) have recently become exceedingly popular in general lighting. As their popularity grows, the demand of more complex and more powerful systems grows as well. While optical characteristics are a crucial component of any lighting product, the main selling point of an LED is their long life and reliability. Unfortunately, the lifetime and reliability of a LED are heavily dependent on the junction temperature of the LED.

Thermal management for LEDs has become an important field study for LEDs. Unfortunately, as the LEDs grow smaller and more integrated, it becomes impossible at times to directly measure their junction temperature. When this occurs, the use of the forward-voltage to junction-temperature coefficient, or Kfactor, can be used to aid in measuring the junction temperature. Often the K-factor value is quoted as a constant, even while the rest of the LED degrades.

This thesis explores the use of the K-factor and attempts to determine if there is a significant change in the $\mathrm{K}$-factor due to degradation. To test this, a custom data acquisition system was built. Two test groups were thermally aged and periodically recalibrated to detect any changes in the K-factor. At the end of the 3000-hour test, one board had failed due to degradation, while the second board did show a statistically significant change in the K-factor; which was slightly more than $10 \%$. 


\section{ACKNOWLEDGEMENTS}

I want to acknowledge all of those people who supported me and were interested in my topic, even if they pretended, as I rambled on about it time and time again. I truly did appreciate you not yawning or letting your eyes glaze over.

I want to thank my parents for helping get to where I am currently in school. They have always made it possible for me to reach my dreams, whatever they were. I want to thank them for the financial support that they gave me so that I could develop all of my electronic projects that allowed me to ultimately design the data collection system for my thesis.

I want to thank Dr. Pan for his support on this project and to thank him for getting me involved with light-emitting diodes. Without him, I would have never written on this topic. He has been a great help to me in developing my thesis and my future career.

I greatly appreciate the time and input that Dr. Braun and Dr. Schlemer have put into this project. With them as thesis committee members it has greatly helped to ensure a well-rounded set of skills to analyze the work in this study.

Finally, I would like to thank Philips LumiLEDs. They provided a great service to this research by donating all of the LEDs . Also, they gave great insight into their products to help guide me. And finally, Philips LumiLEDs helped a great deal by assembling LEDs on metal-cored boards for no charge. 


\section{TABLE OF CONTENTS}

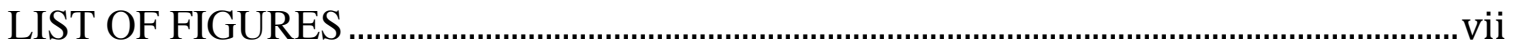

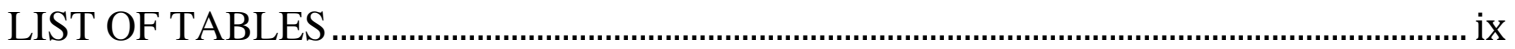

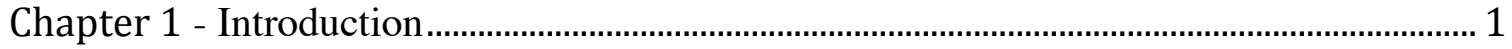

Chapter 2 - Literature Review............................................................................................... 3

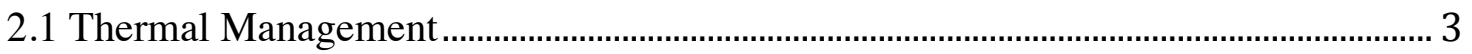

2.2 Forward Voltage Temperature Measurements ……………………………………..... 6

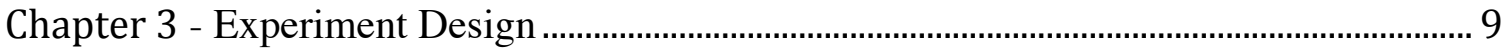

3.1 Data Acquisition System ……………………………............................................... 9

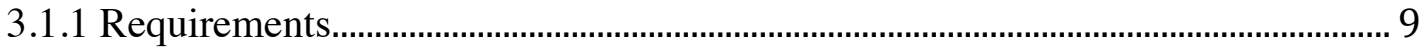

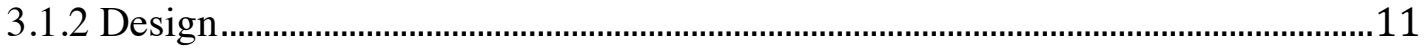

3.1.3 Fabrication ..................................................................................................

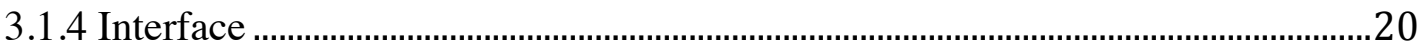

3.1.5 Verification and Calibration..........................................................................................22

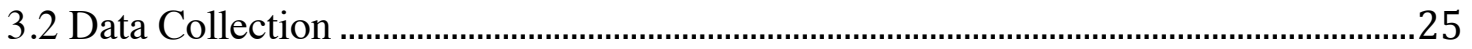

3.2.1 Test Vehicle Design..........................................................................................29

3.2.2 Testing Procedure ..................................................................................................

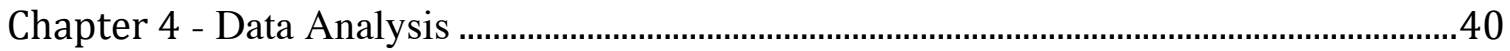

$4.1100 \mathrm{~mA}$ versus $350 \mathrm{~mA}$ and $700 \mathrm{~mA}$ Test Current Data................................................ 41

4.2 K-factor of LEDs aged at $145^{\circ} \mathrm{C}$ (Group A) ………................................................46

4.3 K-Factor Changes for Data Aged at $115^{\circ} \mathrm{C}$ (Group B)...............................................48

4.4 Characteristics of I-V curves ....................................................................................51

4.4.1 Initial I-V Curve Characteristics............................................................................51

4.4.2 Changes in I-V Characteristics due to Aging …………………………………....55

Chapter 5 - Conclusions and Recommendations ……………...........................................63

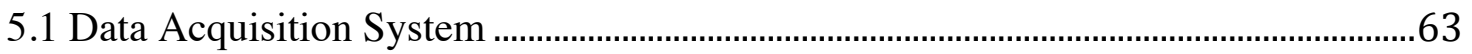

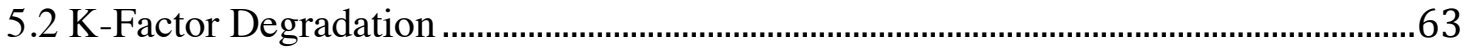

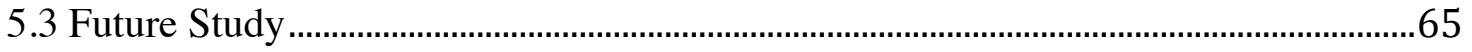

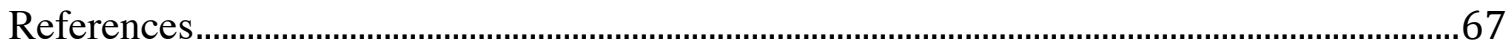

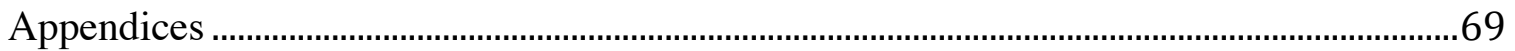

Appendix A - Data Acquisition System.......................................................................69

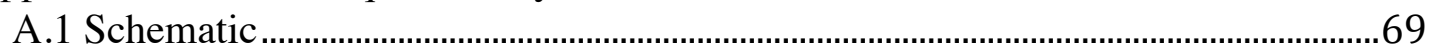

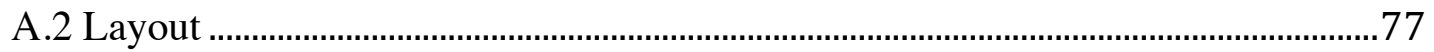

A.3 Pinout from Interface board to NI Breakout Boards ...............................................79

A.4 LabView Interface Screenshots ....................................................................................

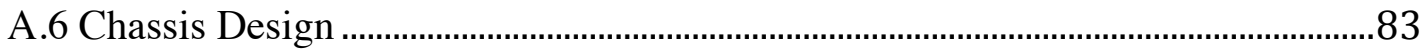

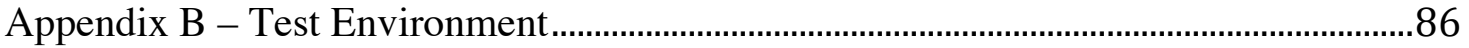




\section{LIST OF FIGURES}

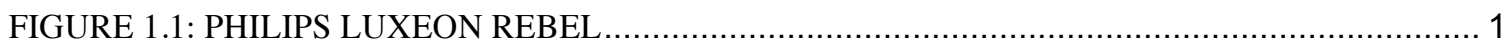

FIGURE 2.1: PHOTOGRAPH OF AN LED THAT IS 235X275X90MM WITH WIRE BONDS............ 4

FIGURE 2.2: EXAMPLE OF A THERMAL RESISTANCE NETWORK FOR A SINGLE LED ............ 5

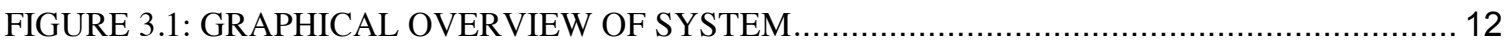

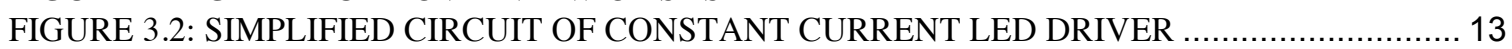

FIGURE 3.3: LINEAR TREND LINE OVERLAID ON DATA TO SHOW INTERCEPT..................... 14

FIGURE 3.4: DISCREPANCY IN LINEAR TREND LINE AND DATA USED FOR INTERCEPT

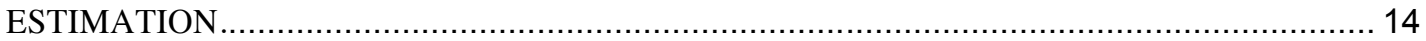

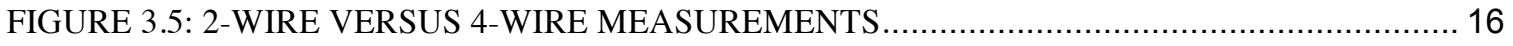

FIGURE 3.6: FINAL REVISION OF THE INTERFACE BOARD IN THE CHASSIS ........................ 17

FIGURE 3.7: SCREEN CAPTURE OF DIPTRACE SHOWING THE TOP LAYER OF THE PCB

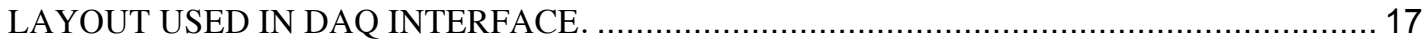

FIGURE 3.8: BOTTOM OF INTERFACE CIRCUIT BOARD SHOWING HEAT SINKS .................. 18

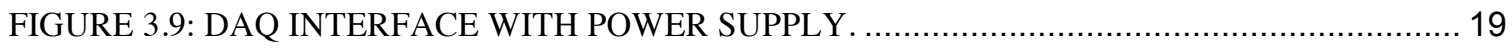

FIGURE 3.10: GRAPHICAL USER INTERFACE DEVELOPED IN LABVIEW TO RUN THE

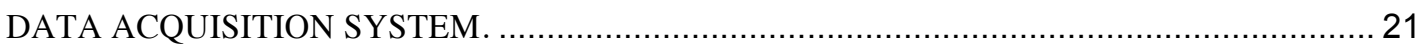

FIGURE 3.11: COMPARISON OF LUXEON REBEL DATASHEET WITH COLLECTED DATA...... 23

FIGURE 3.12: EXAMPLE OF COLLECTED DATA WITH LINEAR TREND LINES. ...................... 26

FIGURE 3.13: PLOT OF HOW THE LED GROUPS WERE FORMED ……................................ 27

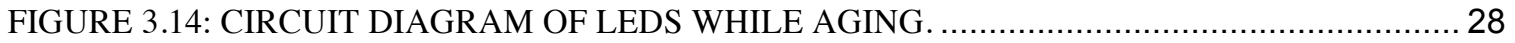

FIGURE 3.15: IMAGE OF PCB VEHICLE AND LINES OF THERMAL SYMMETRY ….................. 29

FIGURE 3.16: THERMAL SIMULATION OF PCB TEST VEHICLE-USING FLOEFD ..................... 30

FIGURE 3.17: PCB LAYOUT OF THE SECOND REVISION OF THE TEST VEHICLE................... 31

FIGURE 3.18: IMAGE SHOWING DETAILS OF PCB TEST VEHICLE FABRICATION WHICH

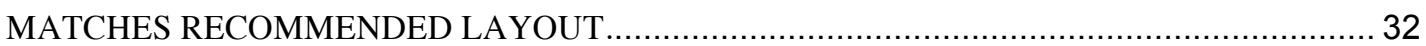

FIGURE 3.19: PCB WETTING VERIFICATION PADS USED FOR SOLDERING. ......................... 33

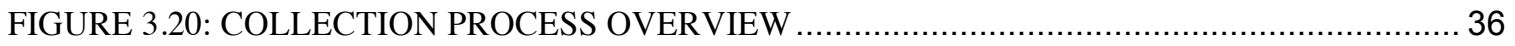

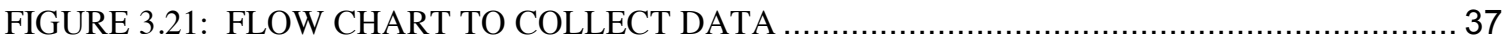

FIGURE 4.1: AVERAGE K-FACTOR VALUES VERSUS TIME. 350 AND 700MA DATA FOLLOWS A LINEAR TREND LINE AS EXPECTED, HOWEVER 100MA DATA IS ERRATIC INDICATING ERRORS AT LOW CURRENT MEASUREMENTS.

FIGURE 4.2: NORMALITY AND RESIDUAL VERSUS FITTED VALUE PLOTS FOR KFACTOR VERSUS TIME AT 100MA, 350MA, AND 700MA. P-VALUE $<0.005$ FOR THE NORMALITY TEST IN EACH CASE INDICATING A LACK OF NORMALITY ..................... 43

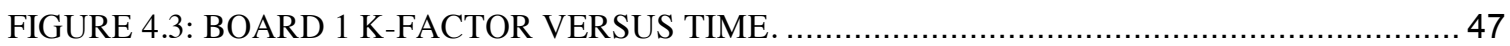

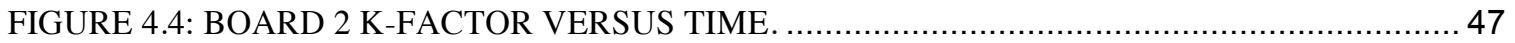

THE 48

FIGURE 4.5: MAIN EFFECTS PLOT FOR K-FACTOR VERSUS BOARD, TIME (HOURS), CURRENT

FIGURE 4.6: RESIDUAL PLOT FOR ANALYSIS OF K-FACTOR VERSUS BOARD, TIME, CURRENT. THE NORMALITY TEST HAS A P-VALUE OF 0.131, WHICH INDICATES

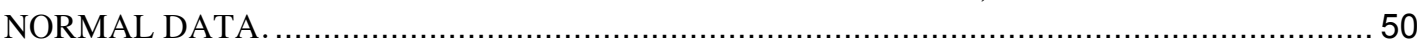

FIGURE 4.7: TYPICAL K-FACTOR PLOT GENERATED FROM COLLECTED DATA....................52

FIGURE 4.8: RECOMMENDED TEST LOCATION USING THERMOCOUPLES ........................... 52

FIGURE 4.9: TYPICAL PLOT OF LED I-V CURVES, AT TIMER ZERO, FOR METAL-CORED PCB USING REFLOW SOLDERING COMPARED TO PHILIPS DATASHEET ...................... 54

FIGURE 4.10: TYPICAL PLOT OF LED I-V CURVES, AT TIME ZERO, FOR FR-4 PCB USING HAND SOLDERING COMPARED TO PHILIPS DATASHEET ........................................ 54

FIGURE 4.11: I-V CURVE OF CONTROL BOARD AVERAGE VALUES. THESE CURVES ARE FROM DIFFERENT TEST POINTS AND COMPARED TO THE DATASHEET. 
FIGURE 4.12: RESIDUAL PLOTS OF AN ANOVA ANALYSIS OF THE CONTROL BOARD SHOWING THE DATA IS NOT NORMALLY DISTRIBUTED. P VALUE FOR NORMALITY TEST WAS $<0.005$

FIGURE 4.13: RESIDUAL PLOTS FOR GROUP A (AGED AT $145^{\circ} \mathrm{C}$ ) FROM AN ANOVA ANALYSIS. THE DATA APPEARS TO BE NORMALLY DISTRIBUTED WITH A P VALUE OF 0.462.

FIGURE 4.14: PLOT OF THE AVERAGE I-V CURVES FOR GROUP A AT DIFFERENT TIMES. ... 59

FIGURE 4.15: PLOT OF THE AVERAGE OF GROUP B (BOARDS 3 AND 4) I-V CURVES VERSUS TIME.

FIGURE 4.16: RESIDUAL PLOT FROM AN ONE-WAY ANOVA FOR GROUP B'S (350MA AGING CURRENT). THE RESULTING PLOTS SHOW THAT THE DATA IS NOT NORMALLY DISTRIBUTED WITH A P-VALUE OF 0.040. 


\section{LIST OF TABLES}

TABLE 4.1: SUMMARY OF EXPERIMENTAL DESIGN.

TABLE 4.2: KRUSKAL-WALLIS TEST FOR K-FACTOR VERSUS TIME FOR THE CONTROL BOARD. THE 100MA TEST CURRENT SHOWS THAT TIME IS SIGNIFICANT, HOWEVER THE 350MA AND 700MA TEST CURRENTS SHOW THAT TIME IS NOT SIGNIFICANT 45

TABLE 4.3: MINITAB ANALYSIS OF K-FACTOR VERSUS BOARD, TIME, AND CURRENT...... 49

TABLE 4.4: ANALYSIS OF THE SIGNIFICANCE OF THE CONTROL'S I-V CURVES VS. TIME. THE ANALYSIS IS BROKEN UP INTO TWO DIFFERENT TEST CURRENT LEVELS, 350MA AND 700MA.

TABLE 4.5: MINITAB ANALYSIS OF GROUP A'S I-V VERSUS TIME. THE RESULTS ARE SEPARATED INTO 350MA AND 700MA TEST CURRENTS. 59

TABLE 4.6: MINITAB ANALYSIS OF GROUP B'S I-V VERSUS TIME. 61

TABLE 4.7: SUMMARY OF RESULTS FOR SECTION 3.2.2..... 62 


\section{Chapter 1 - Introduction}

In the last few years, light-emitting diodes (LEDs) have begun to grow in popularity for general lighting. The claim of greater efficiency and no toxic chemicals, such as mercury, has drawn a great number of customers to the market. This growth of customers has also driven many companies to research LEDs and further the technology.

Originally LEDs were used mostly as indicators. The recent demand of LEDs in general lighting applications such as streetlights and indoor lighting, has created a huge push to increase the amount of light being output from the diode. An example of a newer LED technology for general lighting is the Philips LUXEON Rebel, shown in Figure 1.1. In order to compete with current lighting technologies such as fluorescent tubes, the LED market has to constantly improve the light output of each LED.

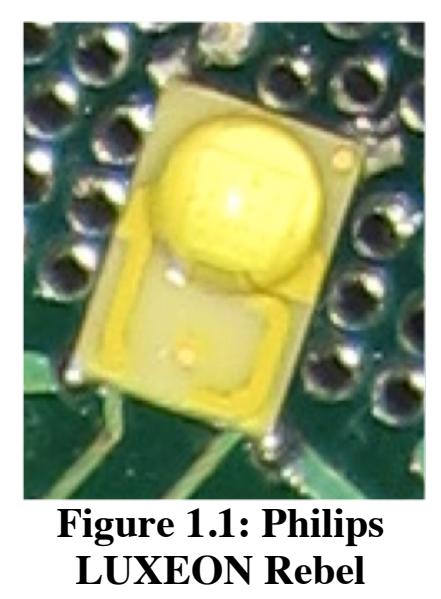

There are two groups attacking the problem of light output. First, the fixture designers have been packing more and more high-powered chips into small areas to get increased overall light output. The other group is the chip manufacturers. Cree, for example, recently announced that they had broken the 200 lumens per watt barrier ${ }^{[1]}$. 
While the chip manufacturers make designers' jobs easier by making each chip work more efficiently, the designers are always pushing the LED chips to their maximum to keep a competitive edge. Even though LEDs are extremely efficient compared to incandescent bulbs, they are not perfect by any means. In fact, most of the power that is put into the diode is still dissipated as heat instead of light output. Also, in contrast to incandescent tubes or halogen bulbs, LEDs do not operate well at high temperatures.

High LED junction temperatures are detrimental in many ways. The first, and most obvious, way that high temperatures can damage an LED is by decreasing its light output permanently. When an LED's light output reaches a certain percentage, typically $70 \%$, the diode is considered to have "failed." Also, high temperatures will tend to cause the diode chip itself to emit a slightly different wavelength of light, which results in a shift in color. Finally, white LEDs use a coating of phosphor on top of a blue LED to emit white light. This phosphor is very sensitive to heat and will degrade rapidly which also causes the light output to change colors. Since heat is so detrimental to LEDs, there is a need for thermal management and characterization of this heat output.

In order to characterize the thermal management solution for an LED product, there needs to be a method to measure temperatures. This thesis analyzes the use of a common way to measure LED junction temperatures via the diode's forward voltage and then attempts to determine if this method works as the diode degrades. 


\section{Chapter 2 - Literature Review}

\subsection{Thermal Management}

Thermal management is a huge part of the LED lighting market. According to

Cree, a majority of LED failure mechanisms are temperature dependant ${ }^{[2]}$. Also, thermal management is a key technology for creating reliable, high lumen, LED systems ${ }^{[3]}$. While thermal management is critical for every LED product, it is often difficult to analyze the thermal characteristics of a product. Since LEDs can last upwards of 100,000 hours, active components such as fans are not an option, as the moving parts of a fan would fail long before the LED does. Additionally, an LED is considered to have failed if it reaches $70 \%$ of its initial light output ${ }^{[4]}$. In fact, Energy Star, a Department of Energy group, requires that luminares used in commercial applications must maintain at least $70 \%$ of initial lumens for 35,000 hours ${ }^{[5]}$. Luminaire manufacturers shall adhere to device manufacture guidelines and test procedures for thermal management ${ }^{[5]}$. Beyond the requirements of the government and chip manufacturers, Underwriters Laboratories, commonly called UL, enforce that a fixture surface exposed to being touched may not exceed $90 \mathrm{C}^{[6]}$ as one of many criteria to receive their safety approval.

Since LED products are now being heavily regulated for safety and quality, it is the job of the thermal engineer to ensure that the chips do not overheat. Each chip manufacturer attempts to help the problem by using an innovated packaging mechanism. Philips LumiLEDs, for example, uses Gold-Gold Interconnects (GGI) ${ }^{[7]}$ to improve thermal performance of their packages. Additionally, the chips can be directly mounted to the heat sink as shown in Figure 2.1. Once the heat is conducted to the heat sink, it 
must be able to transfer thermal energy from the solid to the ambient air. This is called convection, which is composed of two mechanisms: diffusion and bulk fluid motion, ${ }^{[8]}$ or in other words non-stagnant air. Additionally, there is radiation, which can be extremely complicated. Radiation does contribute to the dissipation; however for the sake of simple models, it is sometimes ignored. The input power from the LEDs, the heat sink, and the moving air all are highly variable from design to design. In order to characterize this, properties of the problem must be understood.

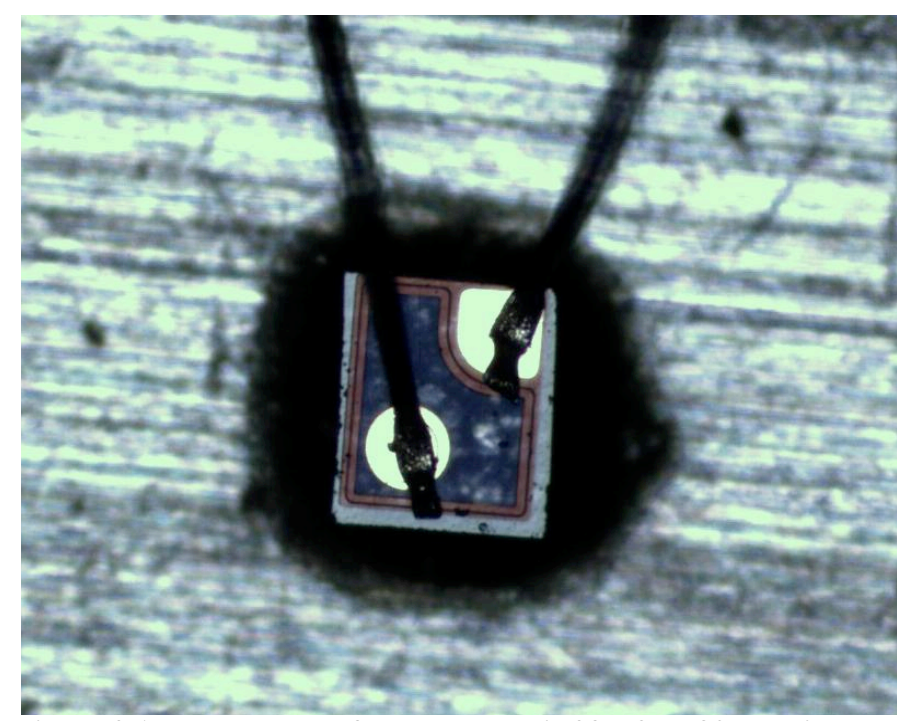

Figure 2.1: Photograph of an LED that is $235 \times 275 \times 90 \mu m$ with wire bonds.

Thermal analysis of basic fixture designs can be modeled as a resistor network. Where temperature is analogous to voltage, input power (Watts) is analogous to current, and thermal resistance is analogues to electrical resistance ${ }^{[8]}$. Figure 2.2 shows how a fixture with a single LED and a heat sink can be converted into a resistance model. Once the model has been developed, values need to be determined. The ambient air temperature can typically be easily measured. The input power can be determined as well and the thermal resistance of the LED package is specified in the datasheet $\left(\mathrm{R}_{\mathrm{LED}}\right.$ in Figure 2.2). However, this still leaves three critical values that cannot be determined 
easily. The first is the thermal resistance of the heat sink, second is the convection coefficient, and the last is the junction temperature of the LEDs. If the junction temperature could be measured, the thermal resistance of the heat sink and convection coefficient could be lumped together which would give insight into the effectiveness of the heat sink design.

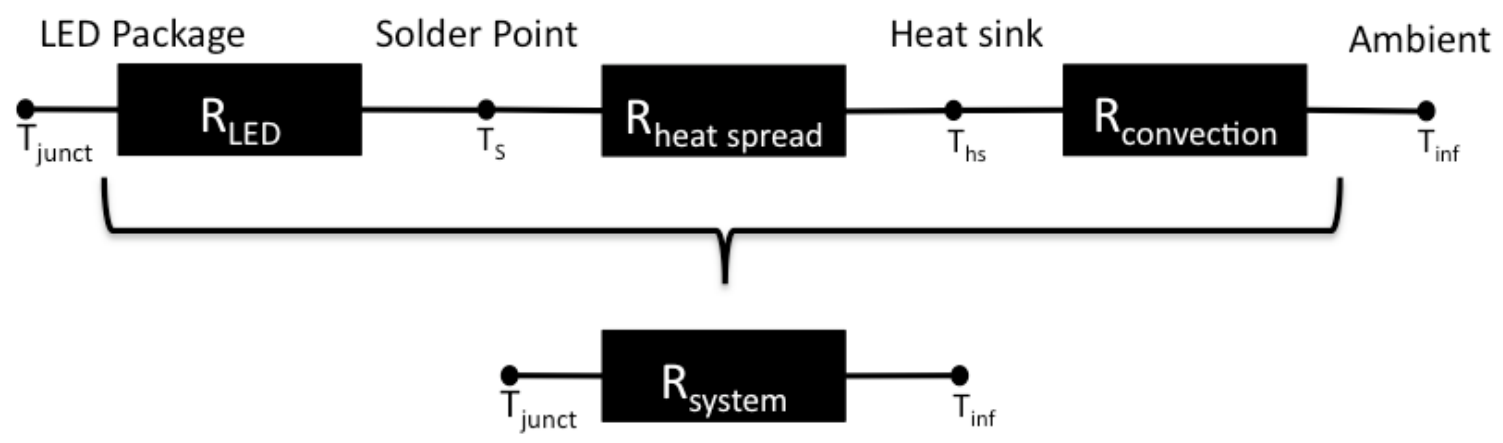

Figure 2.2: Example of a thermal resistance network for a single LED

The junction temperature of an LED is critical because this is the junction between the positively doped region and the negatively doped region. When the electrons begin to flow across the device, there is a voltage drop across the gap. As the energy crosses the gap light is emitted, but also heat is emitted. This region can be very small and often the junction is covered by a lens or phosphor. To use a thermocouple would be ill advised on the junction because the probe would measure the local air more than the junction. There are a myriad of ways to measure a LED's junction temperature. However, a relatively simple and accurate way to measure the junction temperature is to use the forward voltage of the diode. 


\subsection{Forward Voltage Temperature Measurements}

A relationship between the forward voltage of a diode (not just LEDs) and the junction temperature of a diode exists. While it is unclear if it is the average temperature of the junction or if it is the maximum, it still gives a measurement of an otherwise difficult value to measure. Some additional complexities exist; however this process is fairly well understood and is used in other industries.

The use of the forward-voltage to junction-temperature coefficient (or K-factor) has widely been used in the thermal characterization of heat sink solutions for CPUs. A simulation chip package, the size of the CPU, is built with one or more diodes in the package. The desired amount of power is applied to the package via a power resistor or the test diode itself. Using the diode as a temperature measurement, the characterization of the heat sink design can be performed.

If one looks at the ideal diode equation there is a correlation between the current $(\mathrm{J})$, voltage across the diode $\left(\mathrm{V}_{\mathrm{D}}\right)$, and the temperature $(\mathrm{T})$. Values for $\mathrm{q}$ (charge of an electron) and k (Boltzmann constant) are constants. The ideality factor (n) is typically in the range of 1 to 2; however to fit this model to a LED like the LUXEON Rebel, the value is closer to 3, which exceeds the expected range. Equation 2.1 shows the equation, which is also known as the Shockley Ideal Diode Equation.

$$
J=J_{s}\left(e^{q V_{D} / n k T}-1\right)
$$


If Equation 2.1 is reorganized, and $\mathrm{J}_{\mathrm{s}}$ is assumed to be approximately constant, then a simple derivative of diode voltage with respect to temperature can be taken. Equation 2.2 shows the result of this simplified equation.

$$
\frac{d V_{D}}{d T}=n k \ln \left(\frac{J}{J_{S}}+1\right)
$$

Equation 2.2: Derivate with respect to time of Shockley Ideal Diode Equation to show current dependence on K-factor

While Equation 2.2 does not include all of the detail of the saturation current $\left(\mathrm{J}_{\mathrm{S}}\right)$, it does show how the current being applied to the diode does play a role in the value of the Kfactor $\left(\mathrm{dV}_{\mathrm{D}} / \mathrm{dT}\right)$.

Equation 2.2, as mentioned previously does not account for the dependence on temperature in the saturation current. While there is a degree of dependence, it is not terribly significant. The equation that describes the saturation current is shown in Equation 2.3. This equation is taken from the JEDEC (formerly known as Joint Electron Devices Engineering Council) standard for electrical temperature measurement ${ }^{[9]}$.

$$
J_{s}=M * T^{m} e^{-V_{G 0} * q / n k T} \quad \begin{aligned}
& \text { Equation 2.3: Equation to express the } \\
& \text { saturation current }
\end{aligned}
$$

Since the K-factor (or $\mathrm{dV}_{\mathrm{D}} / \mathrm{dT}$ ) is not significantly temperature dependant, the JEDEC standard states that a change in voltage multiplied by the K-factor results in a change in temperature or Equation $2.4^{[9]}$. Y. Xi and E. F. Schubert also state that experimental $\mathrm{V}_{\mathrm{f}}$ versus $\mathrm{T}$ relationship is very close to linear and can be fitted by Equation 2.5 where $\mathrm{T}_{0}$ is the oven temperature and $\mathrm{A}$ and $\mathrm{B}$ are fitting parameters ${ }^{[10]}$. The $\mathrm{B}$ fitting parameter is also the K-factor.

$$
\Delta \mathrm{T}=(\mathrm{K} \text {-factor }) \times \Delta \mathrm{V}_{\mathrm{F}} \quad \begin{aligned}
& \text { Equation 2.4: } \text { K-factor equation } \\
& \text { recommended by JEDEC }
\end{aligned}
$$




$$
\mathrm{V}_{\mathrm{f}}=\mathrm{A}+\mathrm{BT}_{0}
$$

Equation 2.5: Linear model using K-factor

[10]

This measurement system is widely used and many expensive tools have been developed to measure the K-factor for testing. Unfortunately, LED chip manufacturers do not specify how this property degrades over time. It is very well known that optical properties and other properties, such as internal resistance, will change over time. It would therefore not be unreasonable to hypothesize that the K-factor will also change as the LED degrades. According to LumiLEDs, it does change as the LED degrades. However, there is no research available to the public to this author's knowledge. Since there is a lack of data available on this topic, my thesis is to determine if there is a significant change in the K-factor during degradation. 


\section{Chapter 3 - Experiment Design}

In order to collect data to test the hypothesis, two distinct stages were required. First, a data acquisition system capable of measuring the K-factors was required. Second, the physical data collection was required.

\subsection{Data Acquisition System}

The development of the data acquisition system (DAQ) was an enormous undertaking on its own. Fortunately, the requirements, designs, and testing procedure developed for this thesis had begun long before the topic was ever chosen with the intention of building a commercial handheld tool. The following sections give a brief outline of the design process for the DAQ. Detailed descriptions of components can be found in Appendix A.

\subsubsection{Requirements}

Like any project or system, there are a number of constraints that must be all solved at once. This DAQ was no different. Unfortunately, to enumerate all of the requirements for the data collection system would result in a report on its own. However, this project, like any other, has a few notable ones that will be elaborated on. Measuring a LED's K-factor requires a rapid activation and measurement to avoid self-heating of the 
diode. This requires a high speed switching system to turn on and off the LED. Additionally, the analog-to-digital converter (ADC) must be quick enough to gather samples during the time the LED is on. Also, this DAQ must be able to calibrate a diode over a large range of currents and handle multiple LEDs.

The longer a diode is left on, the closer to a steady state temperature it will become. However, when calibrating a diode, it must be calibrated with as little internal heat generation as possible. This is done so that the measured data point is effectively the oven temperature. This problem is compounded by the fact that in order to measure a forward voltage across a diode, the diode must be energized. While the voltage only varies slightly, there is a large range of currents that can be applied to the LED. Considering the worst-case input power condition, which is 1A for the LEDs being tested, an estimation of a maximum pulse length can be obtained. This results in a value around 200 microseconds before the internal heat generation becomes noticeable.

In conjunction with high speed switching, a high-speed data acquisition system is required. A speed on the order 1 million samples per second was required so that a reasonable amount of data can be collected on the diode before it is turned off. There is a tradeoff between speed, accuracy, and cost. At a minimum, 16 bits is required to get reasonable resolution at $1 \mathrm{mV}$ with a $5 \mathrm{~V}$ reference. Ideally, 18 bits would be desired. Also, the analog-to-digital converter (ADC) selected to do this measurement must be simple enough that the entire project is not delayed due to the details of implementing the ADC.

The system also must be able to measure various currents since the forwardvoltage to junction-temperature coefficient (K-factor) is dependent on current (see 
Equation 2.2). The testing of many currents would be useful as the diode may possibly degrade differently with different currents. Many single-chip high-brightness LEDs have a maximum operating current of $1 \mathrm{~A}$. Running anything at its maximum current for long periods time, whether it is an LED or LED driver, may cause damage to the component. Therefore this system must be able to handle $1 \mathrm{~A}$ for long periods of time in the event it needs to drive a LED instead of simply pulsing it. Additionally, it must be able to handle lower currents such as 20 or $100 \mathrm{~mA}$ to ensure a wide measurement range.

Finally, the DAQ must be able to measure multiple LEDs to collect data faster. It is impractical to repeatedly open the oven to rewire the LEDs. Each time the oven is opened; there is a long wait to allow the oven to return to a steady state temperature. This creates the requirement of interfacing at least eight diodes at once.

\subsubsection{Design}

The final data acquisition system design consisted of integrating a National Instruments M-Series PCI Card (model \#2654), LabView 8.6, and a custom designed interface board. LabView was selected because it would allow for rapid development of a graphical user interface (GUI) and the interface with the PCI card. Alternatively, the PCI card could have been interface with DAQMX, which is a compilation of $\mathrm{C}++$ libraries. However, based on time constraints, learning how to use the DAQMX libraries possibly could have been slower than using LabView. The PCI card that was selected was chosen because it was available for student use. Finally, the interface board was designed to address the issue of high speed switching. LabView, on its own, is not 
capable of switching an LED on and off, and also collecting data quickly enough through the PCI card. A few proof of concept tests were performed and it was found that to turn a LED on, collect one sample of data, and turn the LED off took a total of 10 milliseconds. The longest that an LED should stay on for the collection of data is about 0.2 milliseconds. By using an interface board, it was possible to handle the switching while letting the PCI card collect the data at a high speed. Figures 3.1 shows how LabView interfaces with the PCI card, microcontroller, and the LED.

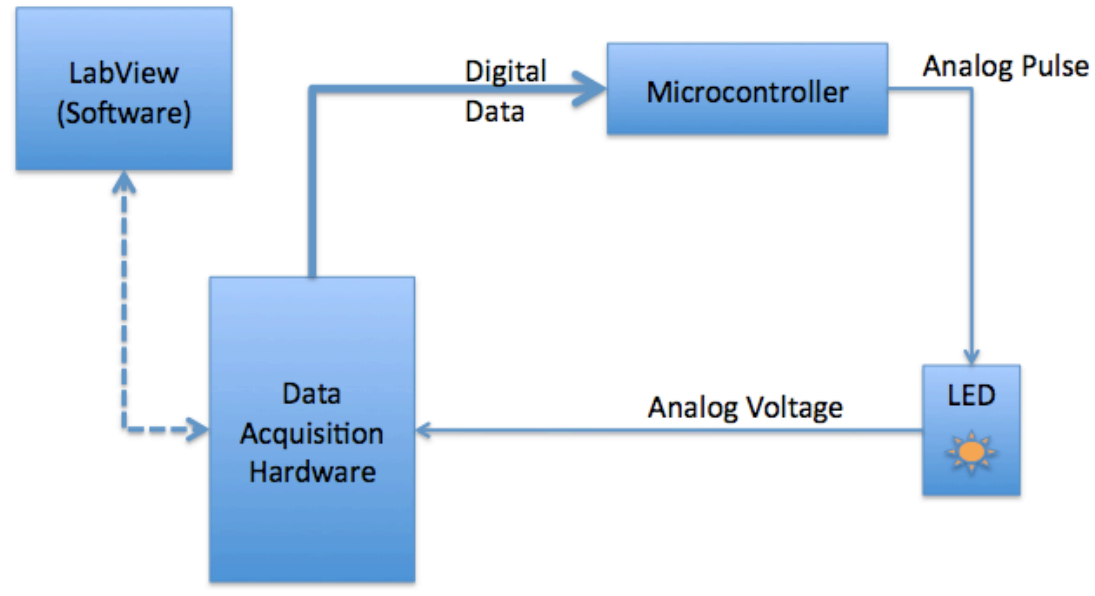

Figure 3.1: Graphical overview of system.

High speed switching is handled by having LabView send a pulse to the microcontroller. The microcontroller has a short delay (programmed currently to $1 / 4$ second), and then the microcontroller enables an analog switch. During this delay, LabView can switch modes to data collection. After the switch is enabled, the analog switch sends a voltage to an operational amplifier, which acts as a constant current driver. When the analog switch is not enabled, the output voltage is zero which results in no current through the diode. Figure 3.2 shows how the analog switch is connected to the op-amp, which is acting as a constant current driver. After a preselected time, the analog switch is disabled automatically by the microcontroller. 


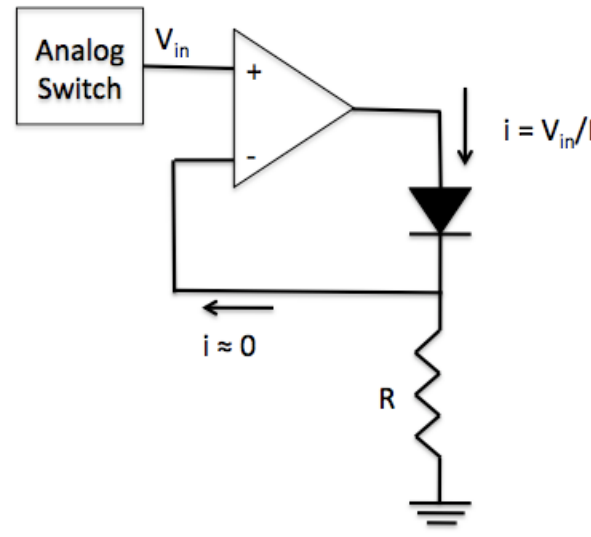

Figure 3.2: Simplified circuit of constant current LED driver

The design uses the PCI card to handle the analog-to-digital conversion. This was done to speed up the design and verification process because the PCI card was verified to be working at the factory (and recently for another student's thesis). The PCI card is able to collect 1.25 million samples per second, which worked out quite well for this application. Within a 200-microsecond period, 250 samples can be collected. During some initial testing, it was found that the op-amp was marginally stable when operating. A few modifications were added to stabilize the circuit. The oscillations were damped out significantly, however the rise time was slowed. The rise time went from about 1 microsecond to 50 microseconds. Losing 50 microseconds out of the original 200 is a sizeable amount of data. To compensate for this, samples were taken for 440 microseconds (550 samples) and a linear model was fitted to the collected data. This model was done so that ideally the intercept along the vertical axis would be the forward voltage at time zero. Figure 3.3 shows how a linear fit would be applied to a $700 \mathrm{~mA}$ pulse test of a diode. While a linear fit does not describe all of the physics, the concept was developed assuming the LED is heating uniformly across the junction surface. 


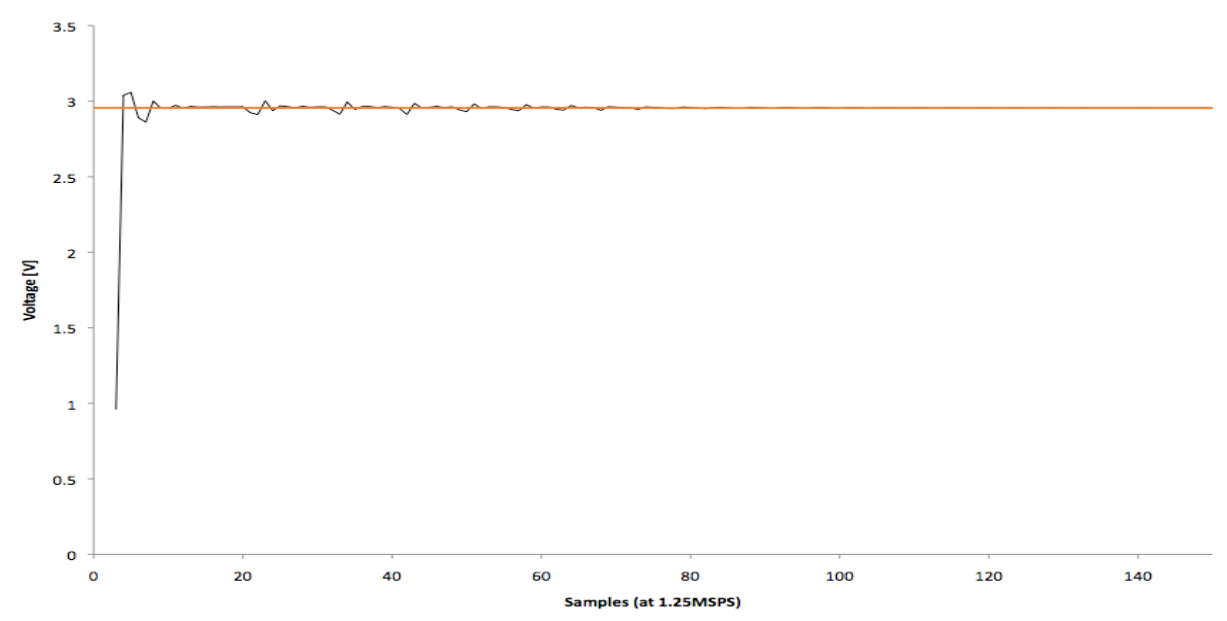

Figure 3.3: Linear trend line overlaid on data to show intercept.

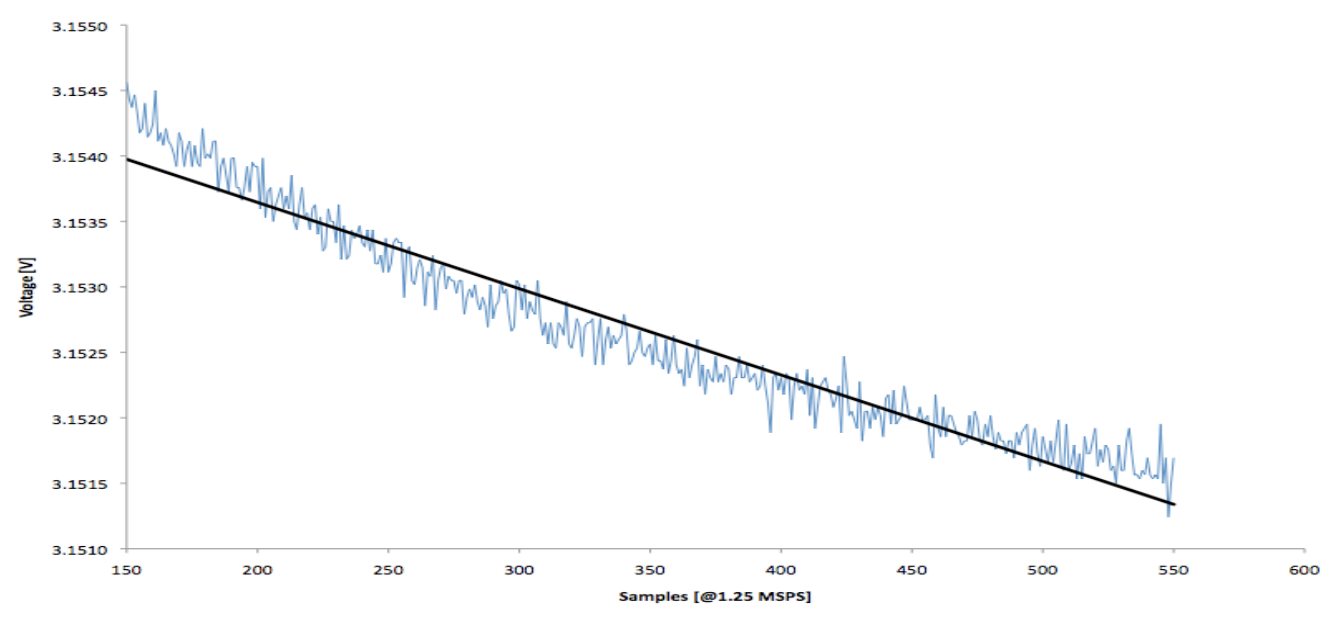

Figure 3.4: Discrepancy in linear trend line and data used for intercept estimation.

Figure 3.4 shows a close up of the data past the initial rise time. The linear trend lines use data from the $150^{\text {th }}$ data point until the $550^{\text {th }}$ data point. This gave sufficient time for voltage to stabilize. There was a substantial overshoot, which was avoided by starting at the $150^{\text {th }}$ data point. While a first order approximation is not perfect, it gives a better estimation of the data point than a simple average of all of the collected samples. It should be noted that in the $100 \mathrm{~mA}$ and $350 \mathrm{~mA}$ test current pulses, the data is nearly linear and horizontal when plotted due to very little self-heating. 
Finally, the design incorporated numerous double-throw double-pole (DPDT) relays to handle multiplexing and current range selection. There were 16 DPDT relays that were dedicated to multiplexing up to eight diodes. Each diode had two relays dedicated to allow for separate powering and/or testing of LEDs. This was done so that an external power source could be used, or simply use the DAQ as a constant current LED driver for long durations without measurement. The choice to use relays over multiplexers for the LEDs and resistors was to accommodate high current pulses. Many multiplexers within the project's price range had a maximum current of $800 \mathrm{~mA}$. The use of relays allowed upwards of several amperes.

Relays were also used to address each current sensing resistor separately. There is one for each of the following: $0.25 \Omega, 10 \Omega, 100 \Omega, 1 \mathrm{k} \Omega, 10 \mathrm{k} \Omega, 100 \mathrm{k} \Omega$, and $1 \mathrm{M} \Omega$. However, due to limitations on addressing from the PCI card, only $0.25 \Omega, 10 \Omega, 100 \Omega$, and $1 \mathrm{k} \Omega$ were used. These resistors allowed for the following current ranges: $1000-$ $100 \mathrm{~mA}, 100-10 \mathrm{~mA}, 10-1 \mathrm{~mA}, 1-0.1 \mathrm{~mA}$ current ranges respectively. Issues with relay contact oxidation were addressed in three separate ways. First, the relays that were selected are resistant to oxidation build up. Second, the LabView user interface only switches contacts when there is no current across the contacts. Finally, measurements of the diodes are made using 4-wire measurements which nearly negates all resistance build up $^{[12]}$. Figure 3.5 shows how in 2-wire measurements, the resistance of the test leads can add error; and how in 4-wire measurements, the test leads do not affect the measurement. For detailed descriptions of components, PCB layouts, and images refer to Appendix A. 


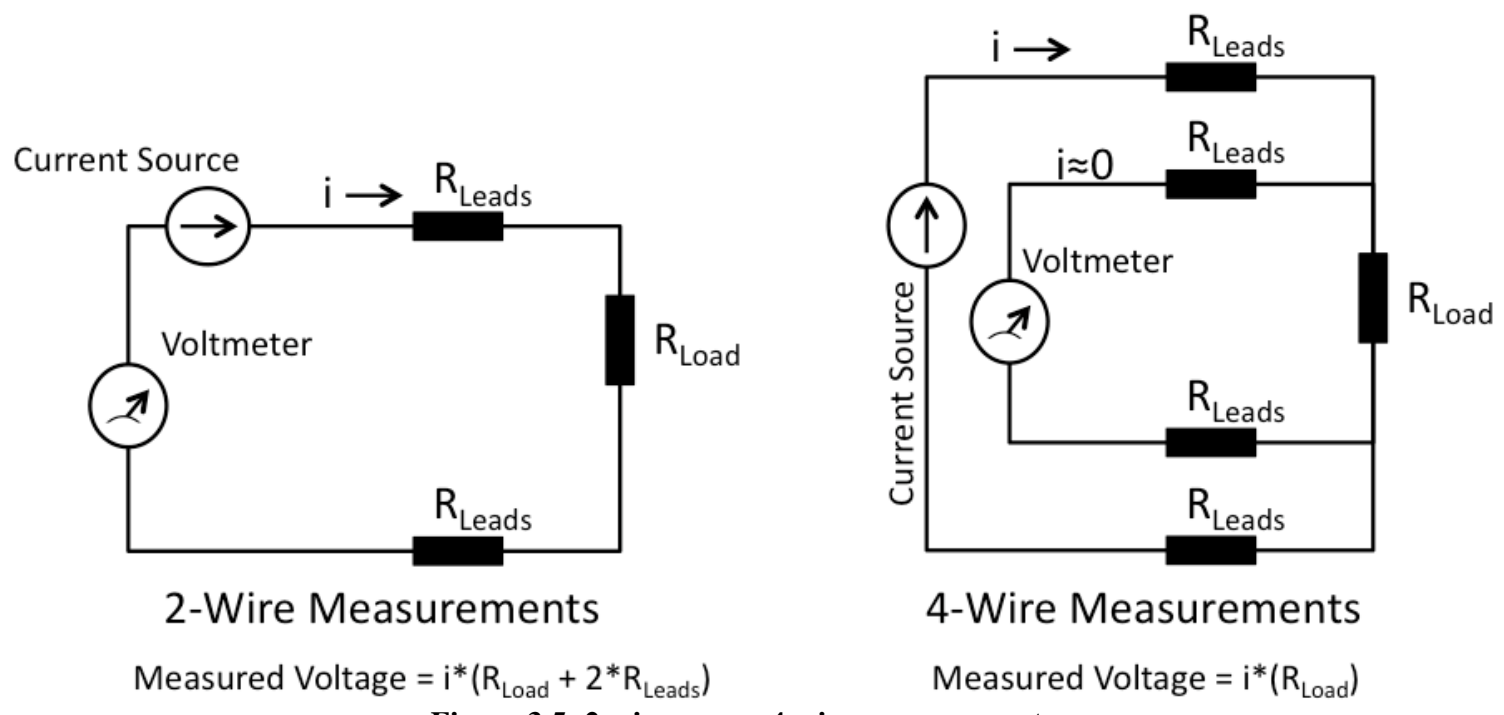

Figure 3.5: 2-wire versus 4-wire measurements.

\subsubsection{Fabrication}

The design of the PCB schematic and layout was done in DipTrace ${ }^{1}$ with a personal license. The Gerber files generated by DipTrace were sent to Advanced Circuits in Colorado for fabrication. The components were ordered from Digikey (see Appendix A.3 for Bill of Materials). Ultimately, two revisions were fabricated. Each board cost approximately $\$ 260$ between components and board fabrication. All components were hand soldered, including both surface mount (SMT) and through-hole (THT) components. Figure 3.6 shows the final revision of the circuit board mounted in the chassis.

\footnotetext{
${ }^{1}$ www.diptrace.com
} 


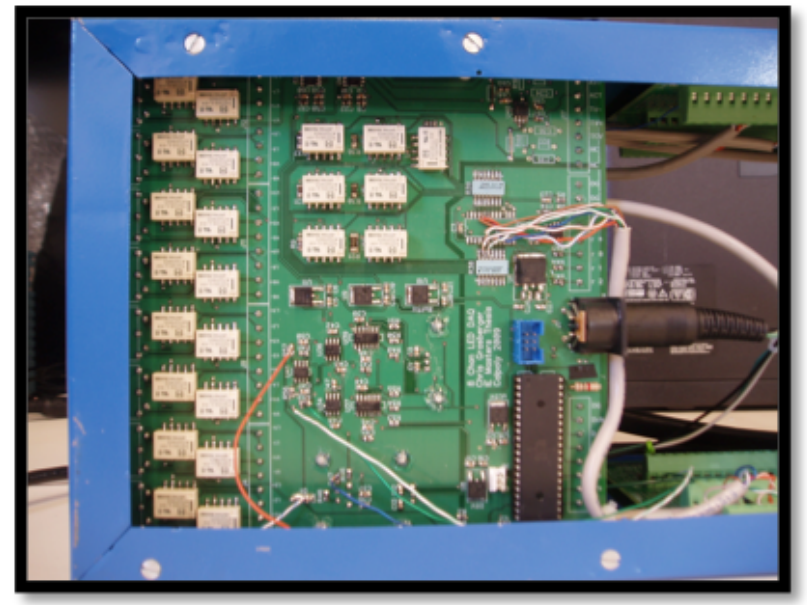

Figure 3.6: Final revision of the interface board in the chassis.

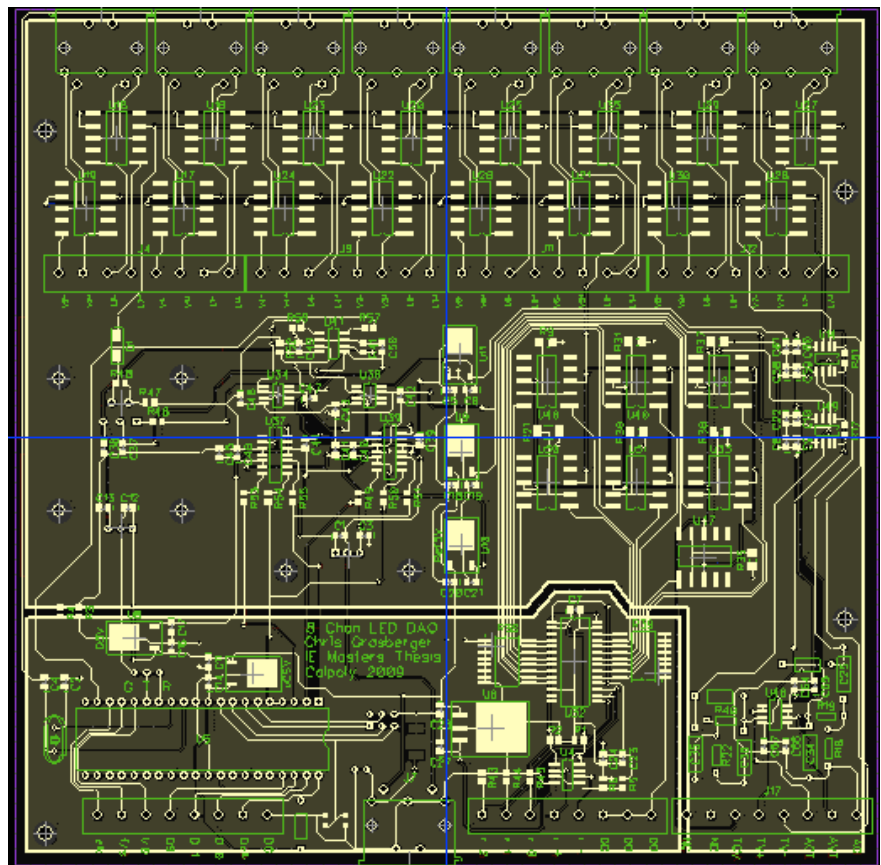

Figure 3.7: Screen capture of DipTrace showing the top layer of the PCB layout used in DAQ interface.

The first revision identified several design flaws including incorrect hole sizes for through-hole connectors. A few logic errors were identified and resolved by fabricating a second board.

The second board (layout shown in Figures 3.6 and 3.7) is the board that was used to collect all of the data for this thesis. While hole sizes were fixed, there were still a few 
logic errors in the same place as before. To resolve this, many modifications were made to the resistor multiplexing, which is why only four resistors are used instead of all seven. After each component was soldered on, it was tested for functionality and tested to verify it affected the circuit correctly. This was done off campus. This allowed for the development of the microcontroller code without bringing all of the components to campus. A couple weeks of working on the microcontroller code was required to test the board with simulated inputs to verify its outputs. After the board was verified as much as possible remotely, it was taken to campus to build a chassis and connect it to the PCI DAQ Card; and then ultimately LabView.

With the assistance of Jason Maynard, we assembled a three-piece chassis. This was done because there are critical test points on both sides of the circuit board. By having the circuit board attached to the middle part of the chassis and having two removable covers (top and bottom), it was possible to test the board with minimal difficulties. See Appendix A.5 for an assembly of the chassis. Figure 3.8 shows a view down from the top of the PCB and chassis with both covers removed.

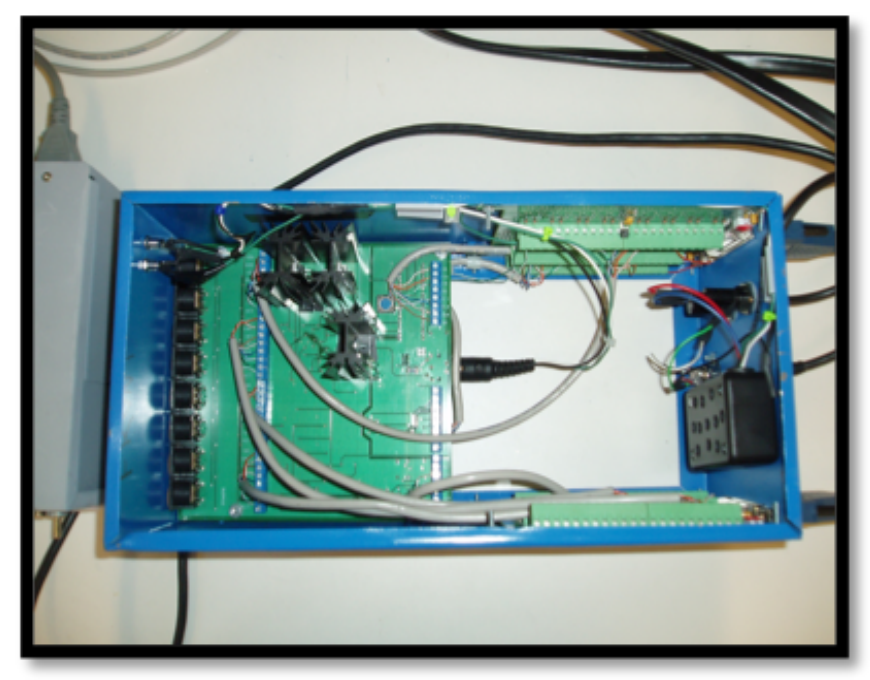

Figure 3.8: Bottom of interface circuit board showing heat sinks. 
Inside the chassis were two breakout boards (they are mounted vertically, see Figure 3.8) that connect to the PCI card DAQ. These breakout boards allowed all 68 possible connection points via screw terminals to be addressed. Using twisted pairs inside of insulation (simply for organization as this insulation is not shielded) the breakout boards were connected to the interface PCB board. Holes were drilled into the front of the chassis for LED power indicators and diode connection sockets. The back holes were made for power input and fuse replacement. Additionally, there were two slots placed on the back so that the custom National Instruments plugs could feed through and connect to the breakout boards. Finally, the chassis was painted. A small modified chassis was also built for a computer power supply to make a dedicated power supply for the DAQ. The power supply is the grey box to the left in Figure 3.9.

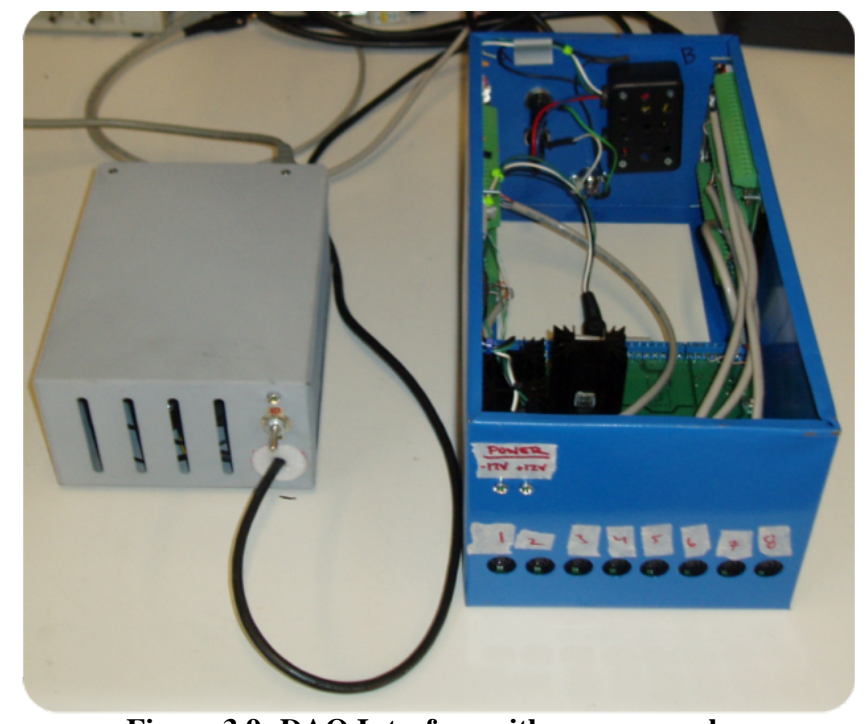

Figure 3.9: DAQ Interface with power supply.

Next, the LabView interface was built up. Jason assisted a few times on the development with the interface by verifying the connections between the PCI card and the interface board; however no assistance was required for everything else described in the following sections. 


\subsubsection{Interface}

In designing the LabView interface, there were numerous false starts. These false starts occurred because it appeared that the DAQ was ready to collect data, but after starting to collect data it became apparent that it was too slow to feasibly collect one set data, let alone several sets of data. Initially only software drivers were made to run the interface board. These were controlled by toggle switches in the interface. Using these toggle switches proved to be extremely slow and this prompted the development of controls, which could automate the slower steps. In doing this, it reduced the collection time of one data set from 80 hours to 30 hours. Another set of controls was later added which reduced the collection time down to 10 hours. The interface was never designed to be used for anything but this research topic, so organization was not planned ahead of time; however in the end, the critical components are in a light blue and neon green backlit section of the interface shown in Figure 3.10. These critical controls allow the user, to select the desired test current, desired oven temperature, and then push "Process Board.” The system then performs all of the required steps to measure all of the LEDs connected to the DAQ. While this device does not directly control the oven, it will not collect data unless the temperature is within $\pm 1^{\circ} \mathrm{C}$ of target temperature. See Section 3.2.2 for a test procedure to operate the system. 


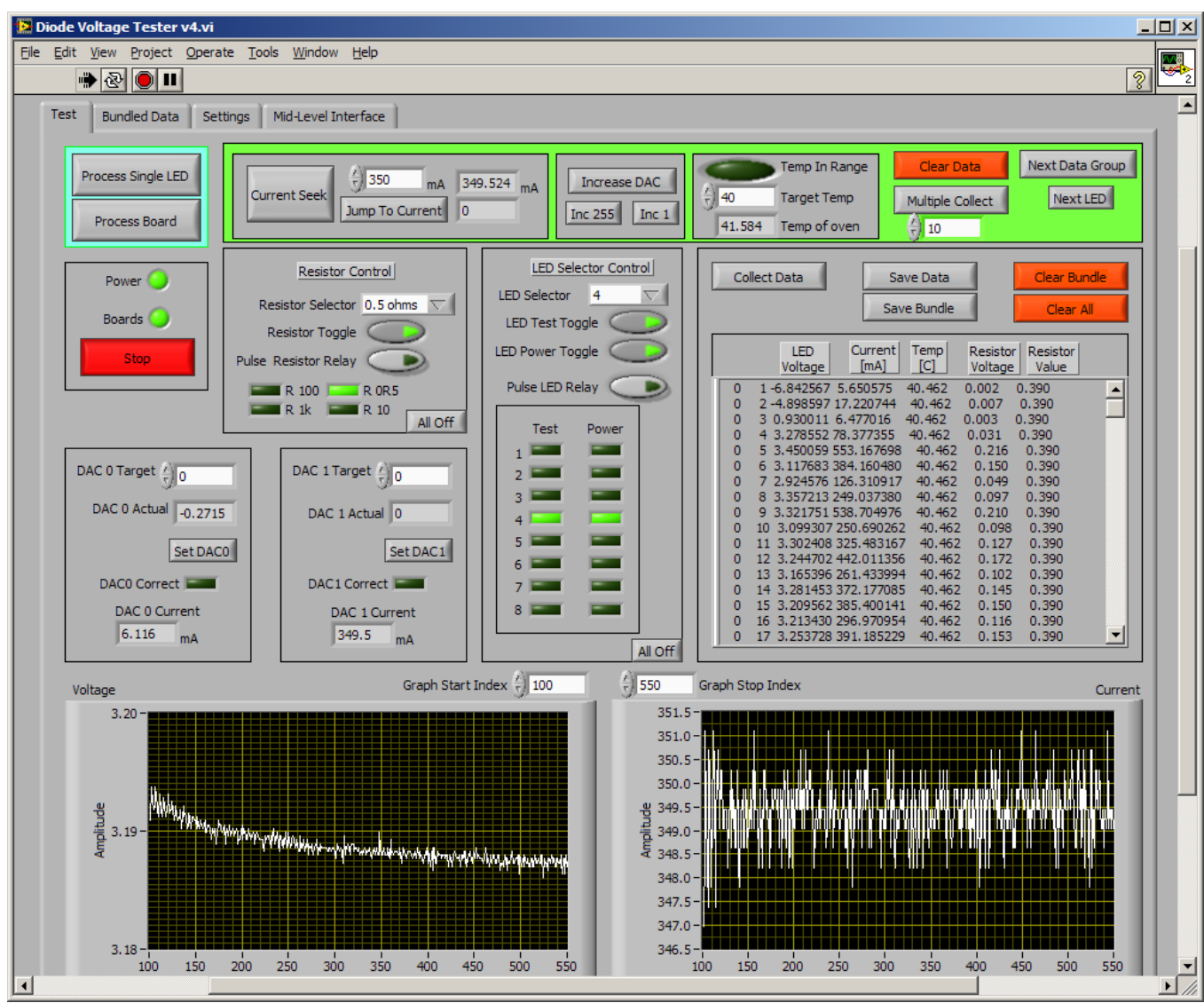

Figure 3.10: Graphical user interface developed in LabView to run the data acquisition system.

The interface also allows control over which resistor and LED is being used.

While these processes are automated, within the green backed regions of the interface,

they can manually be controlled as well. There is also a region to the right that shows the collected data in list format. The GUI allows for the list to be saved, cleared, or bundled ${ }^{3}$. Two other notable parts of the main interface are the two plots at the bottom of the screen. These show the data from the last pulse. They are useful in identifying problematic LEDs. In Figure 3.10 current plot looks unstable, however looking more

${ }^{3}$ Bundling is where the GUI takes the data and puts it into a set of columns of data. Each set of data has the sample number, voltage, current, temperature, and other values. When these are bundled, it takes all of these values (which are stored in columns) and places them in a matrix with other columns. So if each set of data is 5 columns, then if three sets of data are bundled, there will be 15 columns of data when viewed in Excel. 
closely at the vertical axis, the variation in values are within an acceptable tolerance and the average is within $2 \%$ of the target current.

Near the top of the screen, there are a group of tabs to other parts of the interface. One tab allows the user to view the data that has been bundled together. This is useful for checking that all of the LEDs have been measured and to visually verify that the values seem reasonable. There is also a tab to set options relating to timing and thermocouple offsets. Finally, a less used tab shows some of the low-level software drivers that have been incorporated into many of the controls on the main interface. These low-level drivers are used a great deal without the user's knowledge. See Appendix A.3 for screen shots of these tabs.

\subsubsection{Verification and Calibration}

To use this device as a tool, it first had to be calibrated. In doing the calibration, several things were verified and others were identified to be problems. This section is closely tied to the fabrication because testing was done during assembly. A few important things were specially calibrated at the end, which are: forward-voltage to temperature coefficient (K-factor) accuracy, voltage measurement accuracy, speed of measuring, and resistance value of current sensing resistors.

The K-factor verification was actually performed last, however since it is so relevant to the subject, it is presented first. To verify the accuracy during the initial calibration of the LEDs, an average was taken of their K-factors at each corresponding current. This average was composed of 37 LEDs (40 were soldered, but 3 failed). They 
were then compared to the datasheet provided by the manufacture. The results showed an identical match to the datasheet as shown in Figure 3.11.

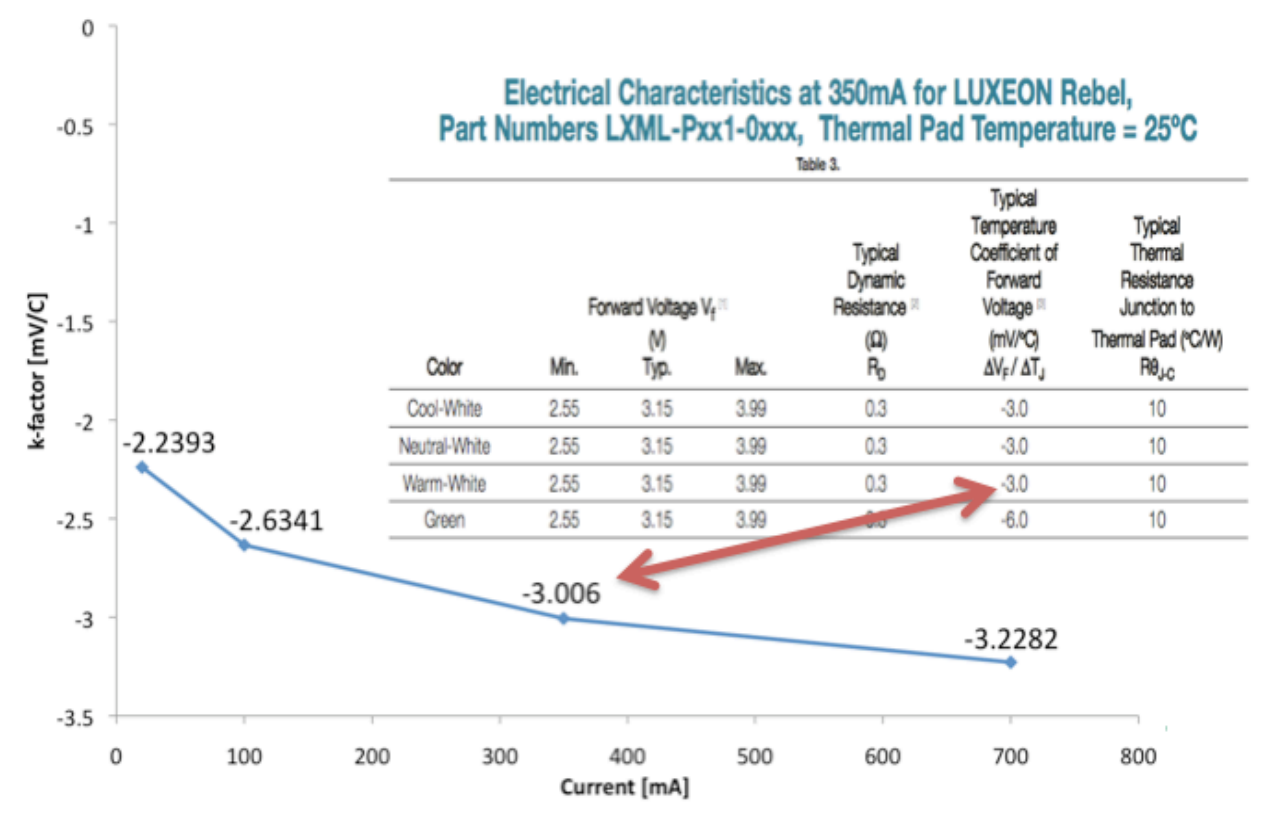

Figure 3.11: Comparison of LUXEON Rebel datasheet with collected data.

The accuracy of the voltage readings from the PCI card was also verified. While these values were quoted to be accurate in the datasheet, it was necessary to verify that the measurement device had not been damaged. Voltages measured by the DAQ were compared against an Instek GDS-1062A oscilloscope when both the DAQ and oscilloscope measured a steady 1 VDC output. The PCI card measured 10 samples and averaged them. These were then compared to the measured value from the oscilloscope. There was less than a $0.5 \%$ difference in values. It was also measured against a Fluke 289 multimeter with similar results. These tests confirmed that the PCI card DAQ was accurately measuring the voltages.

The speed of measurements was important to simply know if the system was actually capable of high-speed measurements. To test this, a function generator generated a $1 \mathrm{kHz}$ square-wave signal. The number of samples measured by the DAQ 
during the high state was counted. An oscilloscope verified the frequency of the signal. The results of this test showed that it was measuring at 1.2 million samples per second.

Finally, the resistance value of the current sensing resistors was verified. The components were selected to have very little variation in resistance due to temperature changes. Additionally, all resistance values, except the $0.25 \Omega$, were specified to be accurate to $\pm 0.1 \%$. The resistance values, other than $0.25 \Omega$, were verified by using a fixed DC output power supply. A Fluke 289 multimeter measured current while the PCI DAQ card measured voltages. The current applied to each of these resistors was selected so it would not violate their maximum rating but still allow for both measurement devices to measure in their most accurate ranges. These resistors were verified to fall into their specified $\pm 0.1 \%$ tolerances. The $0.25 \Omega$ resistor required special treatment.

The $0.25 \Omega$ resistor was tested after being soldered on to the board and the interface board was connected to the PCI DAQ card. Once it was in place, a DC power supply was connected to the resistor through one of the diode channels. A Fluke 289 multimeter was then placed in line to measure the current. The physical measurement of the voltage across the $0.25 \Omega$ was measured by a differential op-amp with a unity gain. This op-amp output its voltage as a pseudo-differential signal, which was then measured by the PCI DAQ card. Using the average of measurements from both the multimeter and DAQ the resistance of the $0.25 \Omega$ was measured. It measured to be $0.37 \Omega$, which includes the resistance from traces. The physical chip had a $\pm 1 \%$ as specified by the manufacturer. The correct value was programmed into the interface and is accurate to $\pm 0.5 \%$ based on the error from both the multimeter and DAQ. While this is not as accurate as the other resistors, it is still sufficient. 


\subsection{Data Collection}

This thesis requires the collection of data that could be turned into a forwardvoltage to junction-temperature coefficient, K-factor, and then this data was used to determine if the K-factor degrades over time. To design this test, several factors were considered: First, how would the K-factor be measured? Second, how could the test remain practical without require an absurd amount of equipment? Finally, how could multiple levels of operation be introduced into the study?

The K-factor is constant for a given current at a specific time. In order to calculate a given $\mathrm{K}$-factor value, at least two data points must be taken at a fixed current. Ideally, these points should be at very different temperatures. EIA JEDEC standard recommends a minimum of a difference of 50 degrees ${ }^{[9]}$. To ensure that one of these data points was not corrupted by measurement errors, five temperatures were measured in this study: $20^{\circ} \mathrm{C}, 40^{\circ} \mathrm{C}, 60^{\circ} \mathrm{C}, 80^{\circ} \mathrm{C}$, and $100^{\circ} \mathrm{C}$. While this took substantially longer to collect this data, it allowed for better verification of the data. By using a linear trend line on the data, the data could be used to verify that there were no outliers or measurement errors. Additionally, the slope of the trend line would be the K-factor. See Figure 3.12 for a plot of typical data collected from a LED and the trend line showing the K-factor. By using five temperatures, any outliers would become apparent, as the data would not fall on the line. 


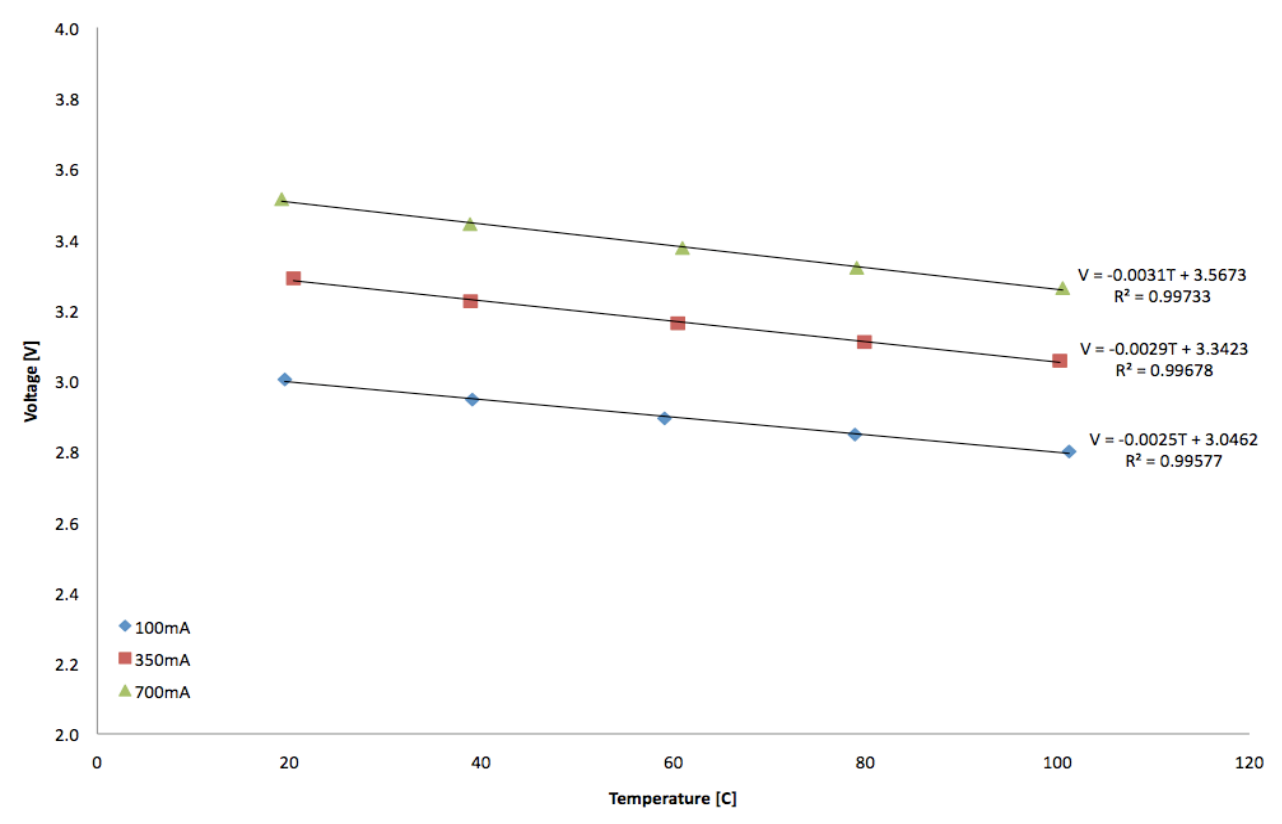

Figure 3.12: Example of collected data with linear trend lines.

Since LEDs can last a very long time, the tests must be accelerated in order to see results in a practical amount of time. LEDs degrade rapidly at high temperatures and thus using high temperatures would be a practical approach to accelerating the tests. There are two obvious ways to heat a LED up to high temperatures. One would be increase the current, which is ultimately increasing the input power. The second is to raise the temperature of the ambient conditions. The problem with increasing the current is that as more current is put in, the temperature will rise accordingly for a set thermal solution. Alternatively, a set current could be used with multiple ambient air conditions to raise the junction temperature. Unfortunately, multiple ovens would be required non-stop during aging. It should be noted degradation from high junction temperature due to ambient conditions might be different from high junction temperatures due to high currents ${ }^{[13]}$. Since there was a limitation on resources available, only the current approach was used.

Two currents were selected, which ultimately determined two junctiontemperatures. One temperature was designed to be very high, near the maximum 
operating conditions or higher; the second was high, but at least 20-30 degrees cooler so that degradation would not be nearly as fast. The goal of this was to ensure that if the lower temperature did not show any results, possibly the higher temperature did. Similarly, if the higher temperature LED degraded too rapidly, the lower temperature would at least have some data to show. Also, there was to be a control board, which was never operated. The currents were selected after the initial data collection. This was done so that a thermal resistance could be determined from the junction temperature to the ambient air. This allowed for currents to be selected that would allow specified average junction temperatures. While the thermal resistance did vary, they were grouped into like averages. This formed two groups: A and B. Group A was aged at 470mA which put the junction temperature at $145^{\circ} \mathrm{C}$ on average. Group B was aged at $350 \mathrm{~mA}$ which resulted in an average junction temperature of $115^{\circ} \mathrm{C}$. The maximum operating temperature for the LEDs according to their datasheet is $150^{\circ} \mathrm{C}$. See Figure 3.13 for an overview of the groupings.
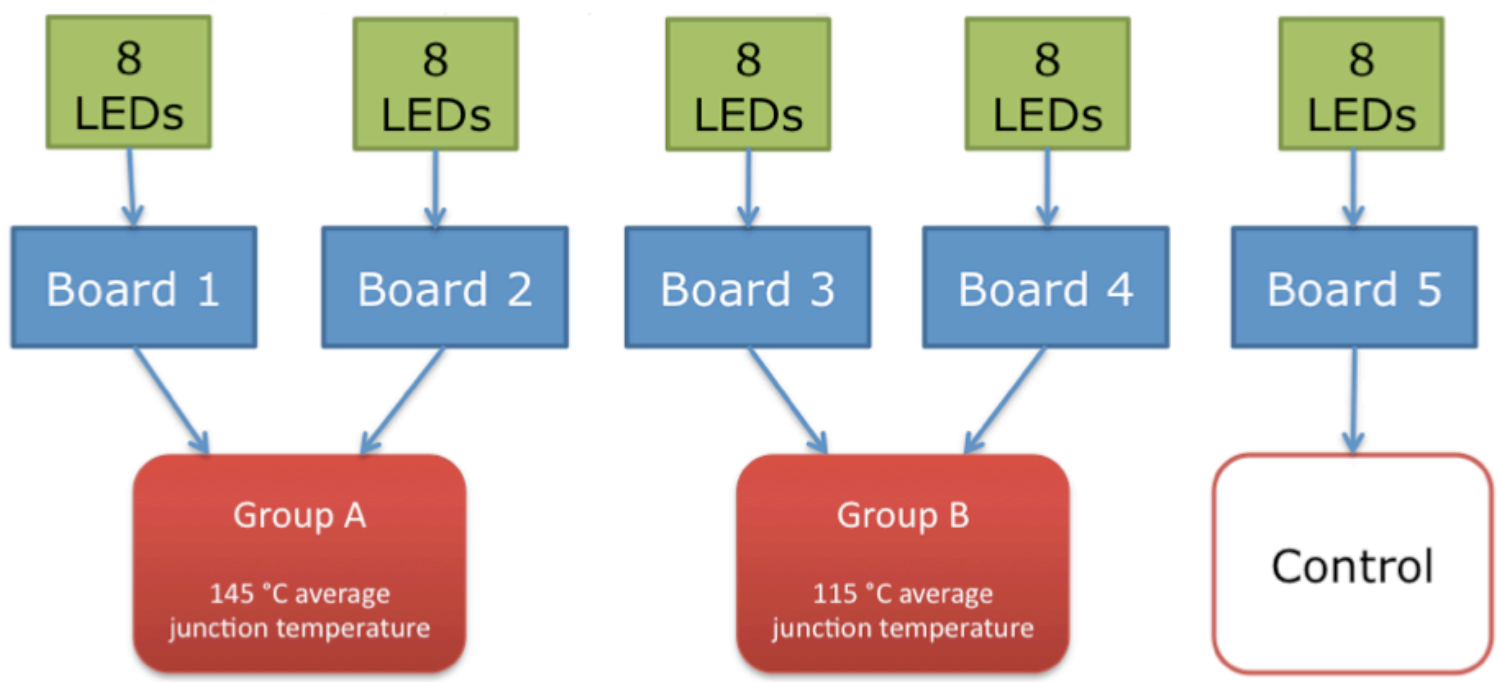

Figure 3.13: Plot of how the LED groups were formed. 
As shown in Figure 3.13, there are five boards to test. The DAQ system was designed to handle eight LEDs without having to opening the oven and rewire for new LEDs. Having multiple replications per aging current level (Group A and B) would help to gather better data. It was decided to use 16 LEDs per level, and 8 for a control test. All 8 LEDs were put in series so that they would receive the exact same aging current. Constant current drivers were used for both Group A and B. Drivers from Thomas Research Products were used for both groups. Group A used a 350mA driver, TRP model TWC-030S035SS; and Group B used two 470mA drivers, TRP model LED17W36-C0470. All drivers are regulated to within $\pm 1 \%$ of nominal value. Figure 3.14 shows how the LEDs were connected to their corresponding drivers.

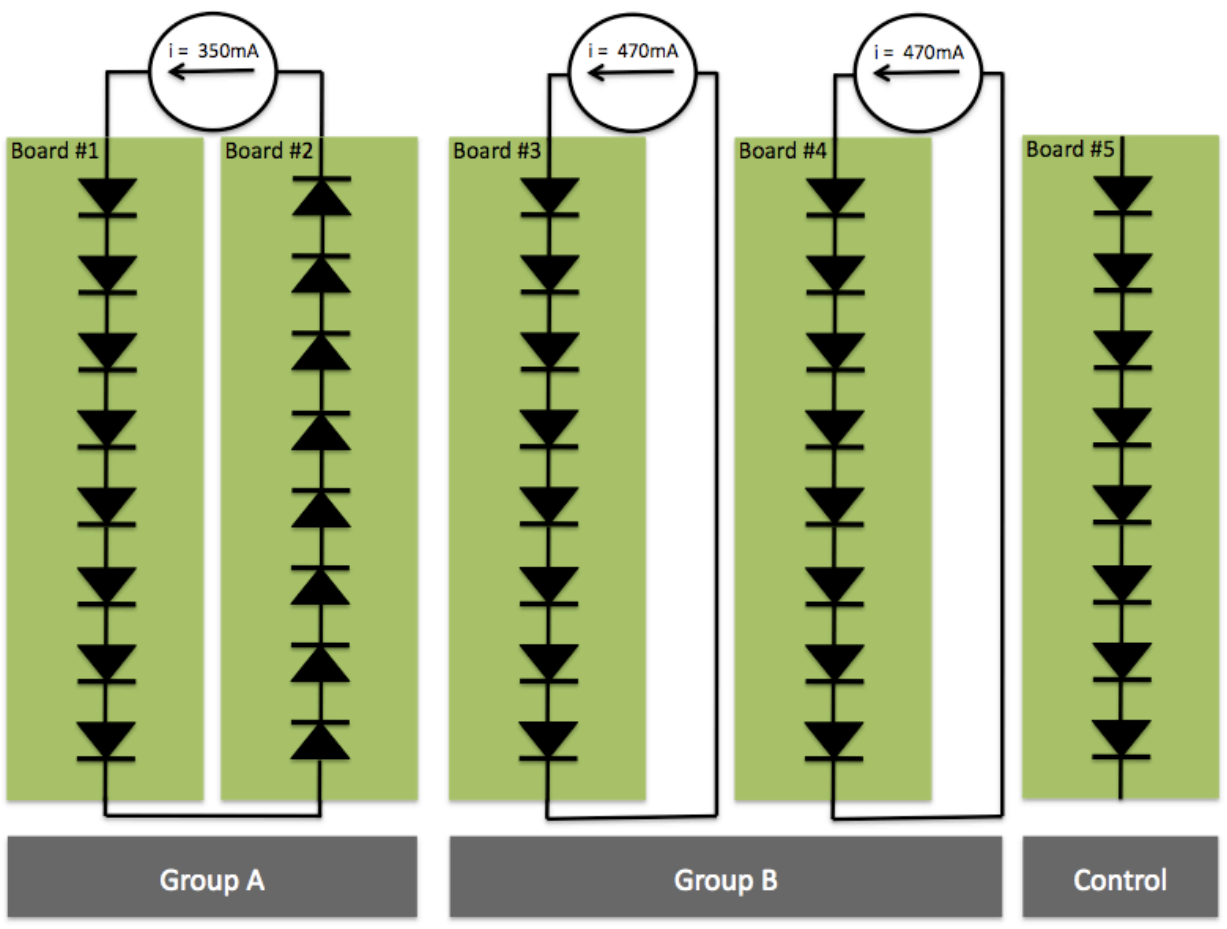

Figure 3.14: Circuit diagram of LEDs while aging. 


\subsubsection{Test Vehicle Design}

After the number of LEDs to be tested had been determined, then a way to mount all of the LEDs was needed. The requirements for the design required that no LED received a different thermal condition than another. This was done so all LEDs could be considered to have aged identically. Numerous layouts were considered, but in the end a circular shape with equal spacing between LEDs was selected. This shape allowed for thermal symmetry between LEDs. This meant that each LED affected the nearby chips equally so the net effect was zero. Figure 3.15 shows the first revision of the PCB.

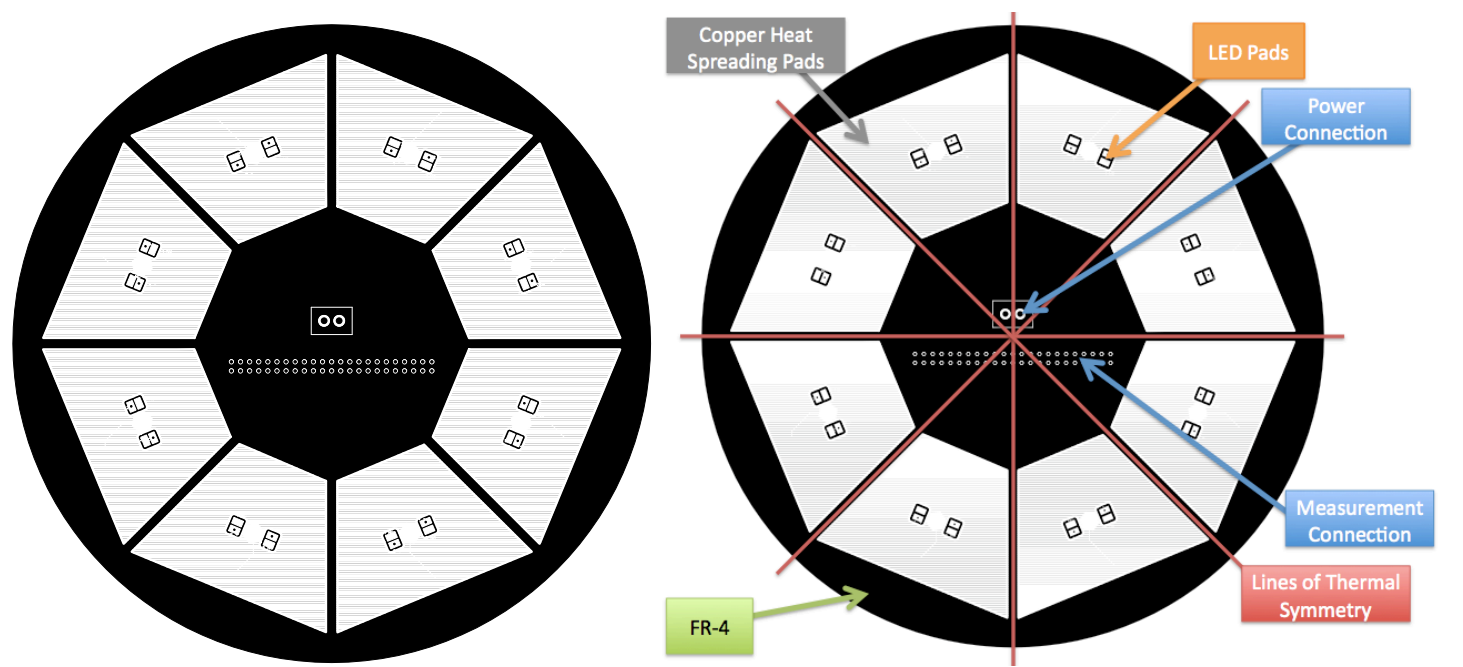

Figure 3.15: Image of PCB Vehicle and lines of thermal symmetry

These boards were modeled in SolidWorks and simulated in EFD.lab ${ }^{4}$. EFD.lab allowed for the analysis of the PCB layout using copper and FR $-4^{5}$ (a very common printed circuit board material), by simulating the shape of the LED chips. This was done to determine what the junction temperature of the LED would be before fabricating the PCB. This test

${ }^{4}$ EFD.lab was formerly known as FloEFD. This package was developed by Flomerics, which also developed FloTherm until Mentor Graphics bought them out. EFD stands for Engineering Fluid Dynamics

${ }^{5}$ FR-4 is made of woven fiberglass cloth with an epoxy resin binder that is flame resistant [20]. This material acts as an insulator between the layers of copper foil, which act as the traces for electrical connections. 
showed that the FR-4 material would be able to sufficiently dissipate the heat. A concern about FR-4's ability to act as a heat sink came up since FR-4 has very low thermal conductivity, around $0.24 \mathrm{~W} / \mathrm{m}-\mathrm{k}$. This is in contrast to aluminum, which ranges from 160-200 W/m-k and copper around $420 \mathrm{~W} / \mathrm{m}-\mathrm{k}$. The simulation showed that by using large copper fills there was sufficient heat spreading away from the LED despite the high junction temperature. Figure 3.16 shows the thermal model of the circuit board being tested. The test utilized lines of thermal symmetry to only solve $1 / 4^{\text {th }}$ of the problem. This saved computational time and resources.

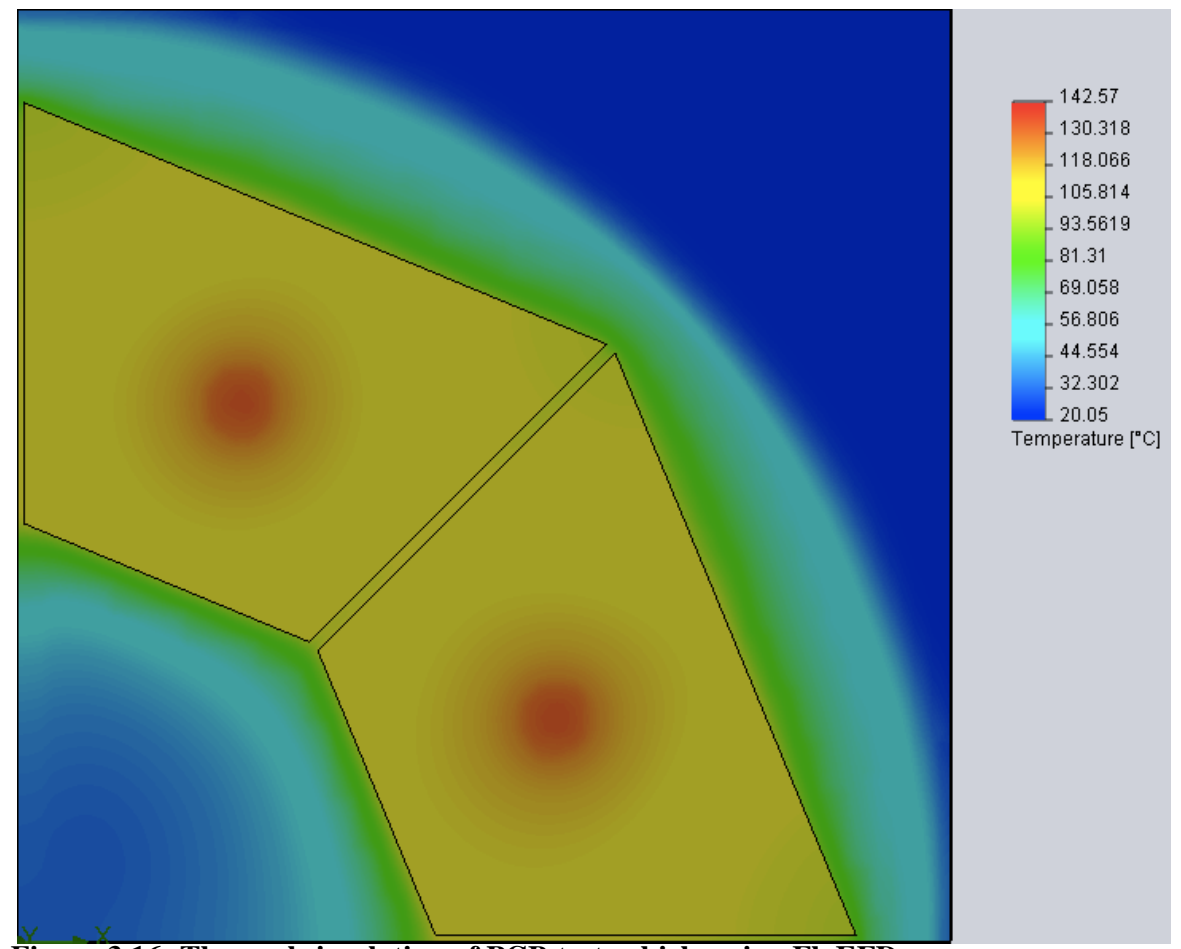

Figure 3.16: Thermal simulation of PCB test vehicle-using FloEFD.

After the thermal model, the boards were fabricated. After receiving the first revision of the boards, it was determined that there was no connector that could accommodate the pin layout that had been designed for the measurement connector. A pin pitch (spacing) of 0.1 " was selected, however it was required to be larger $(0.167$ " 
pitch) to accommodate a wire-to-board style connector that was needed. Otherwise a ribbon cable style connector was required which did not work with the wiring system that was previously designed. The system required twisted pairs and twisted pair ribbon cables were too expensive. It turned out to be cheaper to make a new PCB.

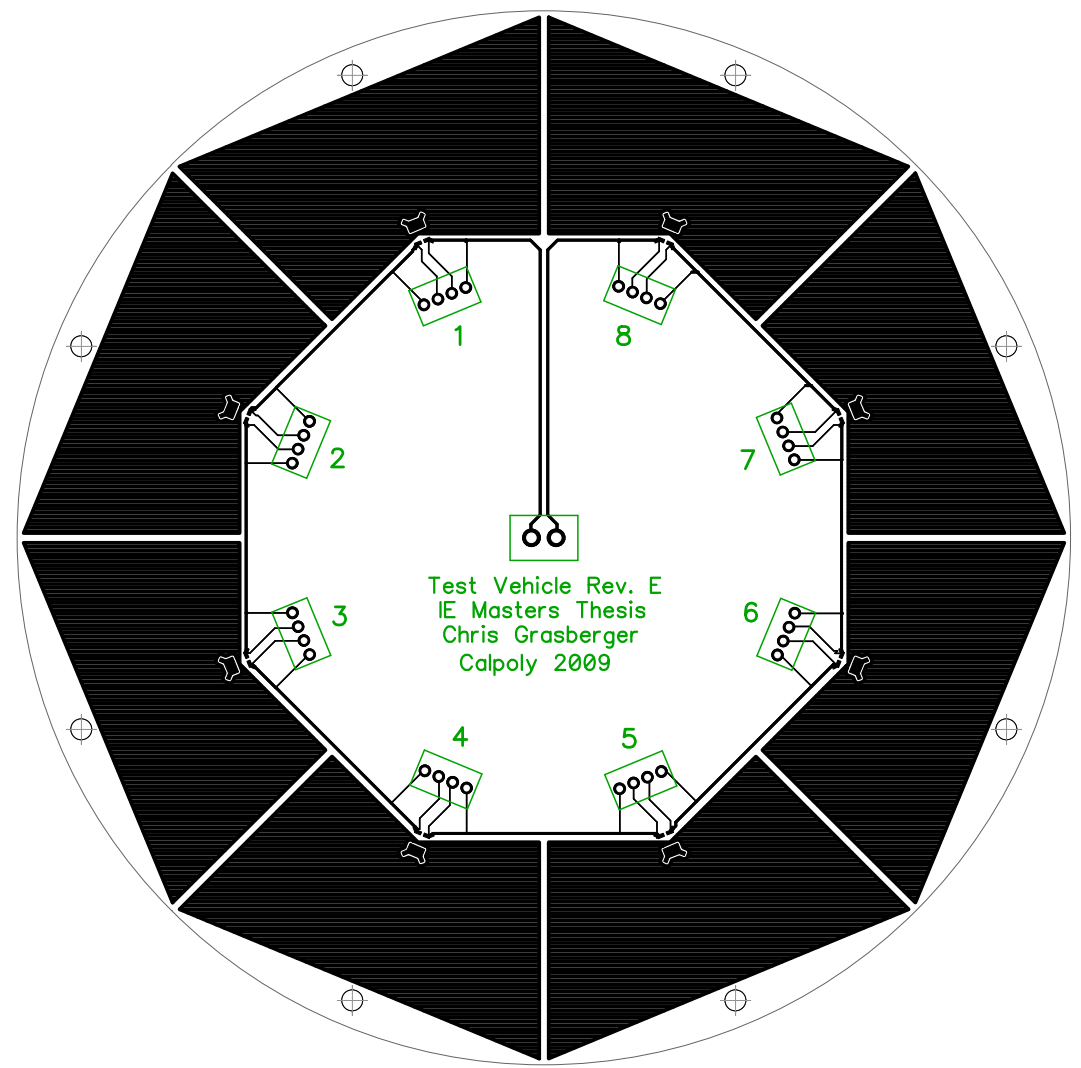

Figure 3.17: PCB Layout of the second revision of the test vehicle.

The new PCB design, shown in Figure 3.17, utilized a slightly different copper fill pattern and used common four position 0.1 " headers with polarizing tabs to prevent incorrect wiring. While the shape is different than the first, it still utilized thermal symmetry. This model was not simulated in EFD.lab because the license had expired by the time this board layout was done. However, the board is very similar to the previous design and should net similar results. 
The second revision of the boards was designed to follow the assembly and handling instructions of the manufacturer. On a side note, these boards were used to collect most of all of the data used in this thesis. Figure 3.18 shows the physical board compared to the datasheet. Only two small holes were removed due the extremely high cost of using a drill size that small. To use those holes would have made the boards cost nearly double the price. In an effort to save money, those holes were omitted. This change in the design would ultimately increase the thermal resistance of the design; however, measuring the thermal resistance and picking an aging current based on the measured value accounted for any change in the thermal resistance.

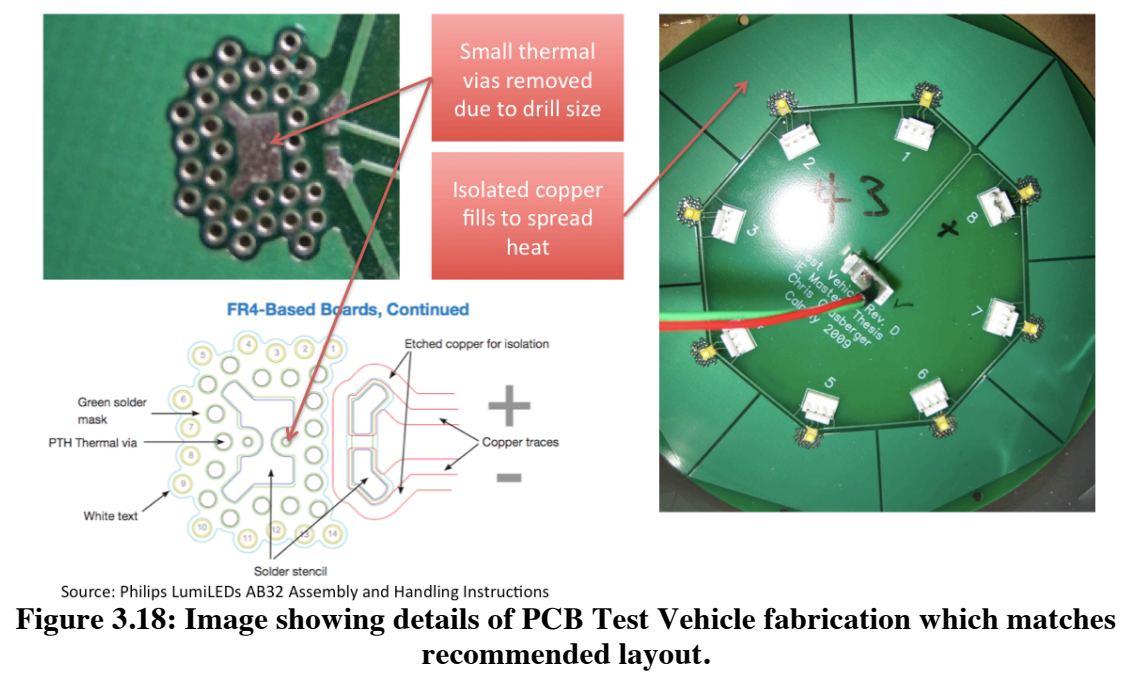

The LEDs selected were Philips LUXEON Rebel chips (LXML-PWM1-0070). Philips donated sixty of Rebel chips for the thesis. A close up of the chip is shown in Figure 3.19. These are high-powered chips; therefore, they are surface mount for improved thermal management.

Typically these chips are attached to PCBs via reflow soldering; however these LEDs were hand soldered. This was accomplished by heating up the wetting verification pads that were attached to the thermal pad that the LED sits on. See Figure 3.19 to see 
the wetting pads on the PCB. After the pads were sufficiently warm and the solder had become a liquid, the LED was carefully placed on top of the hot solder with tweezers. After this solder had cooled, solder was then carefully applied to the wetting pads next to the anode and cathode connections. Once the solder had turned to liquid, capillary action took over and the solder moved under the LED. Shortly thereafter, the solder cooled and created a connection. This process was practiced on 15 chips, using the first revision of the PCB, before applying it to the second revision PCBs for actual testing.

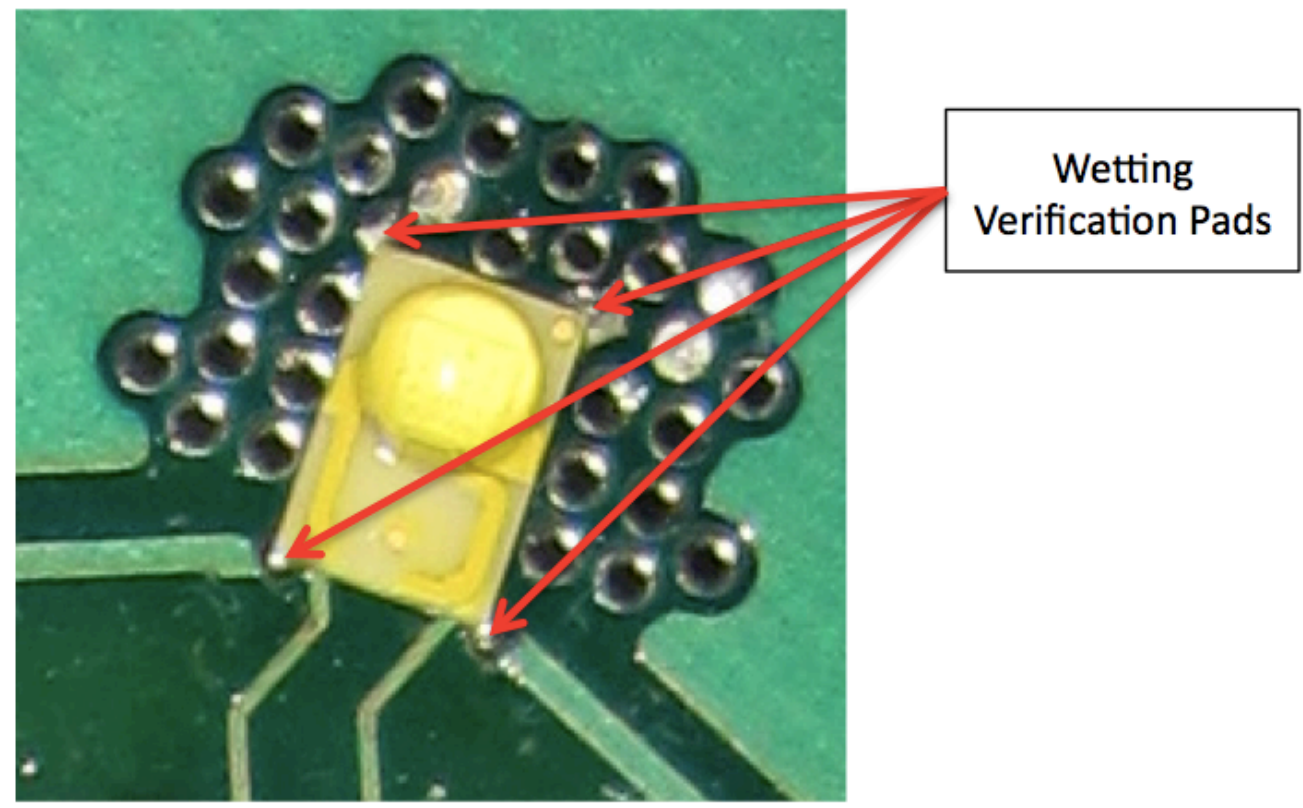

Figure 3.19: PCB wetting verification pads used for soldering.

There were concerns that this process damaged the LED, which may harm the results. Philips engineers said that the LEDs would exhibit damage, possibly in the form of current leakage, due to overheating from manual soldering. To verify this, the I-V curves of the data was plotted and compared with the datasheet. See the Data Analysis section for details on the results. However, the I-V curves were unknown at the time of the discussion with the Philip's engineers. They recommended using a reflow oven and also offered to assemble a new set of boards for this project. Having this opportunity, 
there was a third revision of the PCBs fabricated using aluminum clad PCB (also known as Metal-Cored PCB - MCPCB). These boards also had thermocouples attached directly to the thermal pads for the option of collecting data using thermocouples. These boards were fabricated and some data was gathered from them. However, by the time these boards were ready for testing, it was nearing the end of the testing phase. As a result of this, little is known about the MCPCB circuit boards.

\subsubsection{Testing Procedure}

The design of the data acquisition system and the test vehicles were large parts of the project, however in the end, they were small stepping-stones before the actual thesis could begin. As described in previous sections, the PCB vehicle and data acquisitions system circuit boards were fabricated, assembled, and tested. After that point, the data collection started.

Each set of data combines information about voltage, current, and temperature to determine K-factors for an LED. The information includes five boards each with 8 LEDs, each LED at 3 currents $(100,350$ and $700 \mathrm{~mA})$, and each current at 5 temperatures. Then there were five sets of data: Time $0,1,2,3$, and 4 . These occurred at 0 hours, 405 hours, 1384 hours, 1980 hours and 3009 hours respectively. Ideally there were eight LEDs on each board, but due to LED failure and assembly errors, there were 37 in total between the 5 boards at time 0 . One board with 6 working LEDs (the control), one board with 7 working LEDs, and the rest had 8 LEDs per board. 
Collection of the data starts by placing all five boards into the oven. Once the LEDs had soaked in the oven for enough time to reach steady state, then the DAQ pulsed the LEDs at a specified current. This soak and pulse cycle (effectively a very low duty cycle) was done ten times to each LED, and the results were stored for averaging later. After those ten values were collected, the DAQ switched to the next LED and pulsed the new LED. This process was applied to all the LEDs on the board. Once complete, the current would then be changed. This cycle was continued until all LEDs on a board had been tested at all three currents.

After a board had been measured at the three currents on all the LEDs, the oven was opened, and the DAQ was wired to a new board. Since four-position headers were used, the process of wiring the 4-wire connections with the DAQ was quick. The oven was then allowed to soak again to return to its original temperature. Then this new board was subjected to all three currents on all of its LEDs and the data was stored. This process was repeated until all five boards had the data collected.

The oven was then set to be 20 degrees Celsius hotter than before. Once the LEDs had a chance to soak, data was collected on each of the five boards again. This process ended up being very slow in the end because rewiring the boards at higher temperatures took a great deal of time to allow the oven to reach its steady state temperature again. This process is depicted in Figure 3.20 and 3.21. 


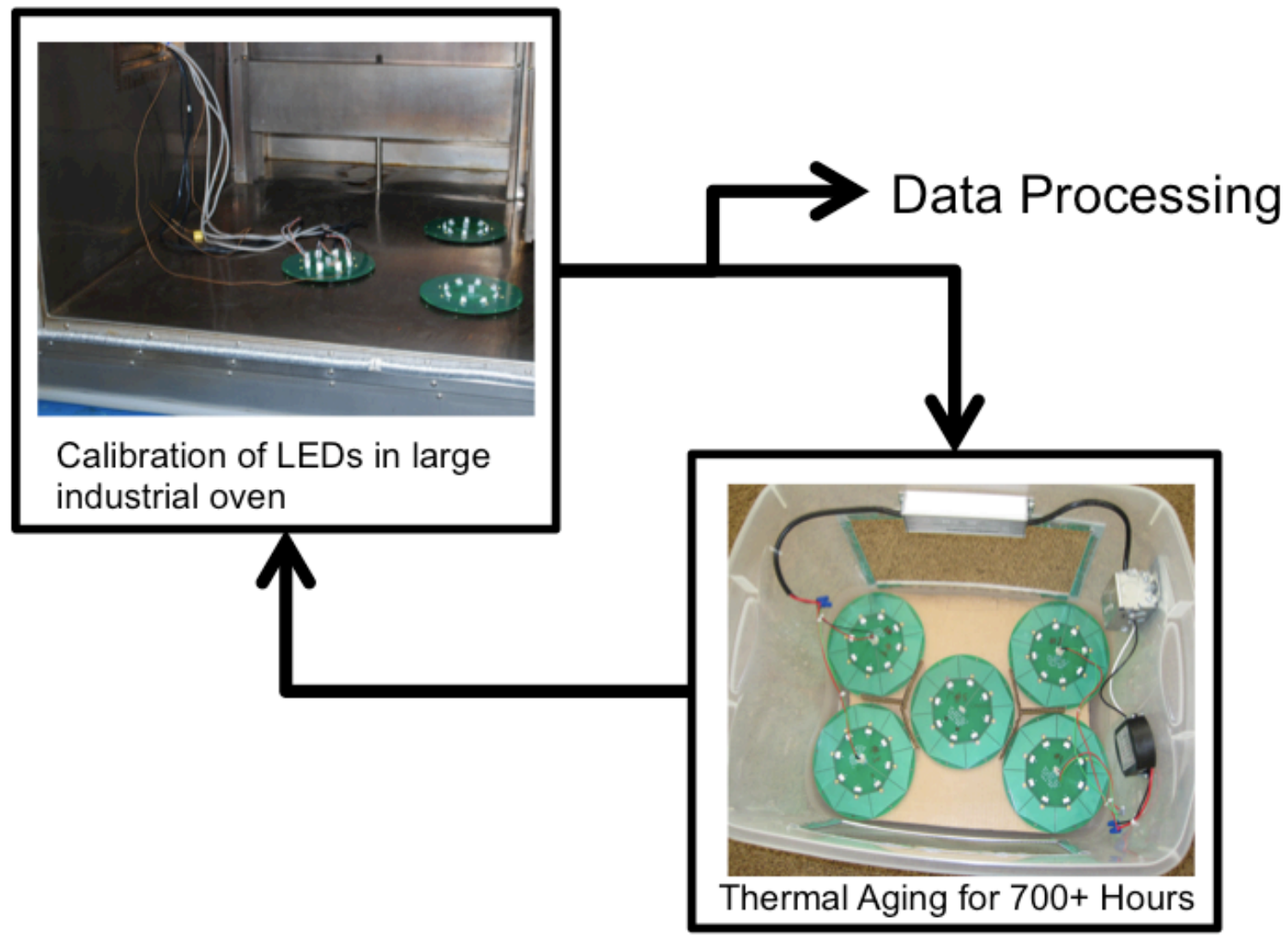

Figure 3.20: Collection Process Overview 


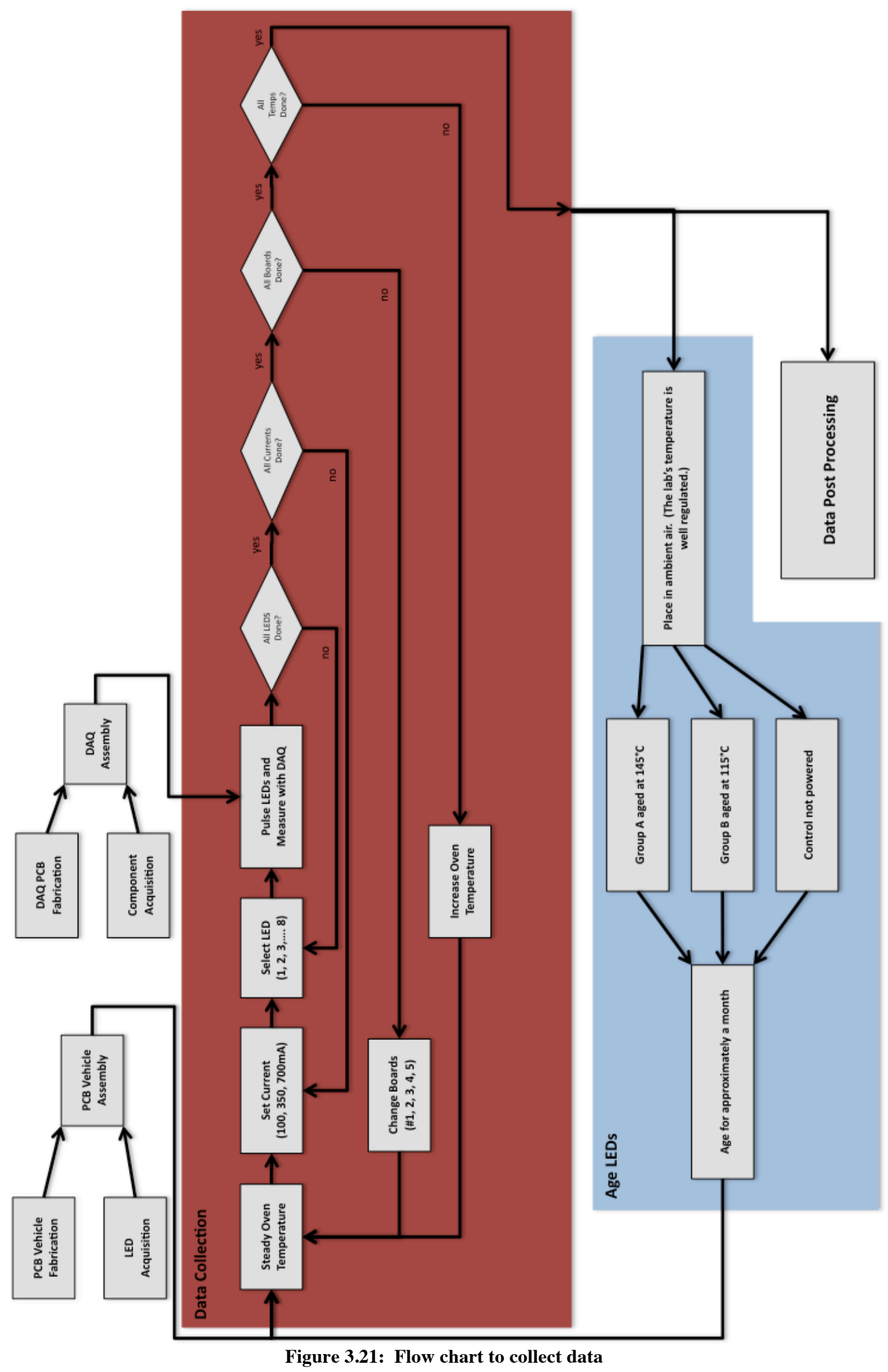




\section{Step-By-Step Procedure}

1. Place test vehicles in oven.

2. Connect first test vehicle to set of eight 4-position ramp headers. Each plug is numbered 1 through 8 . If the board is missing chips or some have failed, connect using the lowest number plugs even if the numbers do not match. Example: If LED 2 is dead, then wire plug 1 to LED 1, plug 2 to LED 3, plug 3 to LED 4 and so on. This will leave plug number 8 disconnected at the end.

3. If the PCBs do not have an onboard thermocouple, there is loose probe within the wire bundle. Place the probe on top of the PCB to measure the air temperature near to LEDs. If the PCBs do have an onboard thermocouple, there is a K-type female connector in the wire bundle. Use this plug for onboard thermocouples.

4. Turn the oven on. There is a junction box to the right of the oven with a red lever. Turn the lever to the ON position.

5. Set desired temperature on the oven controller. The controller is on the side of the blue oven to the left of the junction box. Use the up and down arrows to select target temperature. With the exception of $20^{\circ} \mathrm{C}$, set the oven about 4-8 degrees hotter than desired. The internal measurement is on the ceiling of the oven and there is a significant difference in temperature from top to bottom.

6. Connect the thermocouple plug to a hand held multimeter to read the K-type thermocouple. There are two male plugs next to the junction tester. One is an extension cable for onboard thermocouples, and the other is the male end of the probe inside the oven. Select which one you desire to measure

7. Turn on the computer. Username: droptest Password: leadfree

8. Open LabView 8.6

9. Open latest version of Data Collection system. It should be version 5.

10. Turn on power supply (grey box) to the data acquisition system (blue box). Green power indicators, located on the blue box, should turn on.

11. Press the run in LabView just below the file menu. It is a triangle symbol similar to what would be found on a music player for play.

12. After a small loading delay, the LabView interface should begin to run. Two lights on the screen will illuminate. "Power" and "Boards" after both are green press the run button below them. If "Power" does not turn on, you need to check that you completed step 10. If "Boards" do not turn on, check that the two large cables coming from the computer are connected to the back of the blue the DAQ. If they are, check that they are connected to the right location.

13. Press the "All Off" button in the Resistor section and in the LED section. This will clear all past runs.

14. After both "All Off" sequences are done (the pull down menus for both will stop changing) select the $0.25 \Omega$ resistor in the pull down menu and press "Pulse Resistor." This will connect the $0.25 \Omega$ resistor as the current sensing resistor.

15. Press "Clear All" in the upper right area of the interface.

16. In the upper left corner, there is a teal region. There is a text field where 1-8 is entered. This is the number of LEDs to test on the test vehicle. If less than 8 chips are connected, ensure that the lowest plug numbers are used before the 
higher plugs. If "7" is entered in this field, only plugs 1-7 are tested. After the value is entered, press the enter key to confirm the value.

17. To the right of this region there is a long green region. Within it, there is a section that is target current. Enter in the desired test current. Data collected has typically been $100 \mathrm{~mA}, 350 \mathrm{~mA}, 700 \mathrm{~mA}$ for this thesis, however other chips may not be able to stand those currents. Accurate data can only be collected at $350 \mathrm{~mA}$ and greater. The system can output a maximum of $1200 \mathrm{~mA}$. After the value is entered, press the enter key to confirm the value.

18. Further to the right is a target temperature area. Here is where you enter the oven temperature. This needs to be manually updated by the user by reading the handheld thermocouple reader that is connected to the probe near the PCB. Once the oven reaches steady state, it will not change too much. After the value is entered, press the enter key to confirm the value.

19. Press the "Process Board" button in the teal section. This will systematically measure all of the boards.

20. Press the "Save Bundle" button on the right side of the screen. This is the data collected during the "Process Board" sequence. After the file is saved, press the "Clear All" button.

21. After clearing the data from LabView, return to step 17. After all currents have been processed on the connected board, continue to the next step.

22. Open up the oven, and disconnect the test vehicle from the plugs. Then connect the plugs to the next test vehicle as done previously. Close the oven and wait for it to reach steady state temperature again. Then go to step 16.

23. After all of your test boards have been processed at the desired temperature, change the oven temperature to the next value. Wait until the temperature has reached steady state (about 20 minutes for $20^{\circ} \mathrm{C}$ increase) and go to step 16 . 


\section{Chapter 4 - Data Analysis}

An analysis of the data collected showed that the K-factor did change during aging. The data indicated that time was a statistically significant factor in the change in the $\mathrm{K}$-factor. The change in $\mathrm{K}$-factor was detected while there was no statistically significant change in the I-V curves; a change in the I-V curve might indicate degradation. Finally, the LEDs were damaged during assembly, which may have an adverse affect on these results.

Table 4.1: Summary of experimental design.

\begin{tabular}{|c|c|c|c|c|}
\hline & \multicolumn{3}{|c|}{ Calibration Current } \\
\hline & & $100 \mathrm{~mA}$ & $350 \mathrm{~mA}$ & $700 \mathrm{~mA}$ \\
\hline \multirow{3}{*}{$\begin{array}{c}\text { Aging } \\
\text { Condition }\end{array}$} & $\begin{array}{c}\mathbf{1 4 5} \mathbf{5}^{\circ} \mathbf{C} \\
\text { average junction } \\
\text { temperature } \\
\text { Group A } \\
\text { Boards } 1 \text { and } 2 \\
\text { (Aged with } 470 \mathrm{~mA} \text { ) }\end{array}$ & Data Rejected & Data Rejected & Data Rejected \\
\hline & $\begin{array}{c}\mathbf{1 1 5}^{\circ} \mathbf{C} \\
\text { average junction } \\
\text { temperature } \\
\text { Group B } \\
\text { Boards } 3 \text { and } 4 \\
\text { (Aged with } 350 \mathrm{~mA} \text { ) }\end{array}$ & Data Rejected & Analyzed & Analyzed \\
\hline & $\begin{array}{c}\text { Control } \\
\text { Board } 5\end{array}$ & Data Rejected & Analyzed & Analyzed \\
\hline
\end{tabular}




\subsection{0mA versus $350 \mathrm{~mA}$ and $700 \mathrm{~mA}$ Test Current Data}

When the data acquisition system was designed, it was designed to be able to measure from $0.1 \mathrm{~mA}$ up to $1000 \mathrm{~mA}$. However, with modifications to convert it from constant voltage to constant current, some stability issues arose. To resolve these problems, a resistor that was meant for testing at $1000 \mathrm{~mA}$ was used for all current ranges. This is further discussed in section 2.1. By performing this modification, the ability to measure low currents was adversely affected. When a $100 \mathrm{~mA}$ test pulse is measured across the $0.37 \Omega$ resistor, the measured voltage is $37 \mathrm{mV}$. Compounding this problem, this signal is being measured 15 feet away, with a 30 -foot length of cable. While the signal is transmitted through a twisted pair to reduce noise, noise still gets into the signal. The amount of noise in the signal compared to the signal itself becomes noticeable. This caused the results of $100 \mathrm{~mA}$ measurements to be highly unpredictable. Figure 4.1 shows a plot of the K-factor versus time for the control board. Linear trend lines were applied to all three data series to show their linearity. The data at $700 \mathrm{~mA}$ and $350 \mathrm{~mA}$ shows that they agree fairly well with the trend line. The trend line is nearly horizontal as it is expected to be for a board that has never been stressed with any aging. This is in comparison to the $100 \mathrm{~mA}$ data, which does not agree with a linear trend line. The $100 \mathrm{~mA}$ data should be flat and linear as in the $350 \mathrm{~mA}$ and $700 \mathrm{~mA}$ data sets. Both Group A and B also exhibit this trend of the data being erratic at $100 \mathrm{~mA}$. 


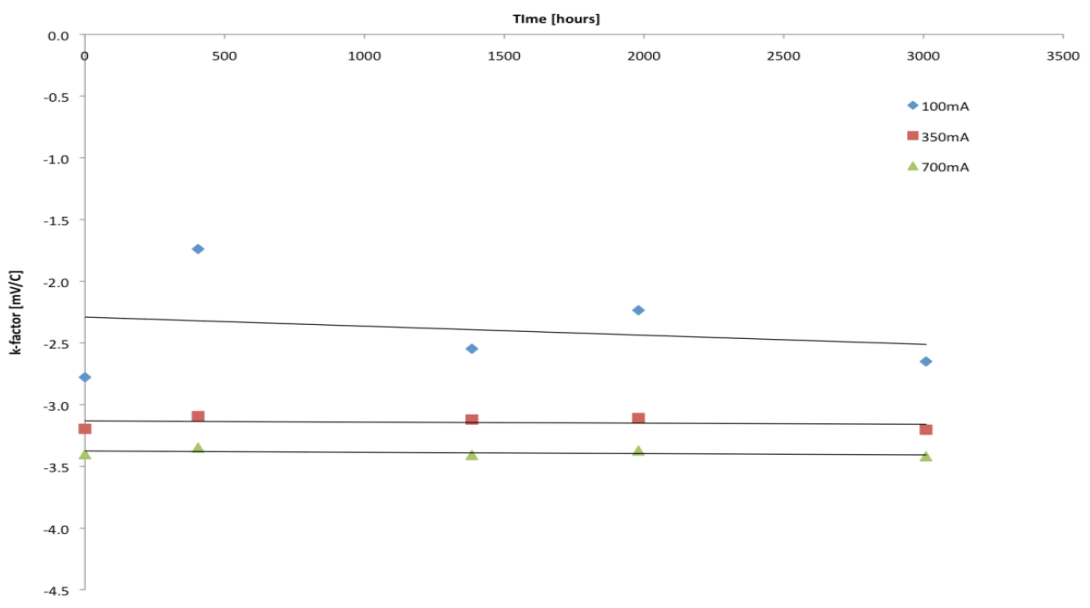

Figure 4.1: Average K-factor values versus time. 350 and $700 \mathrm{~mA}$ data follows a linear trend line as expected, however $100 \mathrm{~mA}$ data is erratic indicating errors at low current measurements.

Using Minitab, the results from K-factor values at different current levels were compared versus time. Initially, the data was assumed to be normal and a One-Way ANOVA analysis was performed on each test current level $(100,350$, and $700 \mathrm{~mA})$ and was compared versus time. For an ANOVA analysis the following two hypotheses are used:

\section{$\mathrm{H}_{0}$ : All means are the same \\ $H_{A}$ : At least one mean is not the same}

The results indicated that the $100 \mathrm{~mA}$ test current was highly dependant on time with a Pvalue of 0.000 . The $350 \mathrm{~mA}$ and $700 \mathrm{~mA}$ test currents were independent from time with P-values greater than 0.9. The board being studied was the control; none of the test currents should be dependant on time.

Unfortunately, the residual plots from the analysis indicated that the data was not normal. Figure 4.2 shows the residual plots for $100 \mathrm{~mA}, 350 \mathrm{~mA}$, and $700 \mathrm{~mA}$ test currents versus time. ANOVA is relatively robust against lack of normality, however a nonparametric study was conducted to verify the results of the ANOVA analyses. 

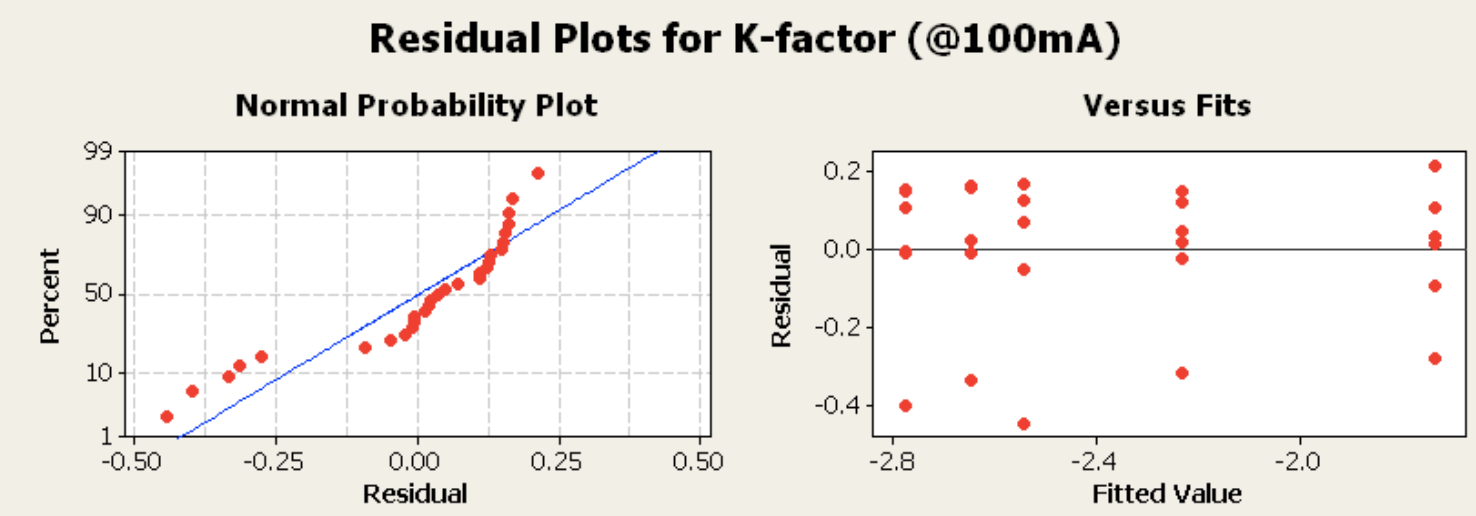

\section{Residual Plots for K-factor (@350mA)}
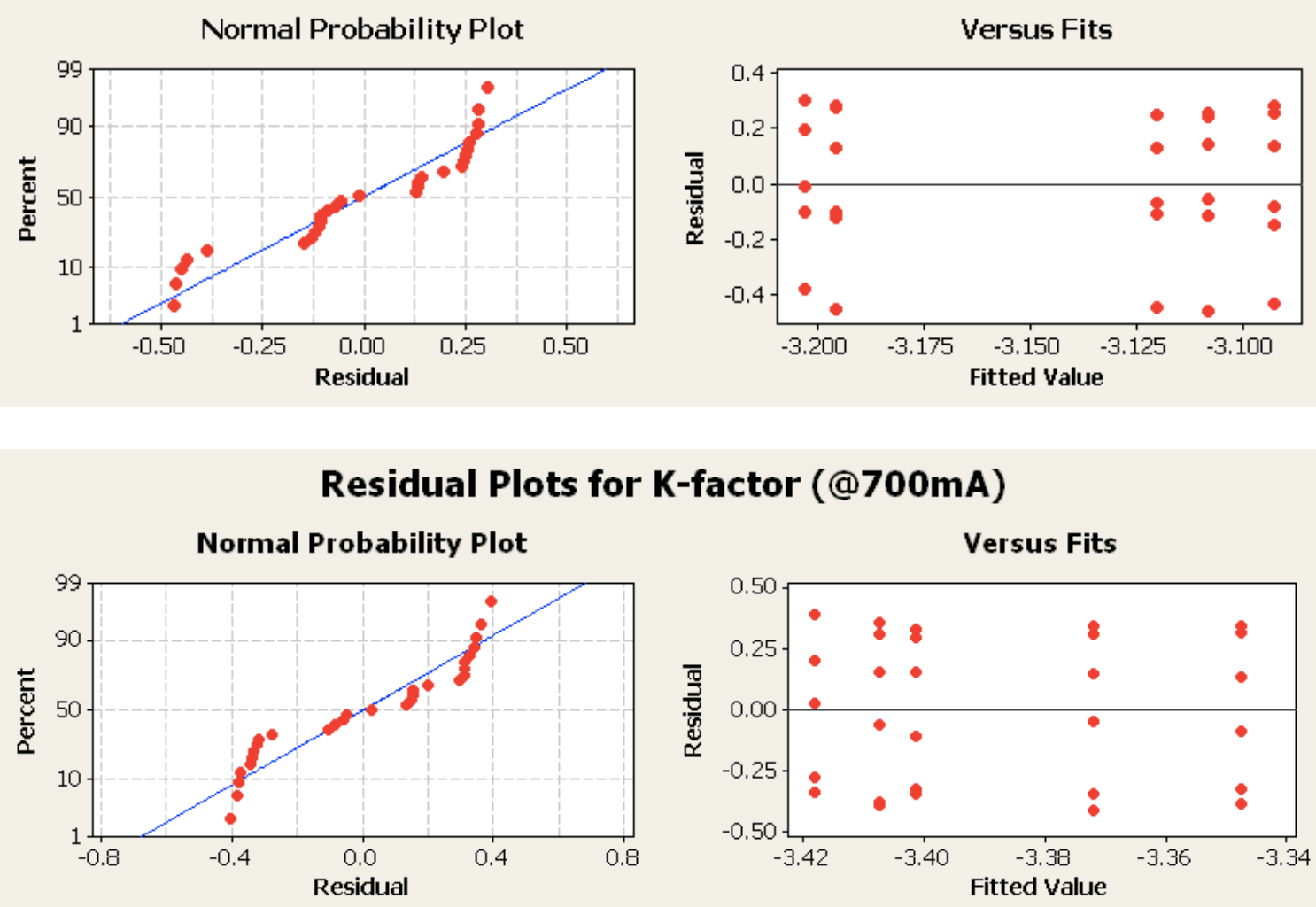

Figure 4.2: Normality and Residual versus Fitted value plots for $K$-factor versus Time at $100 \mathrm{~mA}, 350 \mathrm{~mA}$, and $700 \mathrm{~mA}$. P-value $<\mathbf{0 . 0 0 5}$ for the normality test in each case indicating a lack of normality. 
A Kruskal-Wallis non-parametric test was performed on the data. The hypothesis for this test is different from that of an ANOVA test, which checks if all means are the same. The Kruskal-Wallis test uses the median. The following hypotheses are used for the test:

\section{$\mathrm{H}_{0}$ : Medians are equal}

\section{$\mathrm{H}_{\mathrm{A}}$ : Medians are not equal}

Table 4.2 shows the result for this test for each test current level. At 100mA, a P-value of 0.000 was determined. Therefore, the null hypothesis should be rejected which means that the medians are different. When testing $350 \mathrm{~mA}$, a P-value of 0.743 is calculated. Such a high P-value indicates that the test fails to reject the null hypothesis, which would indicate no significant difference in the medians. A similar result with $700 \mathrm{~mA}$, a P-value of 0.921 was calculated.

The initial One-Way ANOVA analysis of each current level may have been invalid due to lack of normality, however the results from that initial study matched that of the non-parametric study, which does not require normal data. Since the control board had never been aged, there should be no change at any current level. The results from the analyses and plots for $350 \mathrm{~mA}$ and $700 \mathrm{~mA}$ test currents agree that there was no change due to time on the control board, as expected. However, at 100mA there was a statistically significant change when there should not be. As a result of this, the $100 \mathrm{~mA}$ test current data was rejected on all 5 boards. 
Table 4.2: Kruskal-Wallis Test for K-factor versus Time for the control board. The $100 \mathrm{~mA}$ test current shows that time is significant, however the $350 \mathrm{~mA}$ and $700 \mathrm{~mA}$ test currents show that time is not significant.

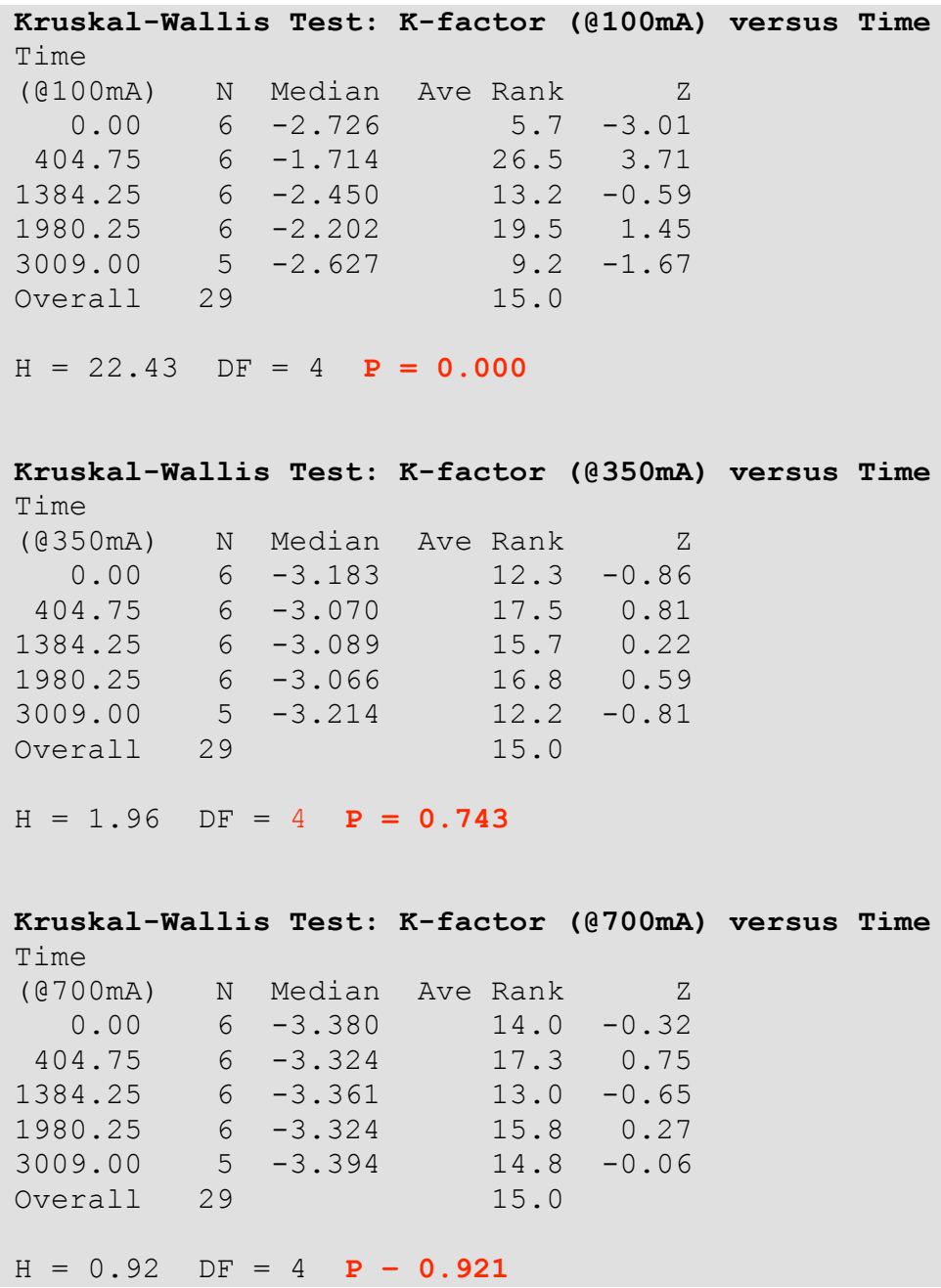




\subsection{K-factor of LEDs aged at $145^{\circ} \mathrm{C}$ (Group A)}

The choice to use two aging temperatures was driven by the need to ensure that data was possible to collect after the duration of accelerated aging. Group A was aged with an average junction temperature of $145^{\circ} \mathrm{C}$ (using $470 \mathrm{~mA}$ during aging) and Group B was aged at $115^{\circ} \mathrm{C}$ (using $350 \mathrm{~mA}$ during aging). While the datasheet quoted a maximum junction temperature of $150{ }^{\circ} \mathrm{C}$, there is reason to believe that a few of the chips still were beyond that temperature.

Group A began to fail very rapidly after 405 hours (approximately 17 days) and $25 \%$ of Group A's LEDs had failed. At 1385 hours ( $\sim 58$ days) all of the LEDs in Group A had failed. While this had always been a possibility, very little data was collected on these LEDs. As a result, only two data points were measured. Time 0 , and Time 1 at 405 hours. It is nearly impossible to gather useful trend data from two data points while knowing that the measurements can vary from time period to time period. Figures 4.3 and 4.4 show the K-factor versus time for board 1 and board 2 respectively. These two boards together make up Group A $\left(145^{\circ} \mathrm{C}\right)$.

The sheer lack of data makes it difficult to compare results and have confidence in the data. Due to the lack of data for Group A, the results will not be considered in the determination of the K-factor's degradation. 


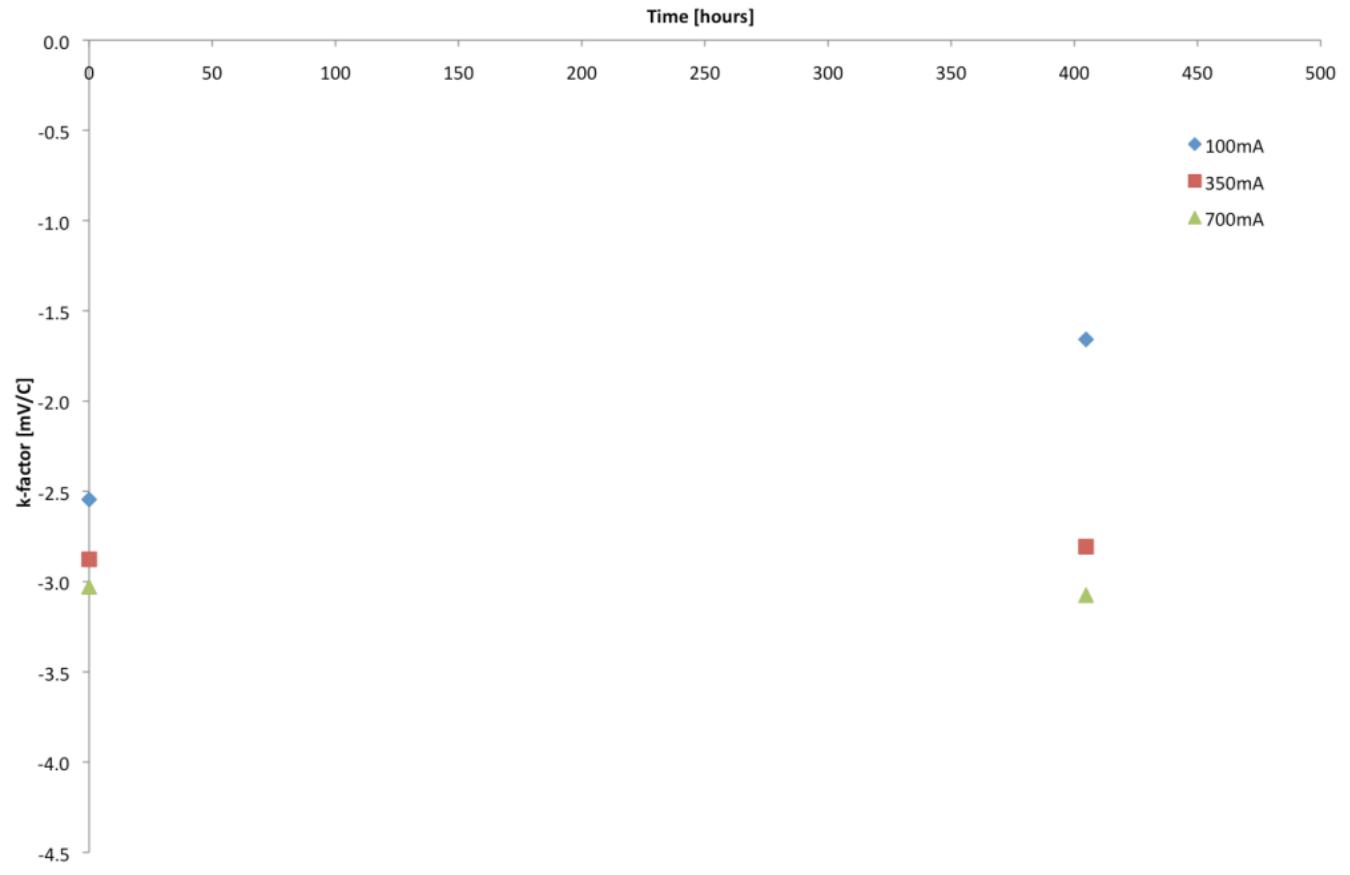

Figure 4.3: Board 1 K-factor versus time.

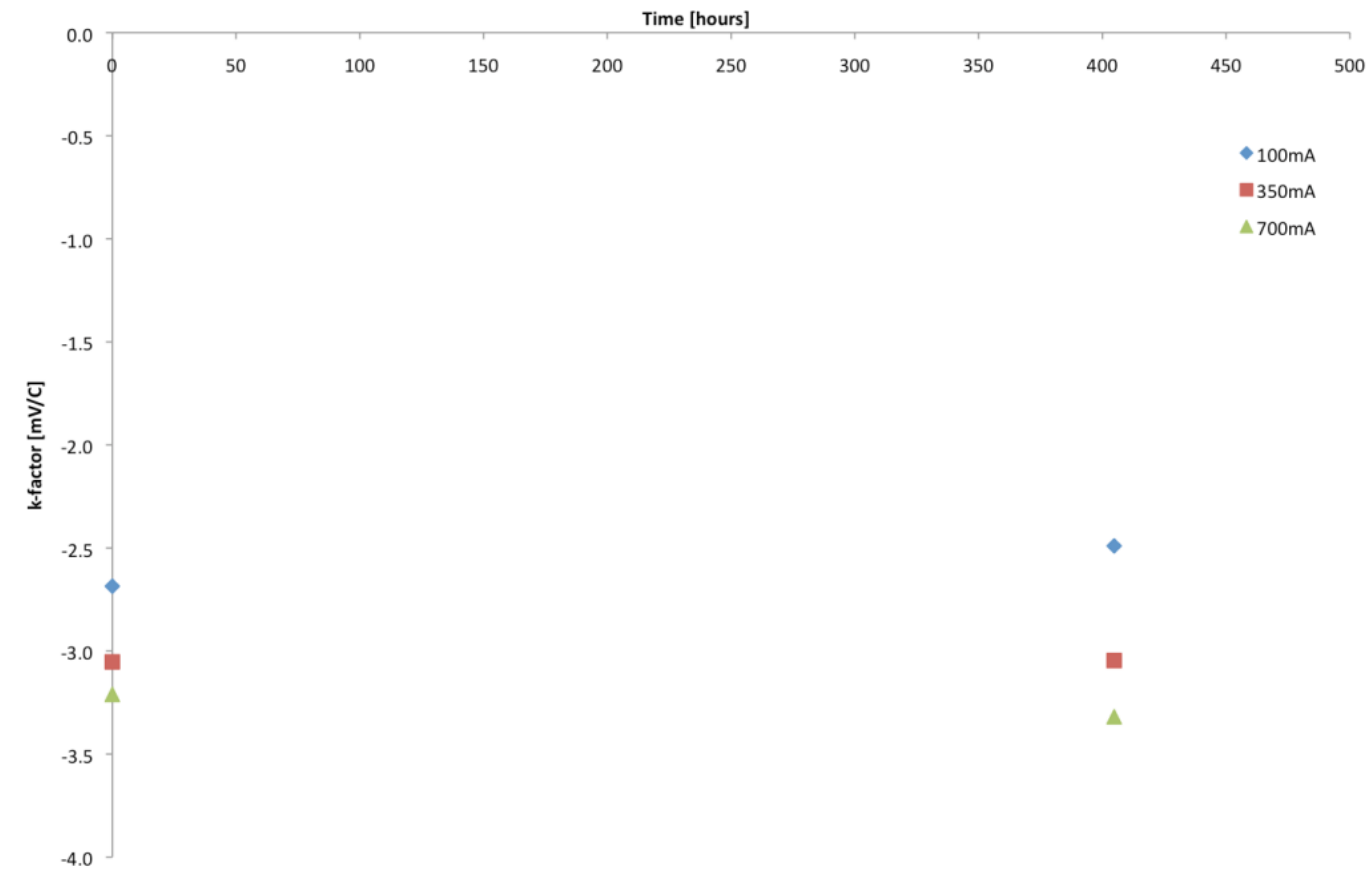

Figure 4.4: Board 2 K-factor versus time. 


\subsection{K-Factor Changes for Data Aged at $115^{\circ} \mathrm{C}$ (Group B)}

The heart of this research is the forward-voltage to junction-temperature coefficient, K-factor, degradation. Despite many setbacks and challenges in verifying data occurred, it does appear that there is a significant effect of time on the K-factor's degradation. While the testing period is too short to determine a model to predict future degradation, there is indeed a statistically different value in the $\mathrm{K}$-factor.

Results in section 4.1 showed that the data collected at $100 \mathrm{~mA}$ was rejected due to erratic values, most likely due to measuring at the limits of the DAQ's capabilities. Results in section 4.2 show that Group A, which was aged at $145^{\circ} \mathrm{C}$, degraded too rapidly to collect useful data. Due to rapid failure of Group A, only Group B's (aged at $115^{\circ} \mathrm{C}$ ) data is used in the analysis of $\mathrm{K}$-factor degradation as presented in section 4.2.

With all of the factors considered in this study, there appears to be a significant change in the means of the K-factor with respect to time. Table 4.3 shows a Minitab General Linear Model analysis of the K-factor versus the boards, time, and test current. While the study is interested purely in the change due to time, the boards within Group B (board 3 and board 4) appear to be significant in this study. The boards have a P-value of 0.033 , which indicates that the null hypothesis is rejected $\left(\mathrm{H}_{0}: \mu_{\mathrm{B} 3}=\mu_{\mathrm{B} 4 ;} \mathrm{H}_{\mathrm{A}}: \mu_{\mathrm{B} 3} \neq \mu_{\mathrm{B} 4}\right)$. In other words, the two boards in Group B were not the same on average. Also, the study shows that the test current is significant. This is expected, as shown in Equation 2.2, that the $\mathrm{K}$-factor is dependant on the test current.

The final, and most important, factor is the time. The time is also a highly significant factor in the analysis. The low P-value of 0.000 indicates that the null hypothesis should be rejected. This means that at least one of the time intervals average 
is different than another. Analyzing the data at each of the time intervals reveals that the initial calibration is significantly different than time period 2,3 , and 4 . This can also be seen in the main effects plot shown in Figure 4.5. The results showed that from the initial calibration to the third calibration that there was a $10.4 \%$ change in the K-factor.

The main effects plot, Figure 4.5, showed that both current and board factors are important. However, the time is also critical. Interestingly enough the values increase and then dips at the end. This dip at the end occurs for an unknown reason at this time.

Table 4.3: Minitab analysis of K-factor versus board, time, and current.
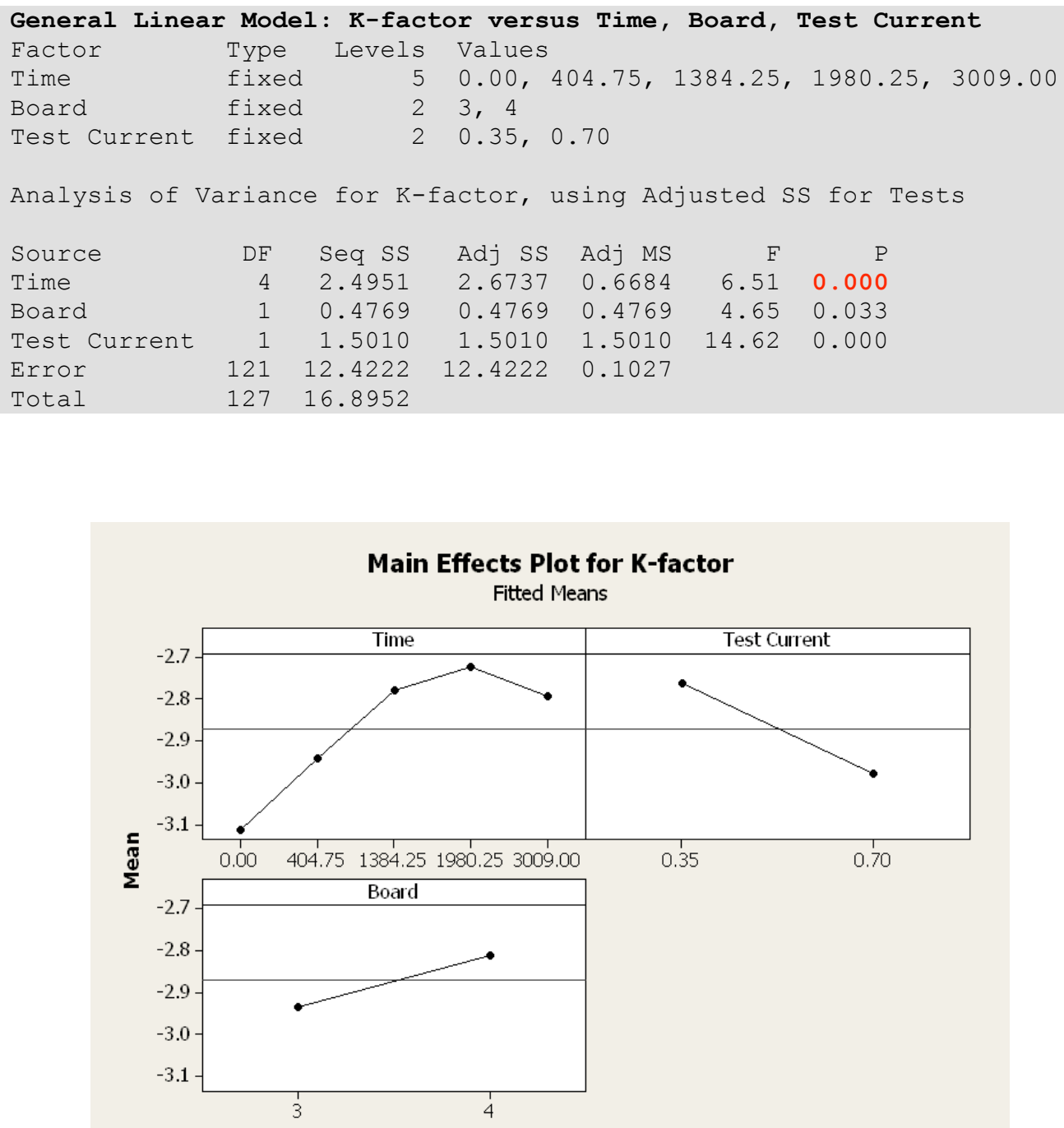

Figure 4.5: Main effects plot for K-factor versus Board, Time (Hours), Current 
Finally, the residual plot was analyzed. Figure 4.6 shows the residual plot. When testing the residuals manually, a P-value of 0.131 is calculated. This indicates that the data is normally distributed. The plot of residuals versus fitted value appears to be reasonably random enough to satisfy the constant variance requirement. Finally, looking at the residual versus observation, there appears to be some data that has a fairly large residual at the midpoint and at the end. The data was entered in as board 3 from time 0 to time 4 and then board 4 from time 0 to 4 . So the middle point and end point that shows a lot of residual in fact is from time 4. At this time, the reason for this large residual is unknown.

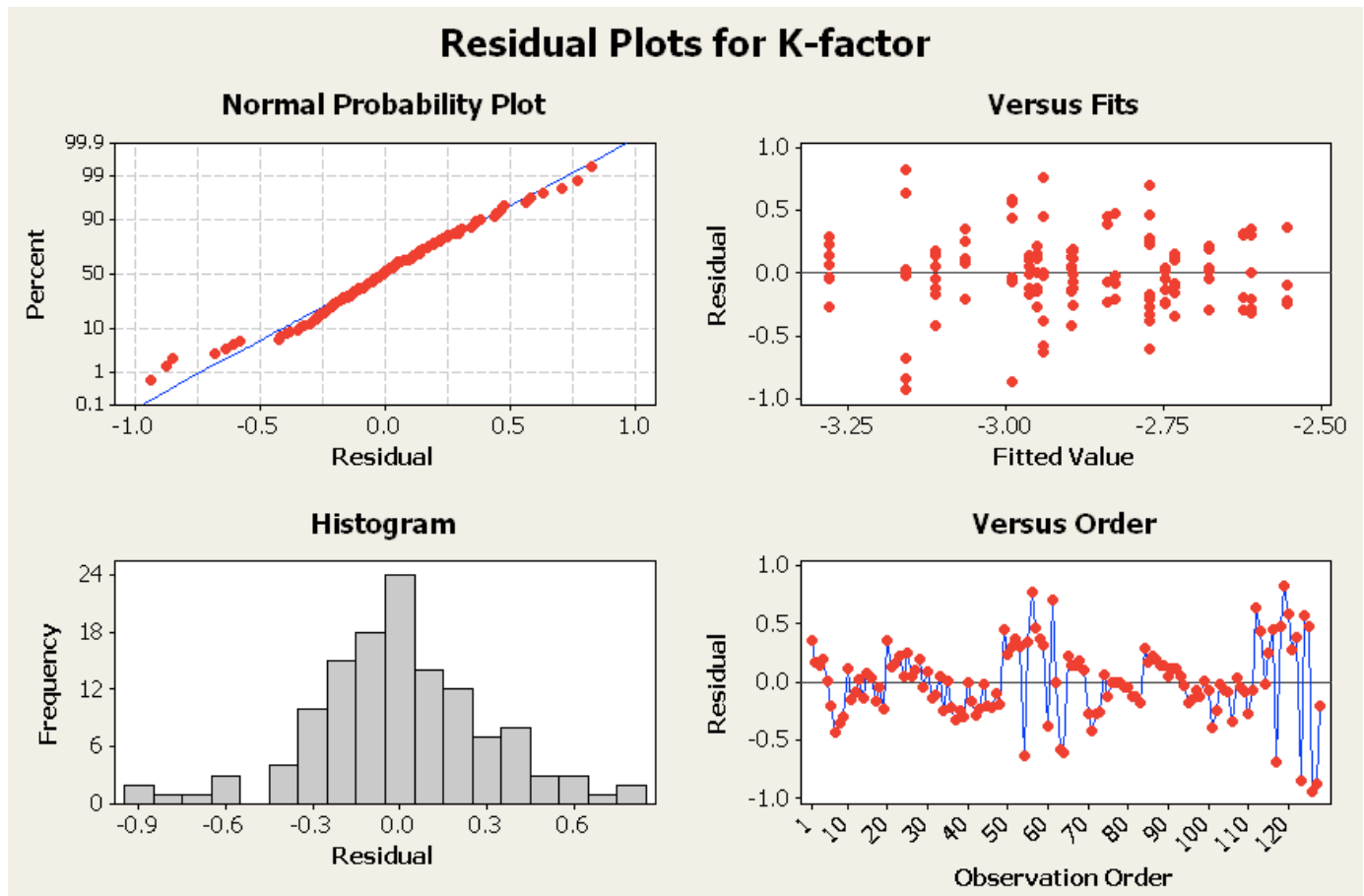

Figure 4.6: Residual plot for analysis of K-factor versus Board, Time, Current. The normality test has a P-value of 0.131, which indicates normal data. 


\subsection{Characteristics of I-V curves}

\subsubsection{Initial I-V Curve Characteristics}

There were concerns that hand soldering the LEDs would cause damage to the chips. Engineers at Philips LumiLEDs recommended checking the I-V curve against the datasheet for LUXEON Rebel chips. At first the data appeared to show that the LEDs were not damaged as the Philips engineers suggested. However, upon comparing to data collected from the boards assembled by Philips and the boards that were hand soldered, there was a distinct difference in the I-V curves, which might indicate damaged LEDs. The LEDs did show above average forward voltages, which according to the datasheet and engineers is a sign of a damaged or degraded LED.

The methodology that Philips uses to measure their I-V curve is not entirely reproducible with this experiment. Their method requires taking a LED and applying a set current. While the LED is operating, they used an environmental chamber where they regulated the ambient temperature so that the LED's thermal pad temperature was always $25^{\circ} \mathrm{C}$ throughout the experiment. Using this approach, they generated the I-V curve for their LEDs. Additionally, Philips grouped Cool-white, neutral-white, warm-white, green, cyan, blue, and royal blue LEDs together to generate the I-V curve.

This approach to generating I-V curves is not reproducible with the collected data for this experiment. It is not feasible due to the time it would take to reach a steady state temperature of $25^{\circ} \mathrm{C}$ for $37 \mathrm{LEDs}$, one at a time and then do this at all five measurement time periods. It becomes especially difficult since I-V plots were not analyzed until after the second of set of data was collected. This problem was resolved by using the 
knowledge about each LED's K-factor and voltage offset. Figure 4.7 shows a typical Kfactor plot developed from collected data.

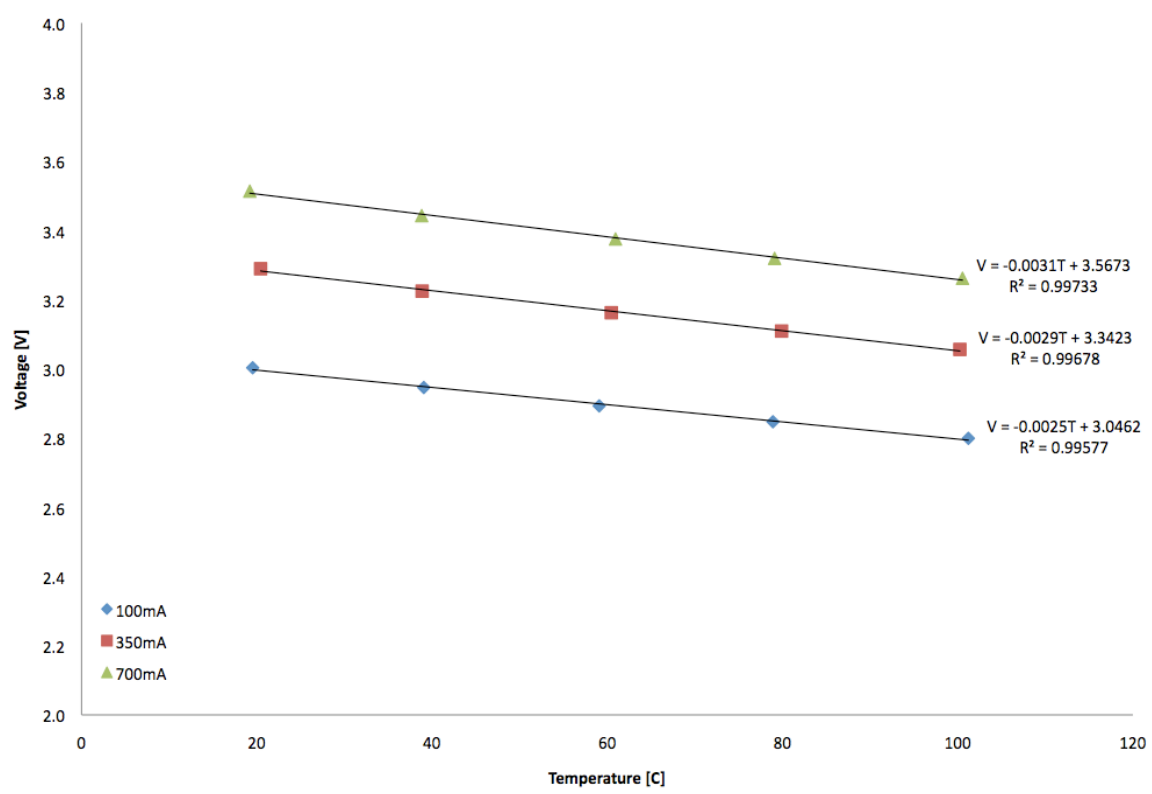

Figure 4.7: Typical K-factor plot generated from collected data.

Using the measured values from each LED, I-V curves were calculated for a junction temperature of $25^{\circ} \mathrm{C}$. This differs from how Philips measures the results by using a thermocouple attached to the base of the LED's thermal pad. The recommended test location is shown in Figure 4.8.

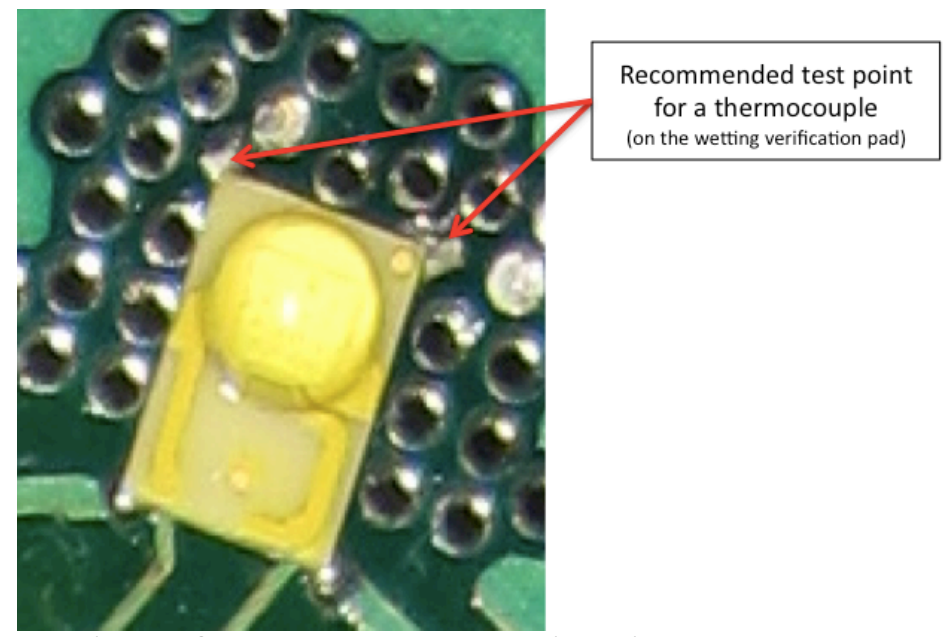

Figure 4.8: Recommended test location using thermocouples. 
By using the thermal resistance of the package to estimate the forward voltage, Equation 4.1 can be developed. This equation determines the forward voltage at a specified thermal pad temperature, $\mathrm{T}_{\text {thermalpad }}$, instead of the junction temperature. The forward voltage of the junction temperature is what was collected in this thesis, which is why Equation 4.1 was needed to convert the data to compare with Philip's results.

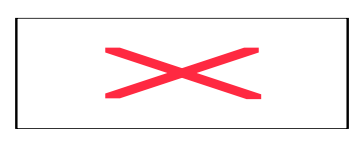

Using Equation 4.1, plots of the I-V curves were made and then compared to the datasheet. Figure 4.9 shows typical board assembled by Philips using reflow soldering to attach the LED packages to a metal-cored PCB. Figure 4.10 shows a typical board that was assembled by hand with a soldering iron. The boards that were assembled with a soldering iron have a distinct shift to the right in the I-V curves for all of the LEDs on the board. This would indicate that there was damage to the LED, which has resulted in an increased the nominal voltage for these diodes. This is in contrast to the boards that were assembled using a reflow oven. Most of the LEDs in Figure 4.9 fall nearly on top of the datasheet's line with the exception of an outlier. Both of these cases are typical for their assembly methods based on the boards that were used to collected data. The board shown in Figure 4.10 is the control test for the data in this thesis.

Between figures 4.9 and 4.10 , there is a distinct difference in the I-V curves. This indicates that hand soldered LEDs were damaged during assembly. This would also indicate that the reflowed boards should be used for data collection instead of the handsoldered LEDs. Unfortunately, too little information is known about the reflowed boards 
due to the time it took to fabricate them. Therefore, the hand-soldered boards are used for the analysis of this topic since adequate data is available on these boards.

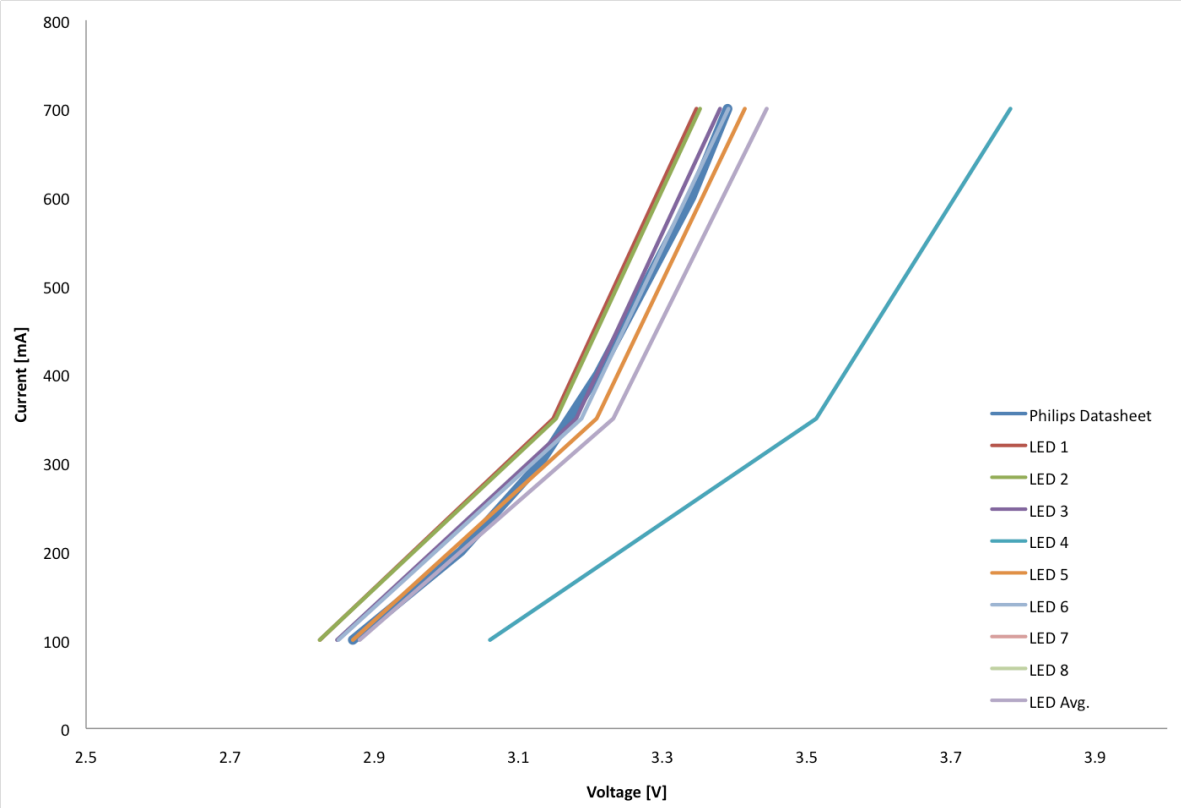

Figure 4.9: Typical plot of LED I-V curves, at timer zero, for metal-cored PCB using reflow soldering compared to Philips Datasheet.

Note: Curve to the far right (LED 4) is not the datasheet curve but rather an outlier.

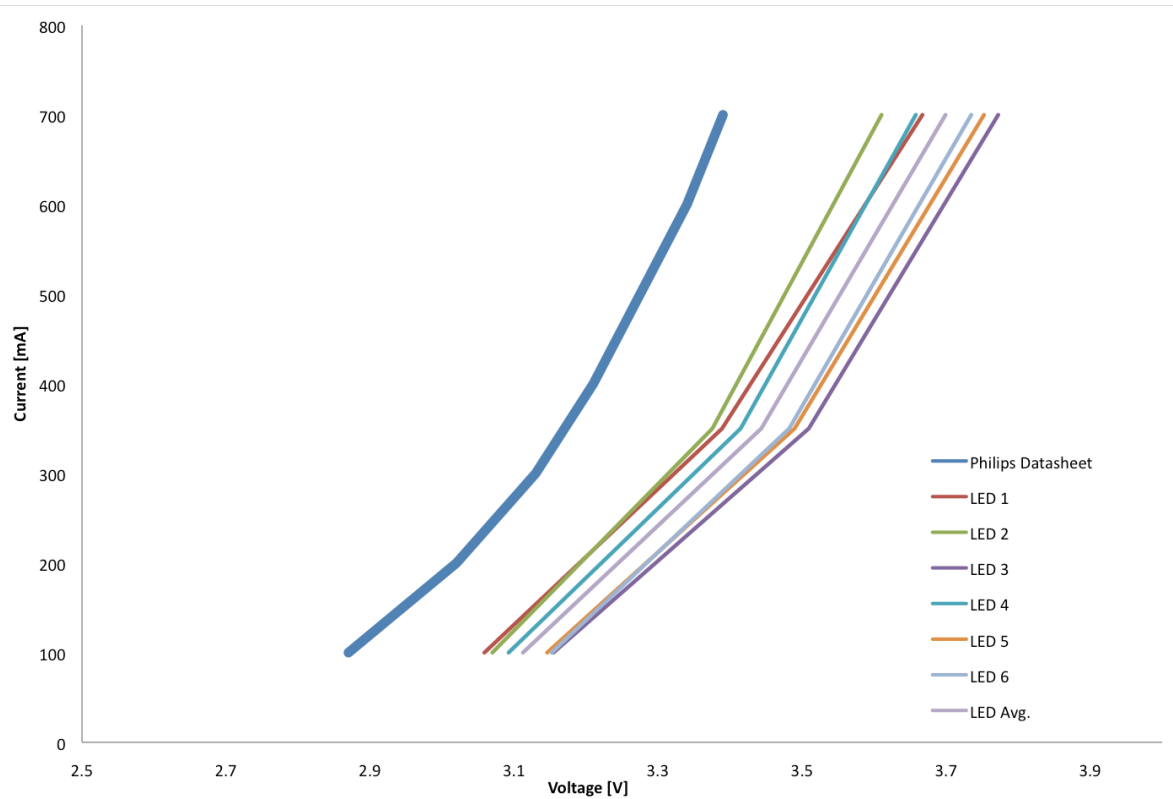

Figure 4.10: Typical plot of LED I-V curves, at time zero, for FR-4 PCB using hand soldering compared to Philips Datasheet. 


\subsubsection{Changes in I-V Characteristics due to Aging}

A critical component of this test was the ability to accelerate testing. Since LEDs can last for over 50,000 hours given the right conditions, it was critical that the tests be accelerated so that results could be seen sooner. The primary objective of having two groups, at different temperatures, was to ensure that there were results due to degradation in at least one of the two groups. As mentioned in section 4.2, Group A (aged at $145^{\circ} \mathrm{C}$ ) failed very rapidly due to high junction temperatures. For this study, Group A was the extreme for too much degradation and the control was the case of no degradation. However, the amount of degradation to Group B (aged at $115^{\circ} \mathrm{C}$ ) needed to be determined.

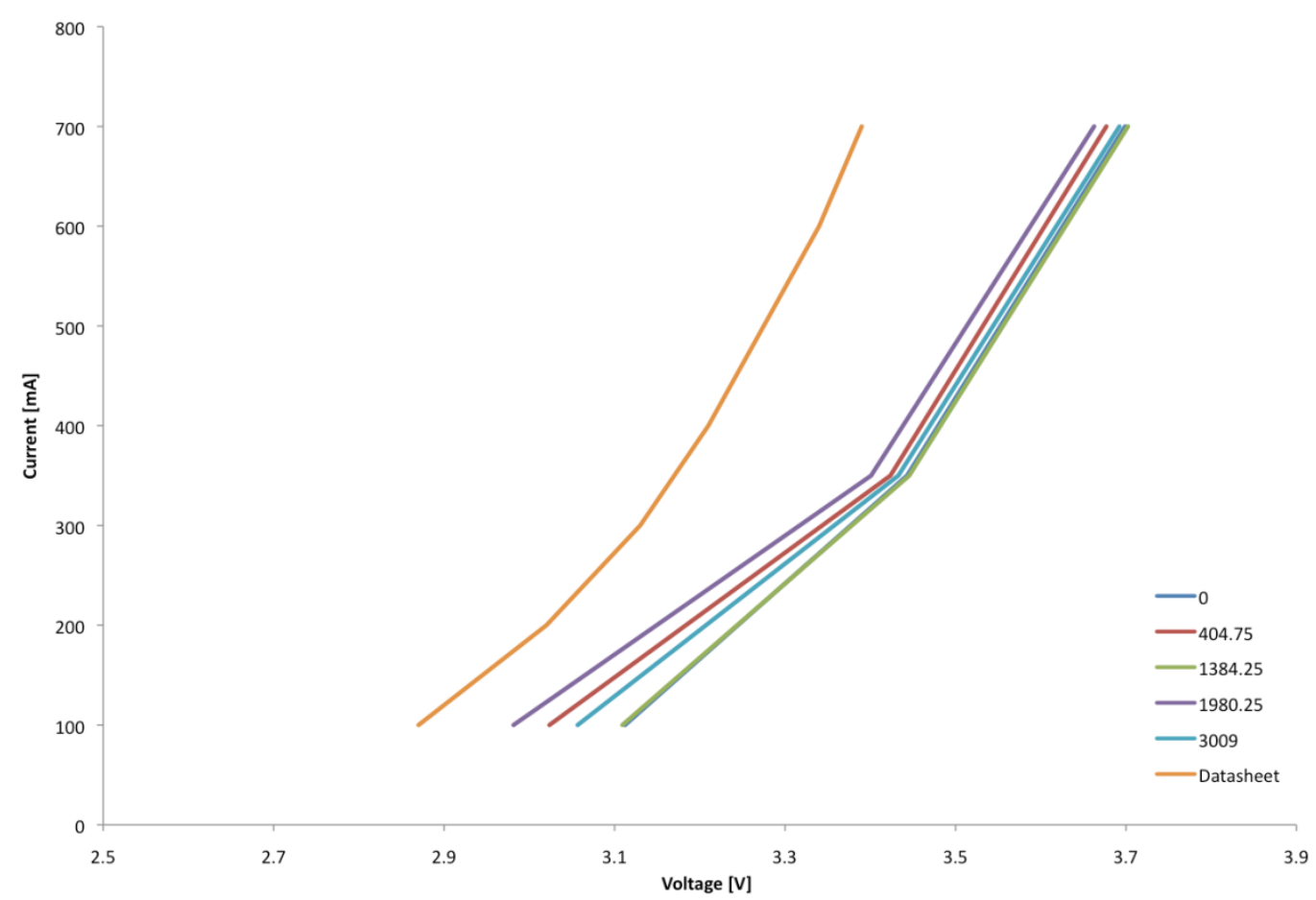

Figure 4.11: I-V curve of control board average values. These curves are from different test points and compared to the datasheet. 
The control board, board 5, was never aged. This would imply that the I-V curves should not show a shift in value. Figure 4.11 shows a plot of the control board average IV curve at each test period compared to the datasheet. As mentioned in section 4.4.1, there was a shift to the right from the datasheet due to degradation caused during assembly. However, there was varying I-V curves at different times and it is necessary to determine the significance of this. Initially an ANOVA test was performed with forward voltage $\left(\mathrm{V}_{\mathrm{f}}\right)$ versus current and time. However, the data proved to be not normally distributed. Figure 4.12 shows the residual plot from the initial ANOVA test.

Since the data was not normal, the Kruskal-Wallis non-parametric test was used. The two hypotheses for the Kruskal-Wallis test are:

\section{$\mathrm{H}_{0}$ : Medians are equal $\mathrm{H}_{\mathrm{A}}$ : Medians are not equal}

Table 4.4 shows the results of the test of $\mathrm{V}_{\mathrm{f}}$ versus time. The study was also broken up into the two different current levels as done in section 4.3.1. In the $350 \mathrm{~mA}$ test current data, a P-value of 0.422 calculated, which indicates that the test fails to reject the null hypotheses and therefore there is not a significant difference in the median value at all time periods for the control board. Similar to the test current data at $350 \mathrm{~mA}, 700 \mathrm{~mA}$ also failed to reject the null hypotheses with a P-value of 0.644 . This result was expected since the control board should have nearly identical I-V curves since it was never aged. 

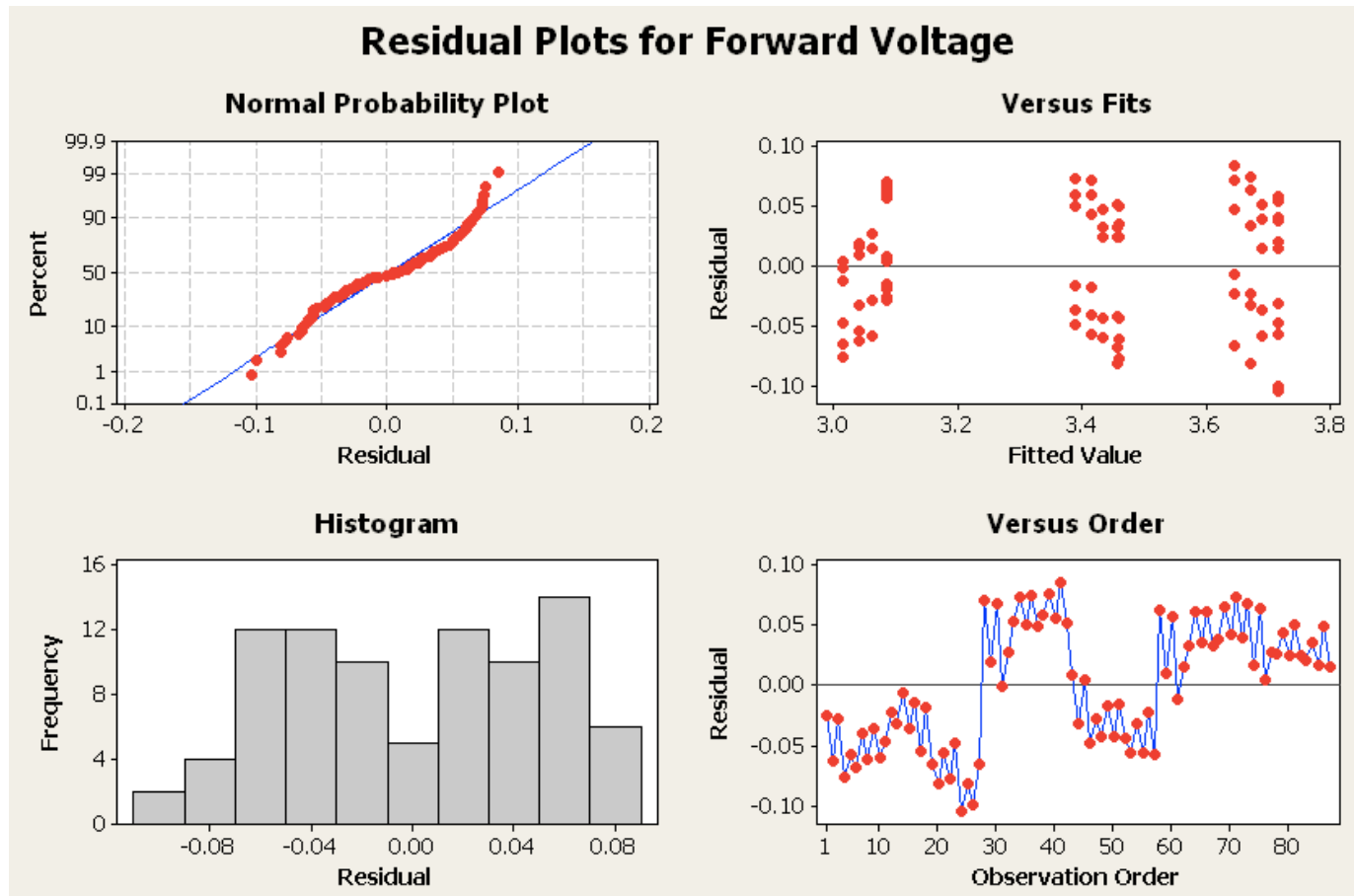

Figure 4.12: Residual plots of an ANOVA analysis of the control board showing the data is not normally distributed. $P$ value for normality test was $<0.005$.

Table 4.4: Analysis of the significance of the control's I-V curves vs. time. The analysis is broken up into two different test current levels, $350 \mathrm{~mA}$ and $700 \mathrm{~mA}$.

\begin{tabular}{|c|c|c|c|c|c|}
\hline \multicolumn{6}{|c|}{ Kruskal-Wallis Test: Vf (@350mA) versus Time (@350mA) } \\
\hline (@ $350 \mathrm{~mA})$ & $\mathrm{N}$ & Median & Ave Rank & $\mathrm{Z}$ & \\
\hline 0.00 & 6 & 3.448 & 20.2 & 0.89 & \\
\hline 404.75 & 7 & 3.424 & 16.0 & -0.31 & \\
\hline 1384.25 & 7 & 3.446 & 20.6 & 1.10 & \\
\hline 1980.25 & 7 & 3.401 & 11.6 & -1.67 & \\
\hline 3009.00 & 6 & 3.445 & 17.2 & 0.05 & \\
\hline Overall & 33 & & 17.0 & & \\
\hline $\mathrm{H}=3.88$ & $\mathrm{DF}=$ & $=4$ & $=0.422$ & & \\
\hline $\begin{array}{l}\text { Kruskal- } \\
\text { Time }\end{array}$ & allis & s Test: & Vf $(@ 700 \mathrm{~mA})$ & versus & Time (@700mA) \\
\hline (@ $700 \mathrm{~mA})$ & $\mathrm{N}$ & Median & Ave Rank & Z & \\
\hline 0.00 & 6 & 3.701 & 19.5 & 0.70 & \\
\hline 404.75 & 7 & 3.677 & 15.9 & -0.35 & \\
\hline 1384.25 & 7 & 3.702 & 19.9 & 0.88 & \\
\hline 1980.25 & 7 & 3.663 & 12.7 & -1.32 & \\
\hline 3009.00 & 6 & 3.699 & 17.5 & 0.14 & \\
\hline Overall & 33 & & 17.0 & & \\
\hline $\mathrm{H}=2.50$ & $\mathrm{DF}=$ & $=4 \mathrm{P}$ & $=0.644$ & & \\
\hline
\end{tabular}


In stark contrast to the control is Group A, which was aged at $145^{\circ} \mathrm{C}$. This group failed due to degradation after the second testing period. If these LEDs had not run at a junction temperature of $145^{\circ} \mathrm{C}$ as long, the degradation would have been less and the LEDs would have not failed. Therefore, the amount of degradation should be strongly dependant on time. Similar to the Control board, an ANOVA test was first done. The resulting residuals were indeed normally distributed. Figure 4.13 shows the result of this test. However to keep the test type the same, a Kruskal-Wallis test was performed. It should be noted that the results from the ANOVA test and Kruskal-Wallis test yielded the same results.
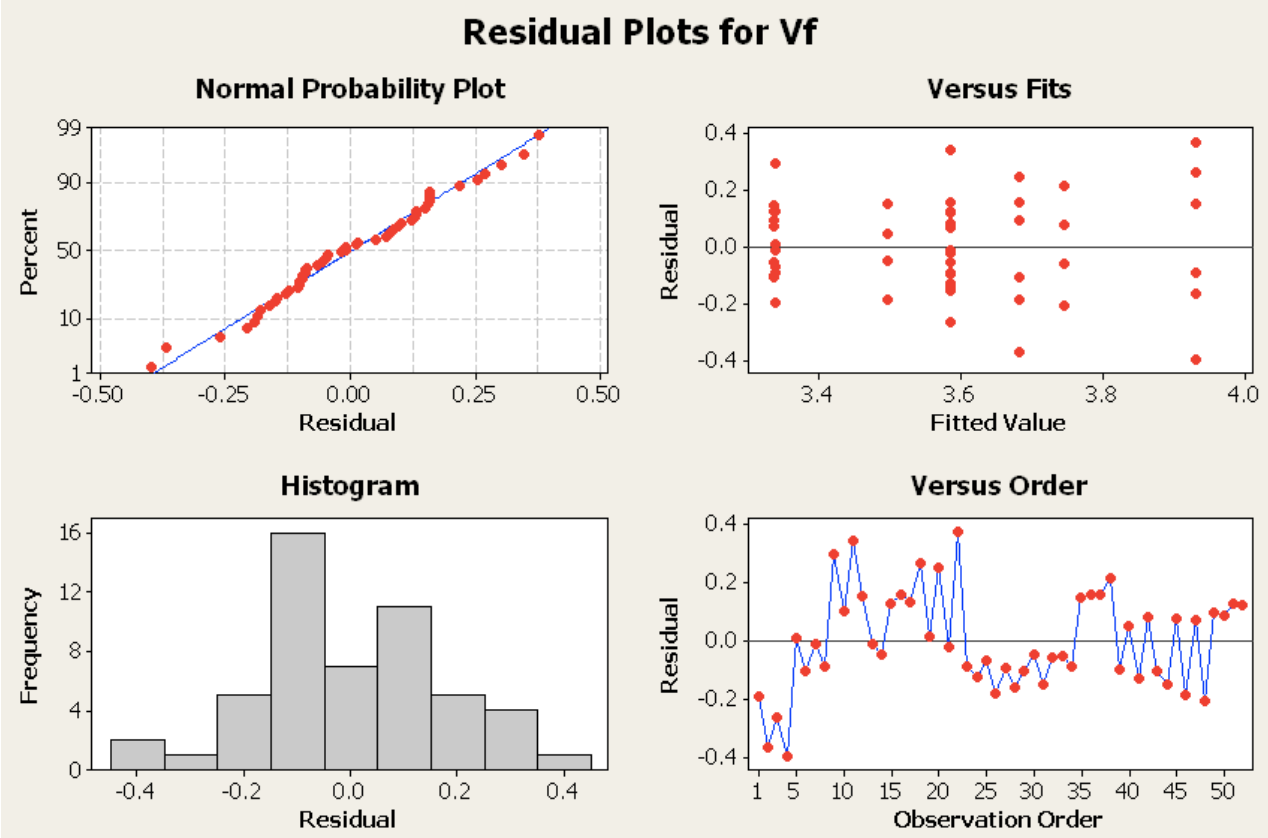

Figure 4.13: Residual plots for Group A (aged at $\left.145^{\circ} \mathrm{C}\right)$ from an ANOVA analysis. The data appears to be normally distributed with a $P$ value of 0.462 .

Figure 4.14 shows Group A's two I-V curves against the datasheet. Since there are only two curves, it is easy to see that there is a shift to the right. However, the plot does not show if this is statistically significant. Table 4.5 shows the Kruskal-Wallis test and the resulting P-value of 0.001 for $350 \mathrm{~mA}$ test current and 0.003 for $700 \mathrm{~mA}$. In both 
cases the null hypothesis was rejected. Therefore there was a statistically significant change in the medians before the LEDs failed. This was expected as it is clear that time at a high current, which resulted in a high temperature, caused rapid failure. It should be noted that any LED that was outside the bounds of the datasheet's nominal value at $350 \mathrm{~mA}$ was considered failed. This means a voltage less than $2.55 \mathrm{~V}$ or greater than 3.99V at 350mA was considered to be failed. However, the LEDs in Group A were all below $1 \mathrm{~V}$, most were below $0.1 \mathrm{~V}$.

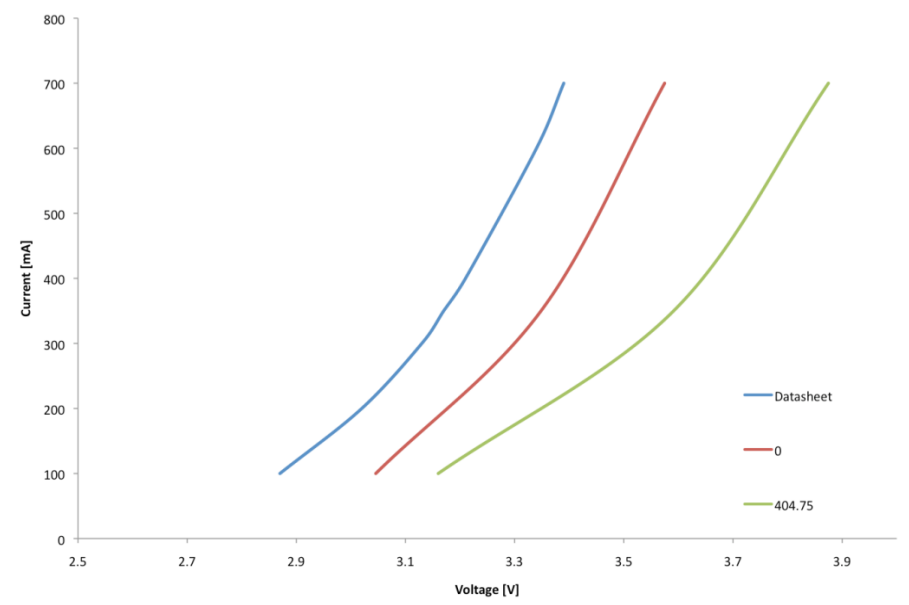

Figure 4.14: Plot of the Average I-V curves for Group A at different times.

Table 4.5: Minitab analysis of Group A's I-V versus time. The results are separated into $350 \mathrm{~mA}$ and $700 \mathrm{~mA}$ test currents.

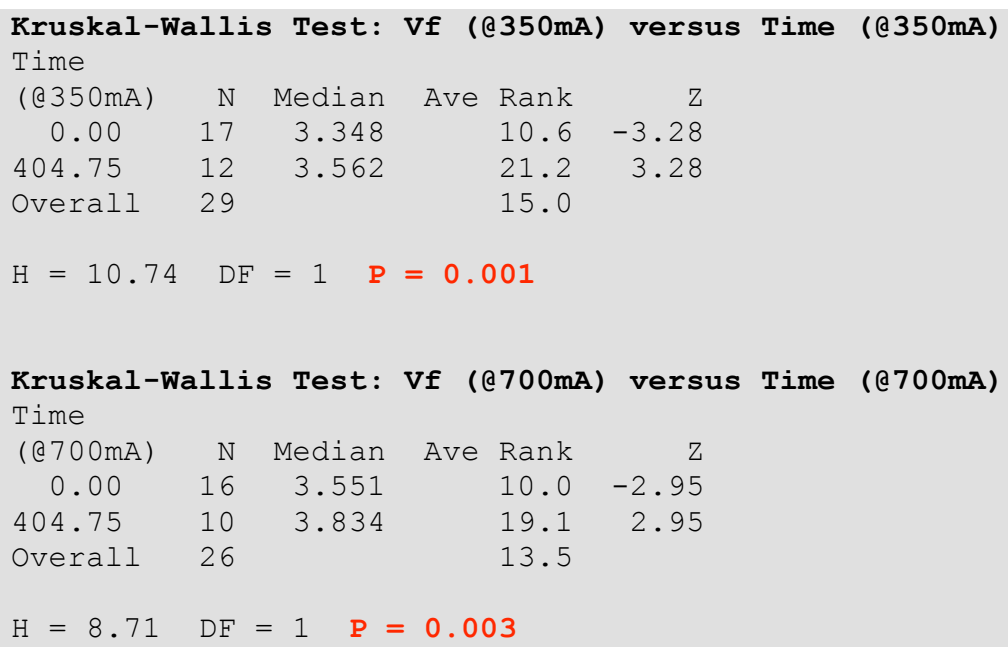


Figure 4.15 shows a plot of Group B's I-V curves at different times. Looking closely at the curves, the value appears to shift left then to the right. The plot appears to be much like that of the control test; however it is hard to be certain. The data for this Board's I-V curves was not normally distributed. Figure 4.16 shows the residual plot for the initial ANOVA test. A non-parametric test was then done which is shown in Table 4.5. These results are somewhat inconclusive. At $350 \mathrm{~mA}$, the P-value was 0.072 . At a $5 \%$ level of significance, the null hypothesis fails to be rejected. At $7.2 \%$ or higher, it is rejected. However, at $700 \mathrm{~mA}$, the P-value was 0.399 , which indicates that the test fails to reject the null hypothesis. The initial ANOVA study determined a P-value of 0.316. These results indicate that there was most likely not a significant change in the I-V curves due to time in Group B.

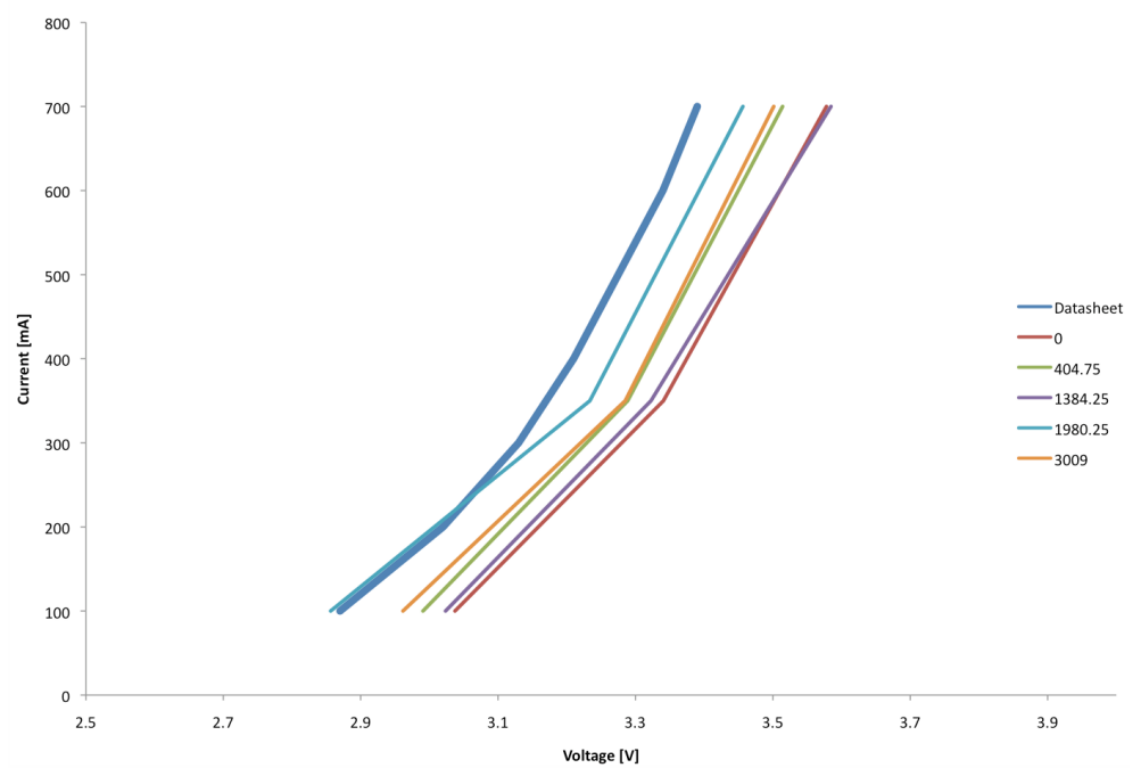

Figure 4.15: Plot of the average of Group B (Boards 3 and 4) I-V curves versus time.

The result of Group B's I-V curves not showing any degradation due to time may possibly indicate that an insufficient amount of time was spent aging these LEDs. 
Unfortunately, due to time constraints of the research, a longer time was not possible. A summary of the results from this section can be found in Table 4.6.

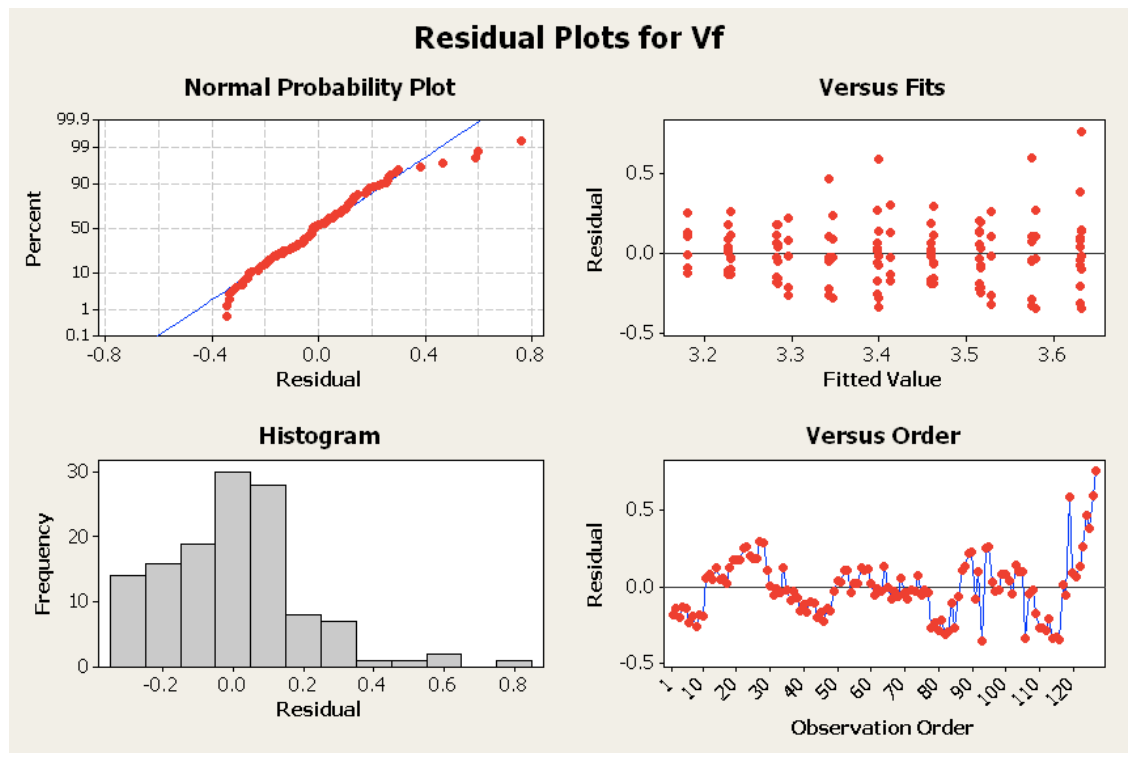

Figure 4.16: Residual plot from an One-Way ANOVA for Group B's (350mA aging current). The resulting plots show that the data is not normally distributed with a $P$ value of 0.040 .

Table 4.6: Minitab analysis of Group B's I-V versus Time.

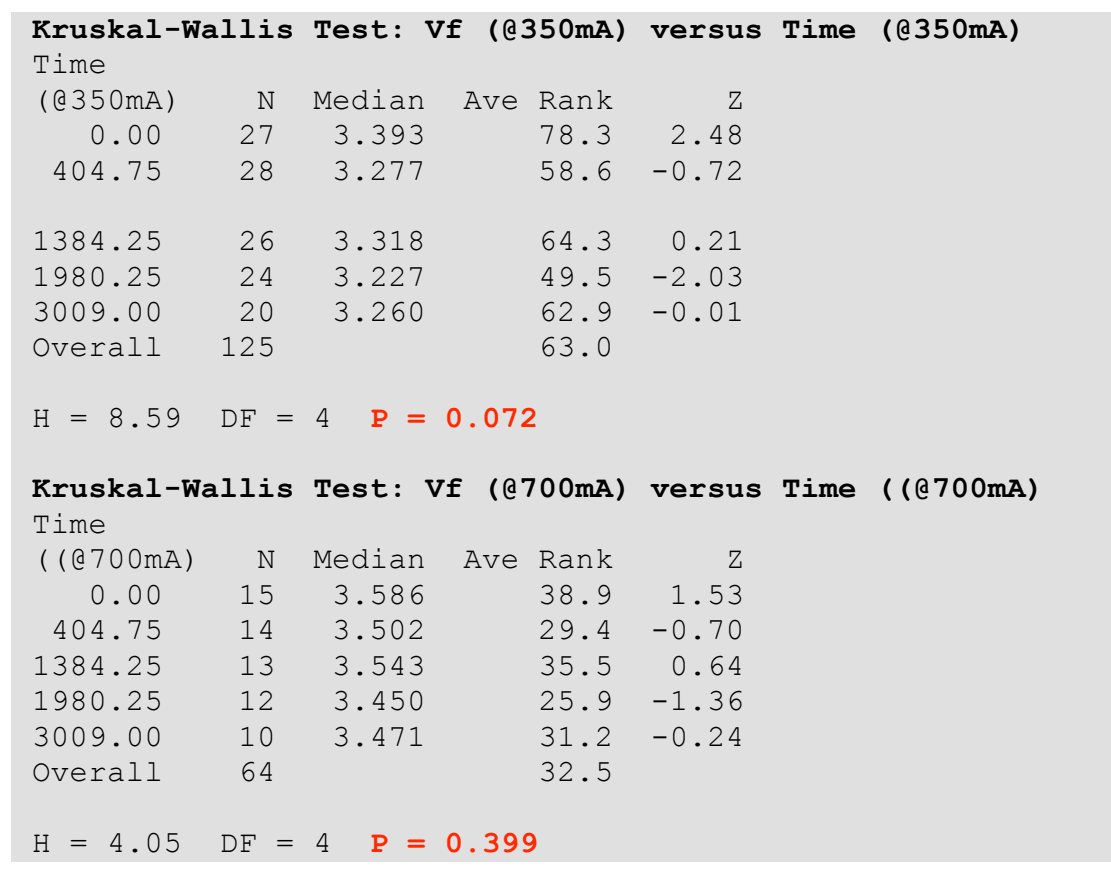


Table 4.7: Summary of results for section 3.2.2

\begin{tabular}{|c|c|c|c|c|c|c|}
\hline & \multicolumn{2}{|c|}{$350 \mathrm{~mA}$ test current } & \multicolumn{2}{|c|}{$700 \mathrm{~mA}$ test current } & \multirow[b]{2}{*}{ Conclusion } & \multirow[b]{2}{*}{ Expected? } \\
\hline & P-value & Result & P-value & Result & & \\
\hline Control & 0.422 & $\begin{array}{l}\text { Fail to } \\
\text { reject } \mathrm{H}_{0}\end{array}$ & 0.644 & $\begin{array}{l}\text { Fail to } \\
\text { reject } \mathrm{H}_{0}\end{array}$ & $\begin{array}{l}\text { I-V curves have not } \\
\text { changed }\end{array}$ & Yes \\
\hline $\begin{array}{l}\text { Group A } \\
\text { (Aging current } \\
470 \mathrm{~mA})\end{array}$ & 0.001 & Reject $\mathrm{H}_{0}$ & 0.003 & Reject $\mathrm{H}_{0}$ & $\begin{array}{l}\text { I-V curves have } \\
\text { changed }\end{array}$ & Yes \\
\hline $\begin{array}{l}\text { Group B } \\
\text { (Aging current } \\
350 \mathrm{~mA})\end{array}$ & 0.072 & $\begin{array}{l}\text { Possibly } \\
\text { reject } \mathrm{H}_{0}\end{array}$ & 0.399 & $\begin{array}{l}\text { Fail to } \\
\text { reject } \mathrm{H}_{0}\end{array}$ & Most likely no change & \\
\hline
\end{tabular}




\section{Chapter 5 - Conclusions and Recommendations}

\subsection{Data Acquisition System}

Overall the data acquisition system worked well. It was able to accurately measure the forward voltage within short pulses. The measured values were verified against the datasheet of the tested chips. As mentioned in the design and testing section, there were numerous problems that were ultimately resolved which allowed for accurate testing. The DAQ design met the requirements of the measurement system. It was able to pulse a LED rapidly, collect many samples during this period, measure multiple chips, and test various currents. There was an issue with low current levels as discussed in section 4.1; however this was a small problem, which was resolved.

\subsection{K-Factor Degradation}

Overall the study was successful in showing that the K-factor does change. A statistically significant amount of change was detected between the initial calibration and the last three calibrations. Within 3000 hours, a $10.4 \%$ change in the K-factor was measured. This degradation was detected on Group B, which was aged at $115^{\circ} \mathrm{C}$. This elevated temperature was high, however only minimal changes in the I-V curves occurred. The I-V curves were monitored for shifts to the right or left which may indicate damage. During the aging process, Group B did not exhibit a statistically significant degradation even though the $\mathrm{K}$-factor changed. The lack of change in the I-V 
curves in Group B was strongly contrasted by the I-V curves from Group A. Group A was aged at average junction temperature of $145^{\circ} \mathrm{C}$. These LEDs degraded so rapidly that before the end of the second aging period, they had all failed. The results from these LEDs were not considered in the study.

The data collected from Group B turned out to be reasonably normally distributed. This result helped greatly in the analysis of the data. An analysis of Group B's results also indicated that the two boards that made the group were statistically different from each other despite receiving identical aging currents. At this time, the source of this difference is not fully understood; however it may have been due to the amount of damage done to the LEDs during assembly.

The boards that were analyzed in this study were assembled by hand. Surface mount chips were attached by using a soldering iron. This resulted in clearly damaged LEDs when comparing these boards to boards assembled using a reflow oven. This conclusion was drawing from comparing the I-V curves of both assembly methods relative to the values specified by Philips LumiLEDs. On a final note, datasheets from most LED manufactures only specify a single K-factor at one specified current. The LEDs used in this study were only specified at $350 \mathrm{~mA}$ for K-factor by the manufacturer. Theory suggests that there should be a different K-factor for each current, and there indeed does as this study has shown. Having multiple current levels specified by the manufacturer would have greatly aided in verification of the collected data. The values collected at $350 \mathrm{~mA}$ did indeed match the datasheet, however more data points for comparison would have been helpful. 


\subsection{Future Study}

Currently there are no plans to continue this study. However, this study would greatly benefit from more aging. The LEDs that were tested may have a break-in period, which causes some tests to require a reset of data after the first 1000 hours. A data reset was not done in this test. Also, more calibration periods with shorter aging durations between calibrations would enhance this study. This would allow for a better understanding of the data trend and possibly allow the development of a model to forecast the K-factor for certain parameters.

This study also needs to be run in a way to isolate the current from the temperature. This would probably require a few aging currents and ovens to maintain the junction temperature at specific temperatures. This would require a lot more equipment; however, it would greatly assist in determining how the K-factor changes with respect to time.

The PCBs that were used in this study should have been reflowed. Ultimately there were some boards assembled using a reflow oven. These boards were fabricated from metal-cored PCB late into the study, which meant there was not enough time to collect data. However, even FR-4 with reflow soldering would greatly reduce the damage to these LEDs during assembly. Due to the damage of hand soldering, there is no way to tell if the K-factor changes that were seen are due to degradation or because of the hand soldering.

The data acquisition had many shortcomings that hindered the collection of data. Due to such a time constraint, LabView was used. Using LabView caused many 
problems that could have been avoided simply by using an imbedded processor.

LabView had many runtime errors because of the multiple requests to take measurements. This would cause errors that would crash the collection system; unfortunately there was no way to bypass this type of error with a simple redesign. Also, LabView was painfully slow at collecting data. If this type of data acquisition system is redesigned, LabView should not be used.

Finally, a better extrapolation model should be used to find the forward voltage during calibration. Currently a simple linear fit is being used. A model that incorporated more of the solid-state physics and heat transfer would provide a superior model. This model, if possible should include the rise time associated with the driver. The rise time could be improved with redesign of the circuitry; however there will always be a rise time and this is why the model should include it. 


\section{References}

[1] Cree. "Cree Breaks 200 Lumen Per Watt Efficacy Barrier.” 3 Feb 2010. 14 May 2010. <http://www.cree.com/press/press_detail.asp?i=1265232091259>.

[2] Cree. Cree XLamp LED Thermal Management. 2006. Jan 2009. $<$ http://www.cree.com/products/pdf/XLampThermalManagement.pdf>.

[3] Mehmet Arik, Charles Becker, Stanton Weaver, and James Petroski. "Thermal Management of LEDs: Package to System.” 2004. Jan 2009. <http://lib.semi.ac.cn:8080/tsh/dzzy/wsqk/SPIE/vol5187/5187-64.pdf>.

[4] Alliance for Solid-State Illumination Systems and Technologies (ASSIST). LED Life for General Lighting: Definition of Life, Volume 1, Issue 1. New York Lighting Research Center, Rensselaer Polytechnic Institute. 2005. May 2010.

[5] United States. Department of Energy. Solid state Lighting Energy Star Requirements. 9 Dec 2007. Dec 2009. <http://www.energystar.gov/ia/ partners/prod_development/new_specs/downloads/SSL_FinalCriteria.pdf $>$.

[6] Underwriters Laboratories Inc. UL 8750: Light-emitting diode Equipment for Use in Lighting Products. Standard for Safety. 25 Jan 2010. May 2010. 34.

[7] Shatil Haque (LumiLEDs). "Packaging of Power LEDs Using Thermosonic Bonding of Au-Au Interconnects." California Polytechnic State University. 14 April 2009.

[8] Incropera, DeWitt, Bergman, and Lavine. Introduction to Heat Transfer. Wiley. 2007. 6-7 \& 98-99.

[9] Electronic Industries Association. Integrated Circuits Thermal Measurement Method - Electrical Test Method (Single Semiconductor Device). December 1995. November 2009. < http://www.jedec.org/standardsdocuments/results/taxonomy:2480>.

[10] Y.Xi and E. F. Schubert. "Junction-temperature measurement in GaN ultraviolet light-emitting diodes using diode forward voltage method." Applied Physics Letters. Volume 85, Number 12. September 2004. September 2009.

[11] Vektrex Electronic Systems Inc. "Measuring LED Junction Temperature. 2009. $<$ http://www.vektrex.com/Support/kb/InSitu\%20Junction\%20Temperature\%20.pdf $>$. 
[12] Fluke. 2x4 wire resistance simplifies precision measurements. 2006. Feb 2010. $<$ http://support.fluke.com/calibrationsales/Download/Asset/2557732_6200_ENG_A_W.PDF >.

[13] Gu, Y., N. Narendram, and J.P. Freyssiner. "White LED performance.” Fourth International Conference on Solid State Lighting, Proceedings of SPIE 5530. Bellingham, WA: International Society of Optical Engineers. 2004.

[14] Buso, Simone, Giorgio Spiazzi, Matteo Meneghini, and Gaudenzio Meneghesso. "Performance Degradation of High-Brightness Light-emitting diodes Under DC and Pulsed Bias." IEEE Transactions on Device and Materials Reliability. Vol. 8, No. 2, June 2008. Jan 2010.

[15] Cao, X. A., Stokes, P. M. Sandvik, S. F. LeBoeuf, J. Kretchmer, and D. Walker. "Diffusion and Tunneling Currents in GaN/InGaN Multiple Quantum Well LightEmitting Diodes.” IEEE Electron Device Letters. Vol. 23, No. 9, September 2002. April 2010.

[16] Meneghini, Matteo, Lorenzo-Roberto, Gaudenzio Meneghesso, and Enrico Zanoni. "A Review on the Reliability of GaN-Based LEDs." IEEE Transactions on Device and Materials Reliability, Vol 8, No 2, June 2008. November 2009.

[17] Sze, S. Physics of Semiconductor Devices. $2^{\text {nd }}$ Edition, Wiley, 1984. May 2009.

[18] Philips LumiLEDs. LUXEON Rebel Thermal Measurement Guidelines. Application Brief AB33. 2008. <http://www.philipslumileds.com/pdfs/AB33.pdf>.

[19] Philips LumiLEDs. LUXEON Rebel Assembly and Handling Information. Application Brief AB32. 2008. <http://www.philipslumileds.com/pdfs/AB32.pdf>.

[20] Wikipedia. "FR-4." <http://en.wikipedia.org/wiki/FR-4>. Accessed February 2010.

[21] Philips LumiLED. Power light source LUXEON Rebel. Technical Datasheet DS56. This datasheet has been replaced by DS63. 2007.

[22] Philips LumiLEDs. LUXEON Rebel Illumination Portfolio. Technical Datasheet DS63. 2010.

[23] Levine, David M., Patricia P. Ramsey, and Robert K. Smidt. Applied Statistics for engineers and scientists. New Jersey: Prentice-Hall Inc, 2001. 


\section{Appendices}

\section{Appendix A - Data Acquisition System}

\section{A.1 Schematic}

Unfortunately, I did not know how to use the sheet function of the software when I made the circuit. Each sub-circuit is separated onto a separate appendix page.
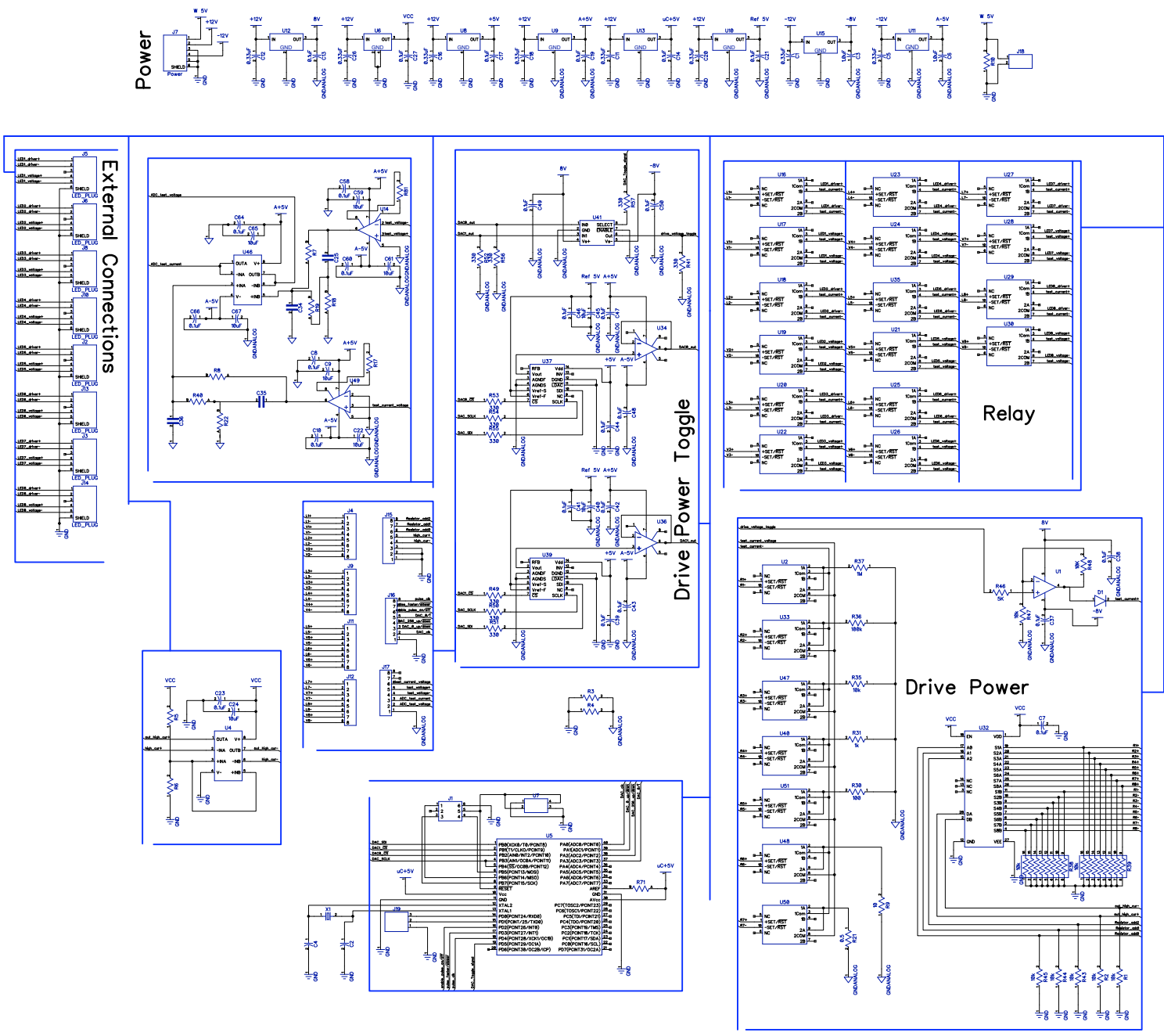

Overview of custom data acquisition interface board 


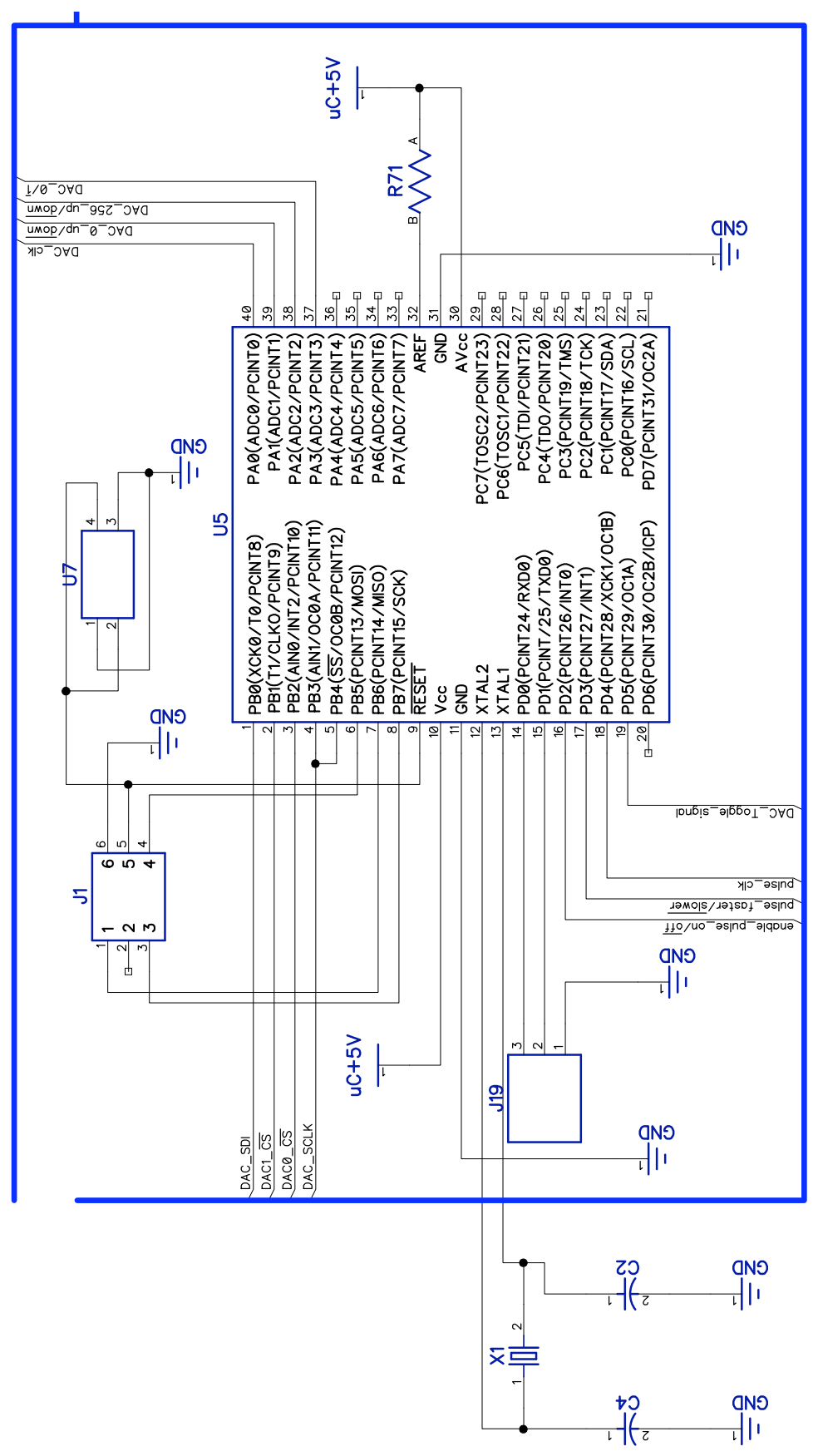

Schematic of microcontroller circuit 


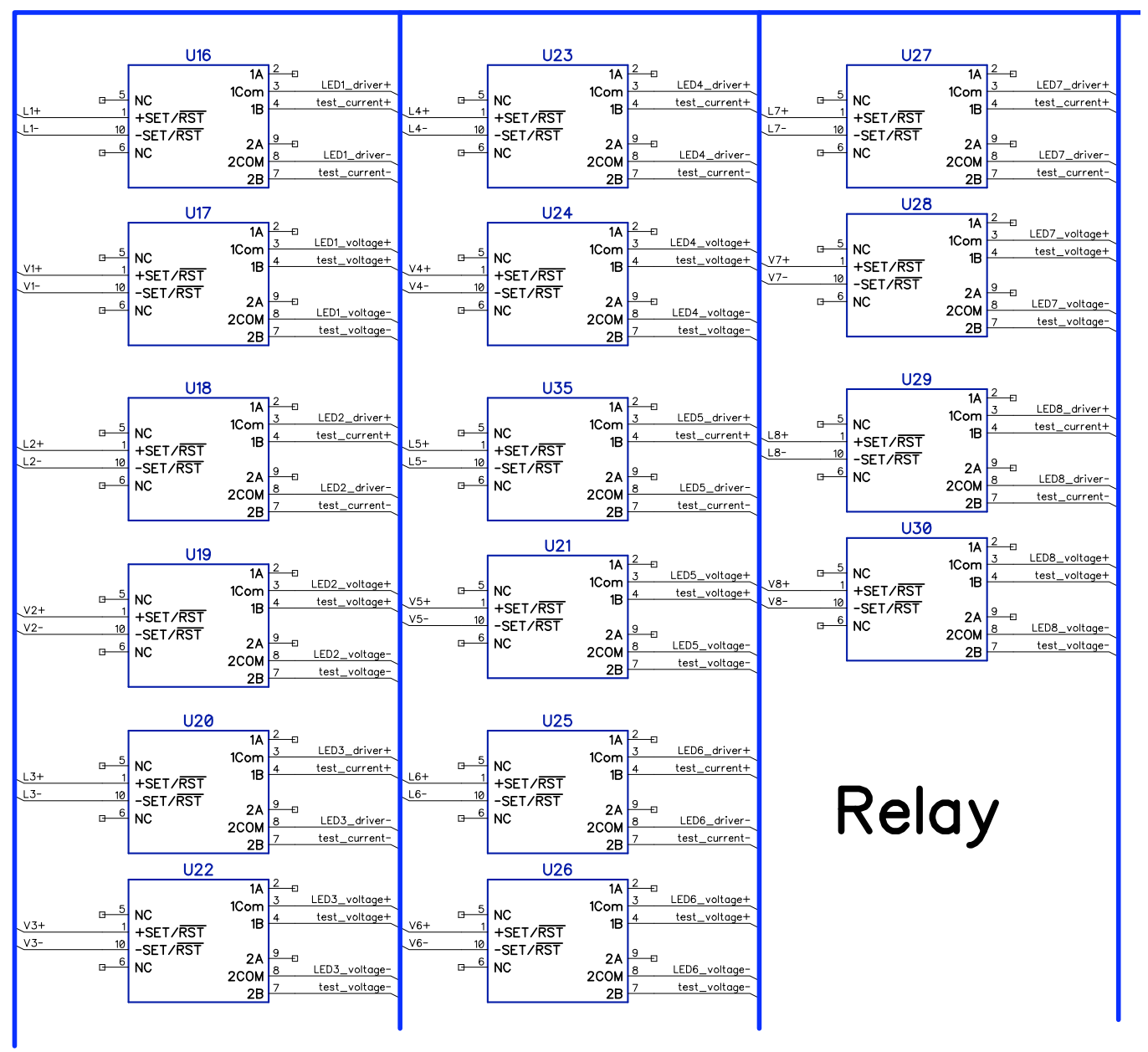

Schematic of LED multiplexing relays 


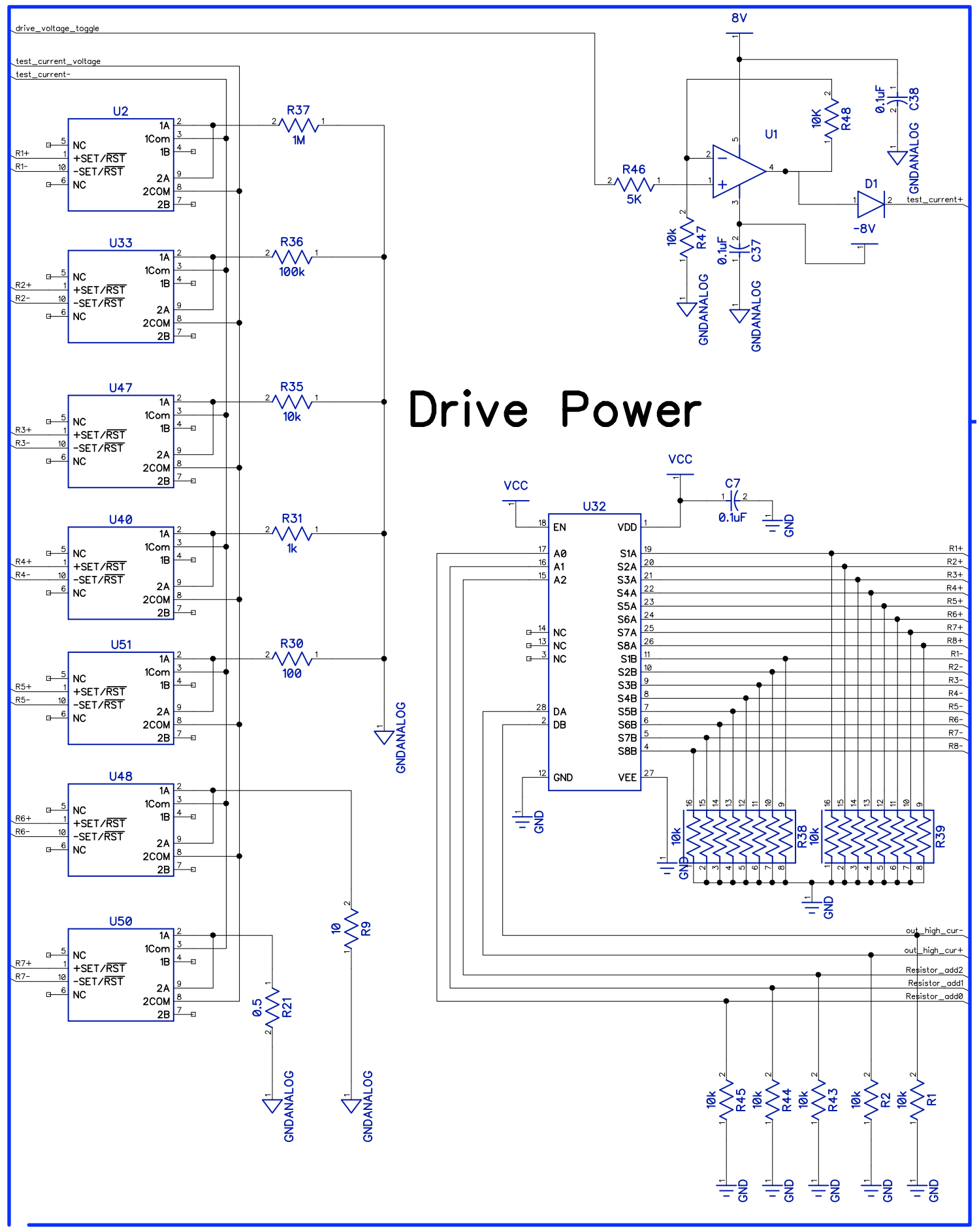

Schematic driver circuit with current range selection relays 


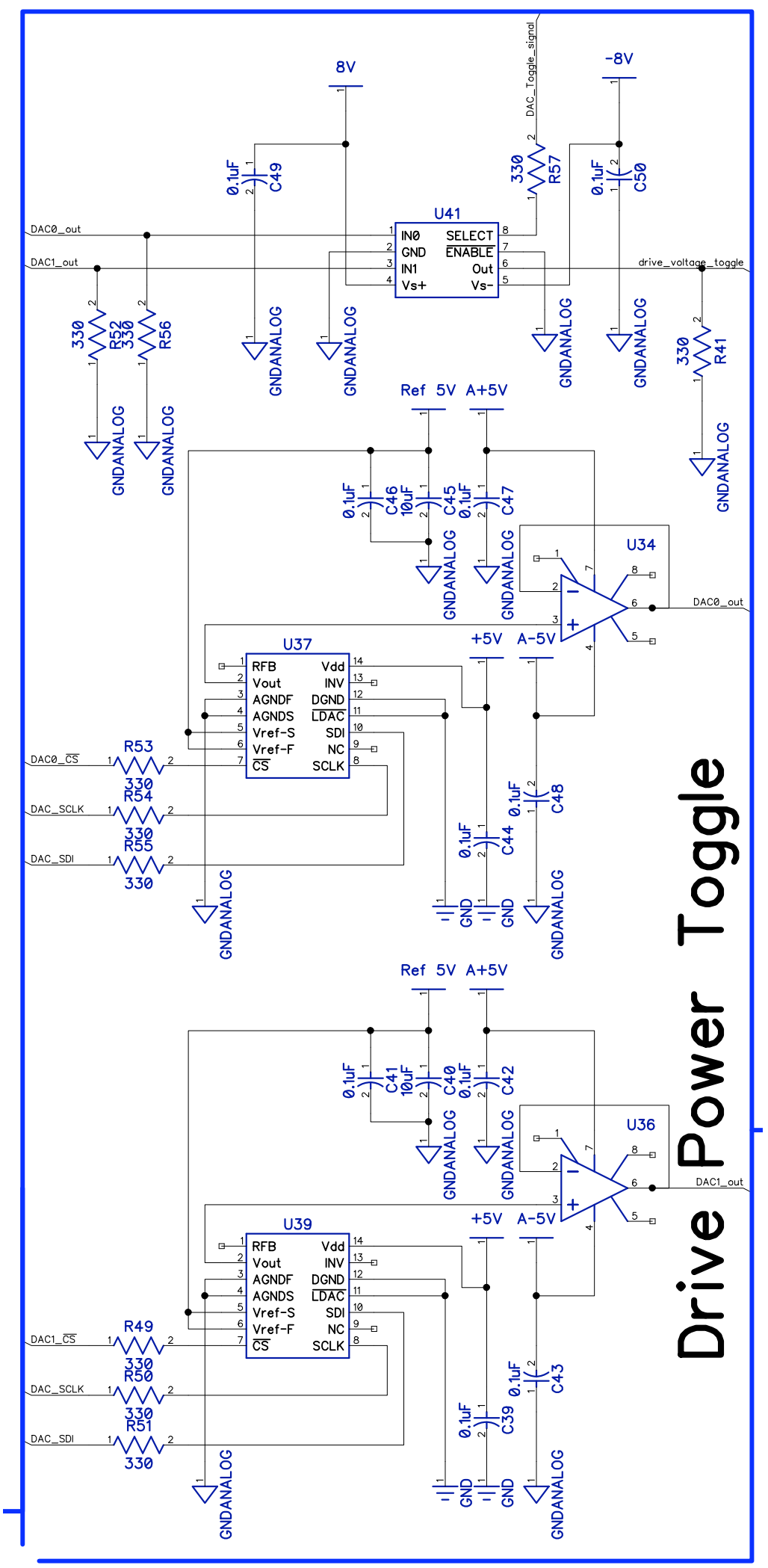

Schematic to toggle LEDs on and off. 


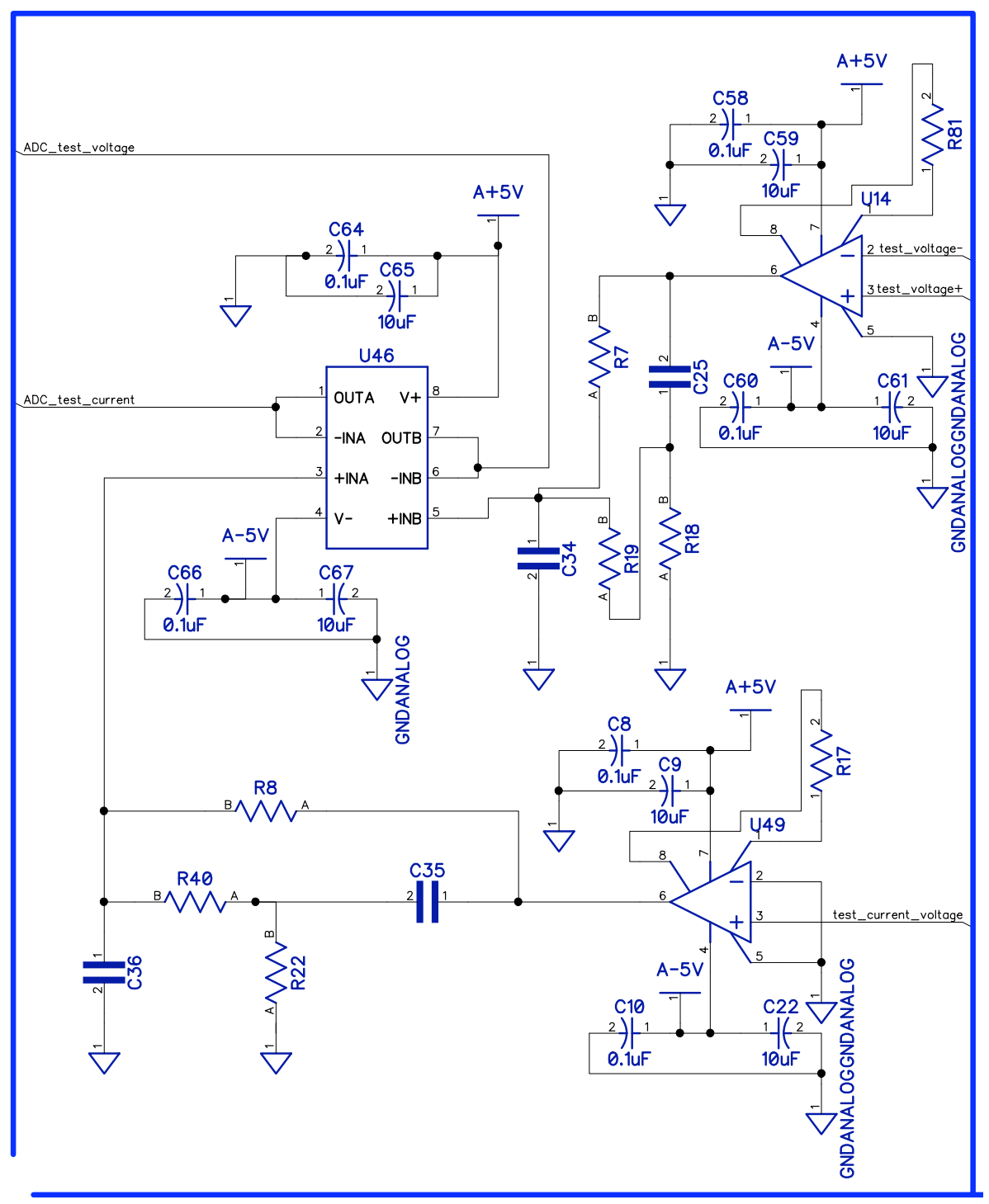

Schematic of optional analog band-pass filter 


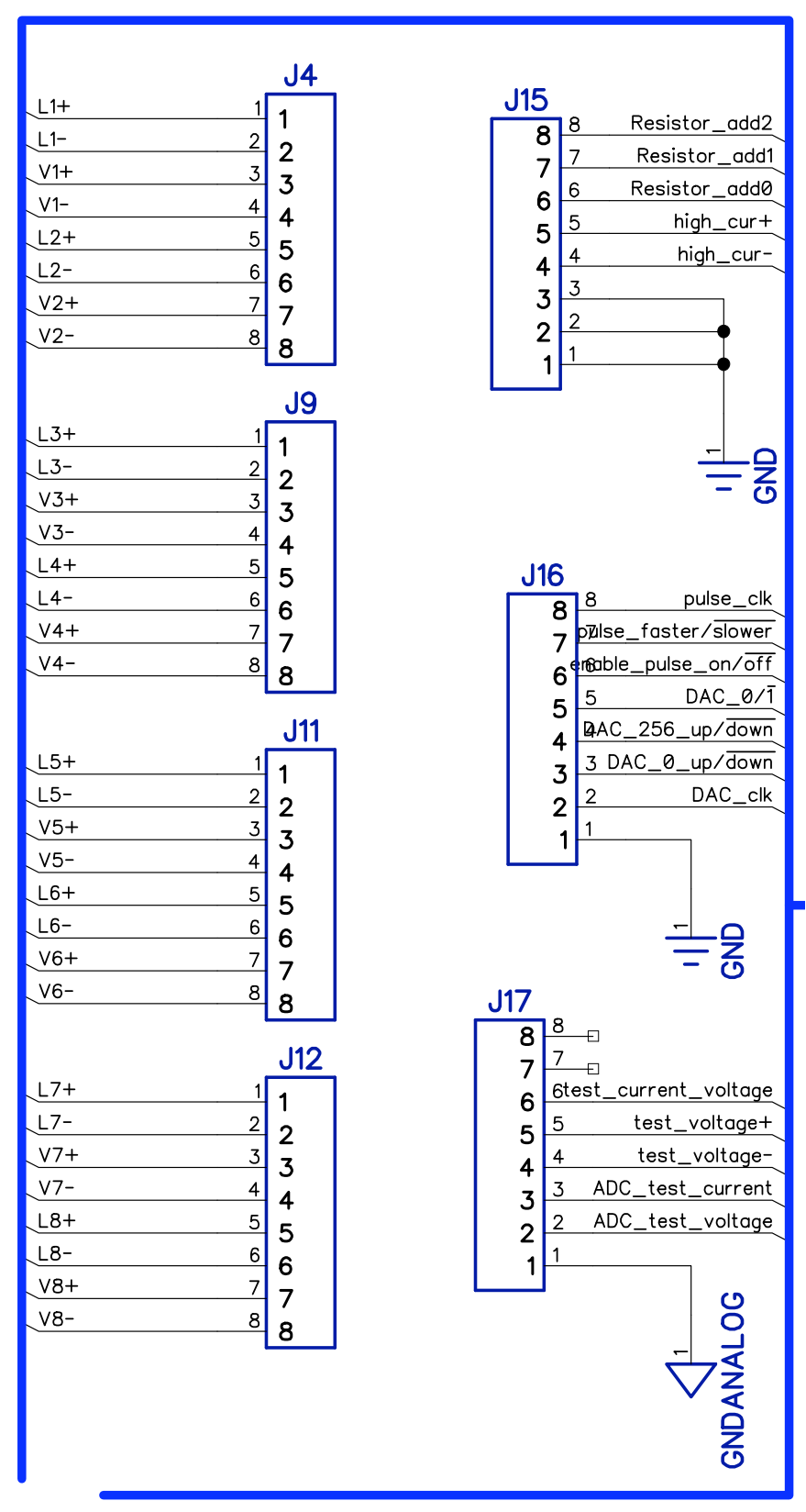

Schematic of terminal blocks for connecting with NI PCI DAQ card 


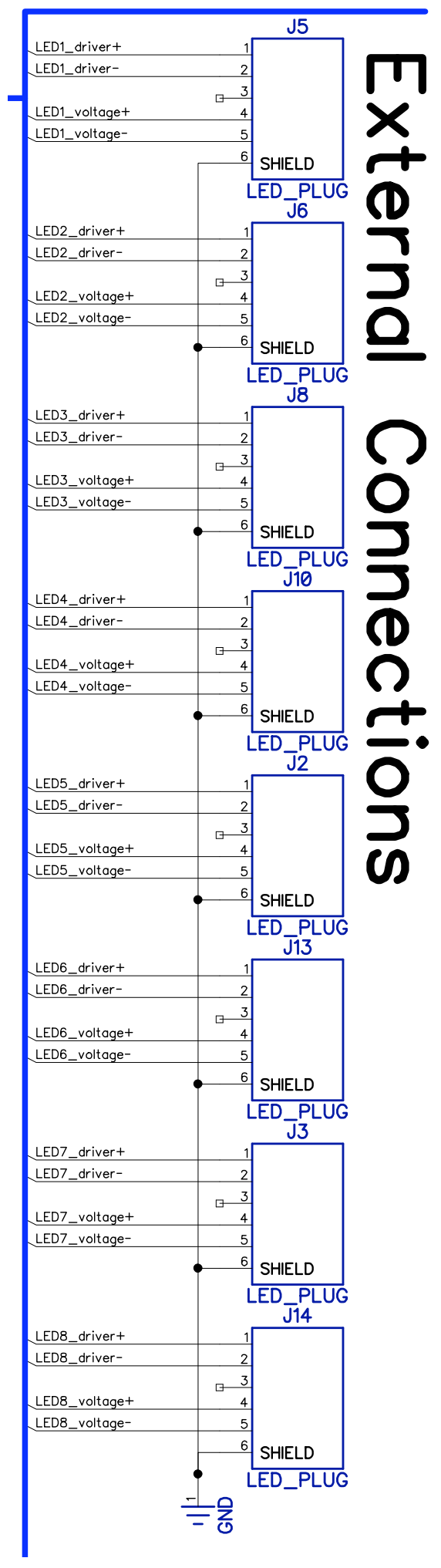

Schematic of LED connectors

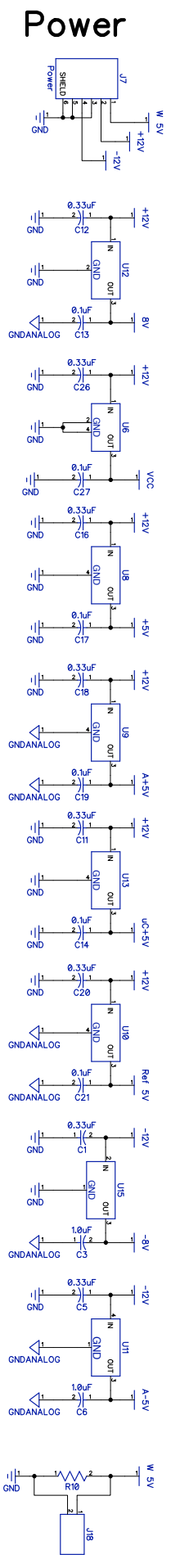

Schematic of power distribution. 


\section{A.2 Layout}

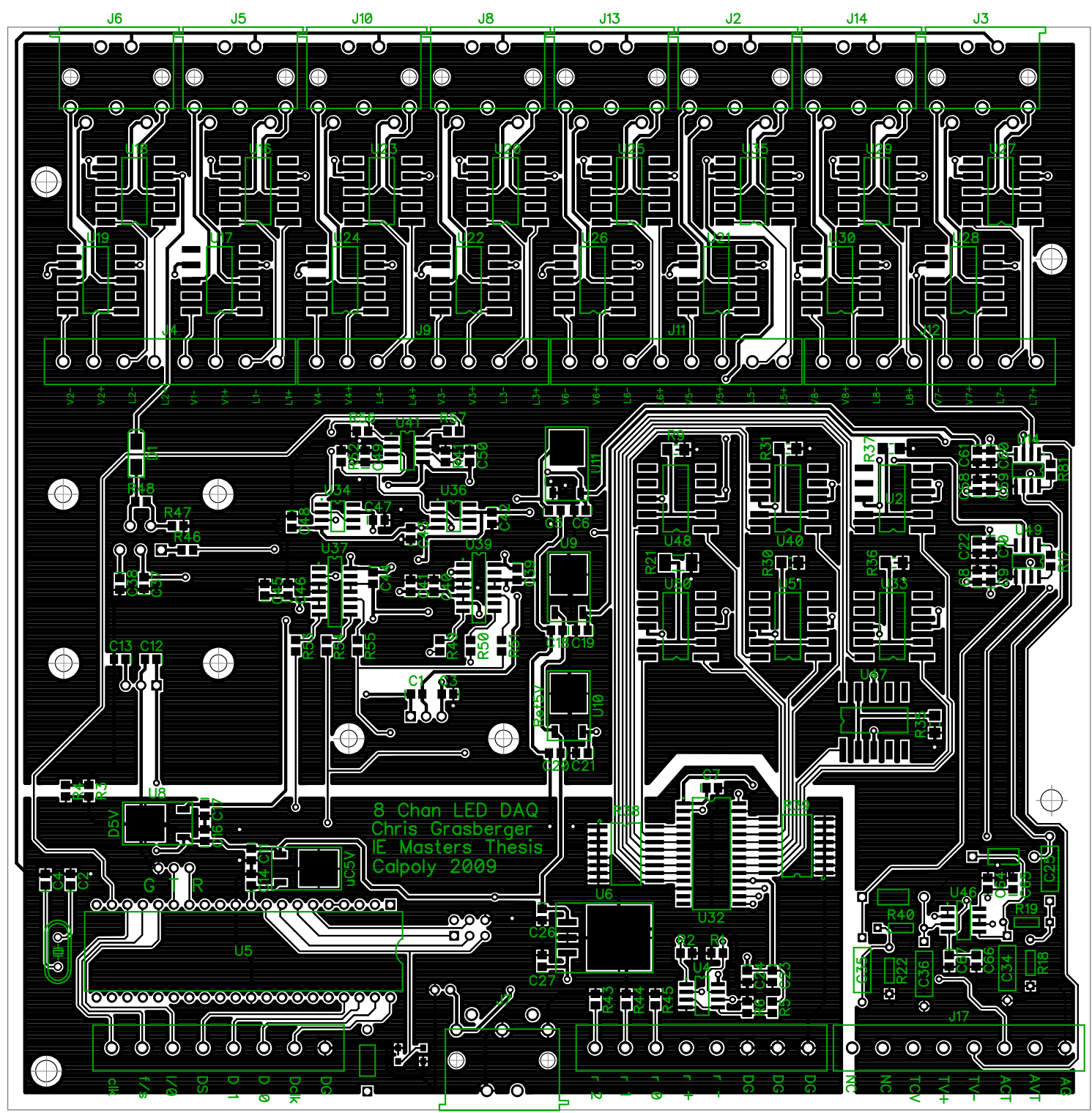

Top layer of the PCB layout for interface board 


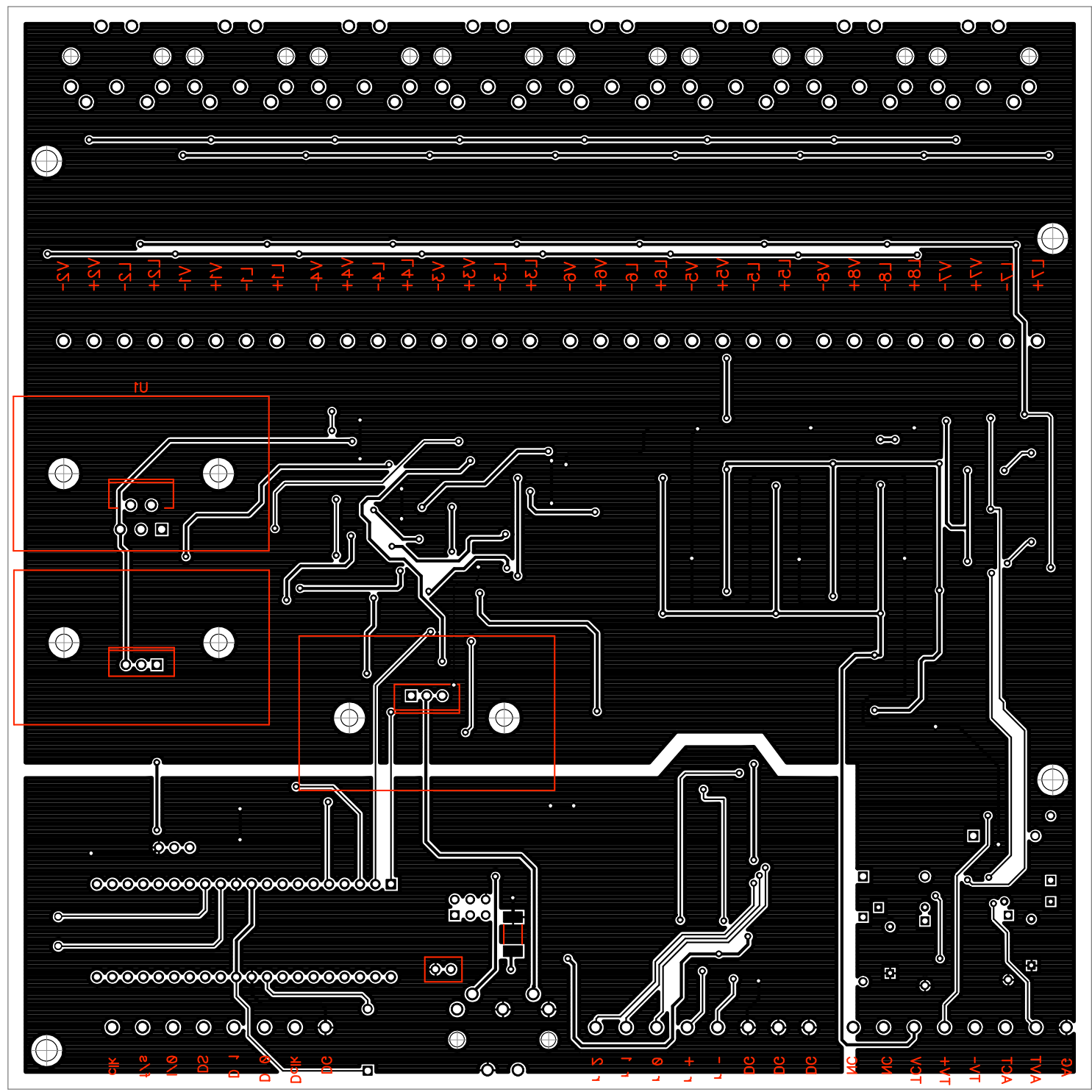

Bottom layer of PCB layout for interface board 


\section{A.3 Pinout from Interface board to NI Breakout Boards}
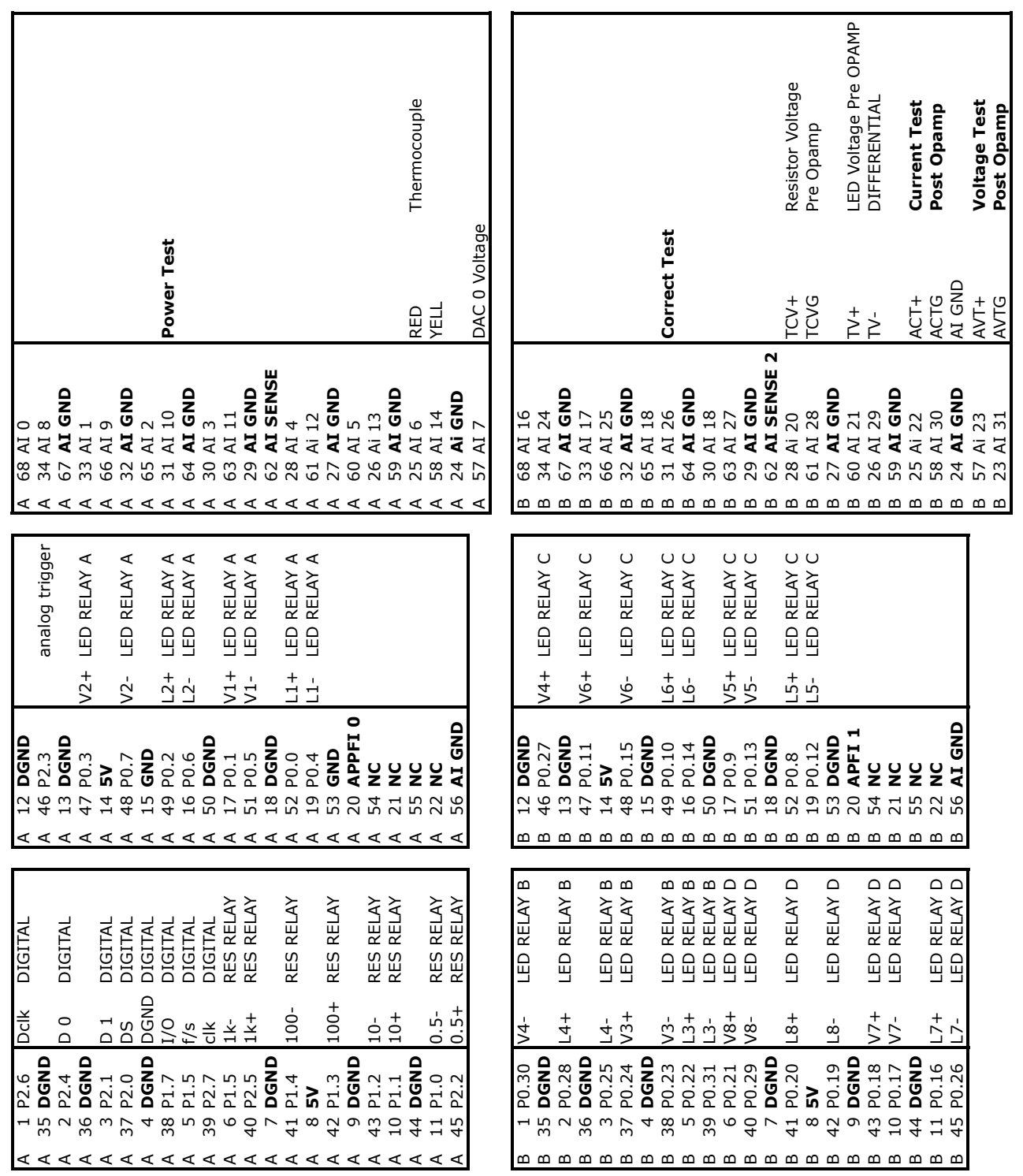


\section{A.4 LabView Interface Screenshots}

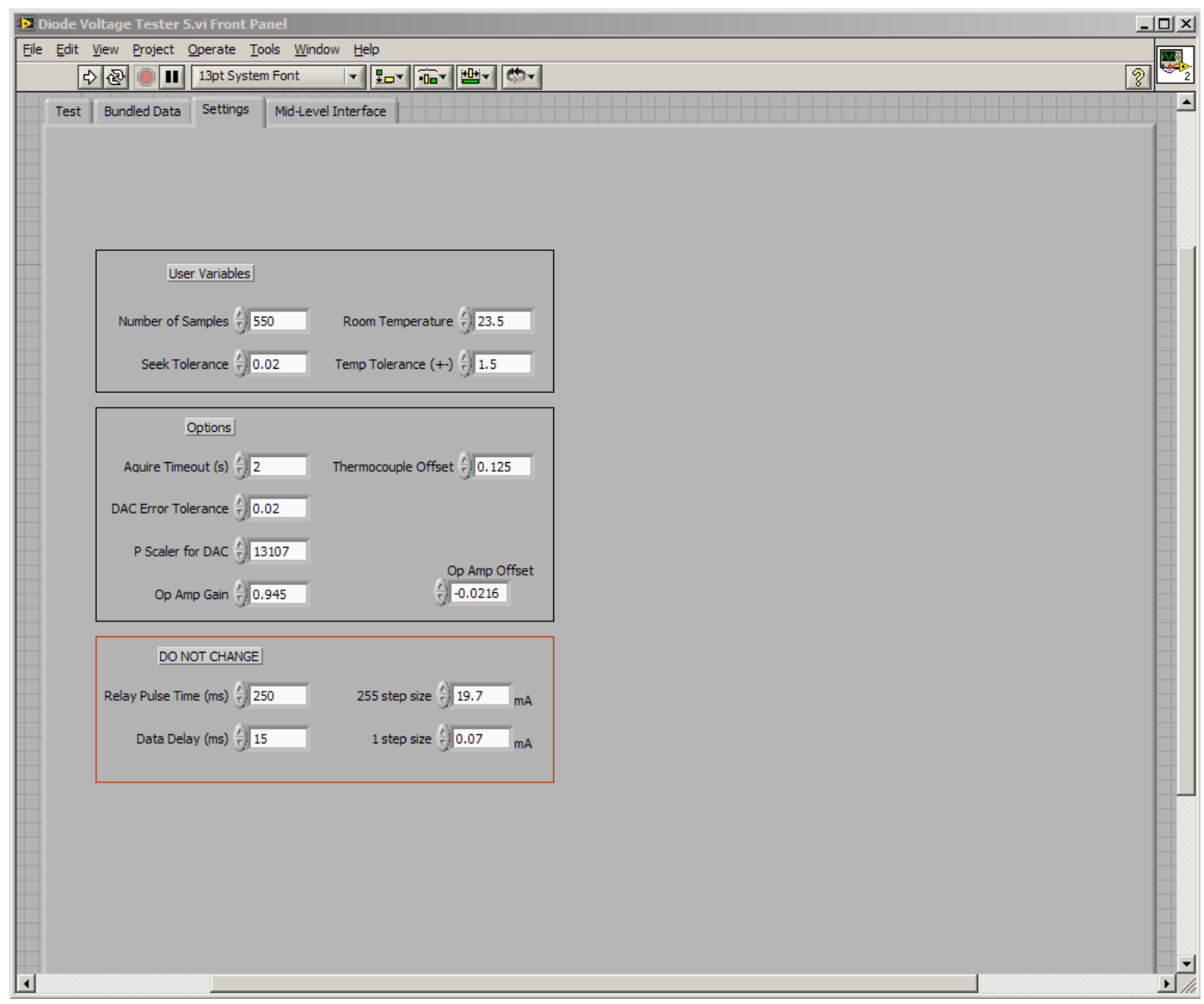

Screen shot showing the settings tab. This tab can be used to adjust timing, thermocouple offsets, and other values. 


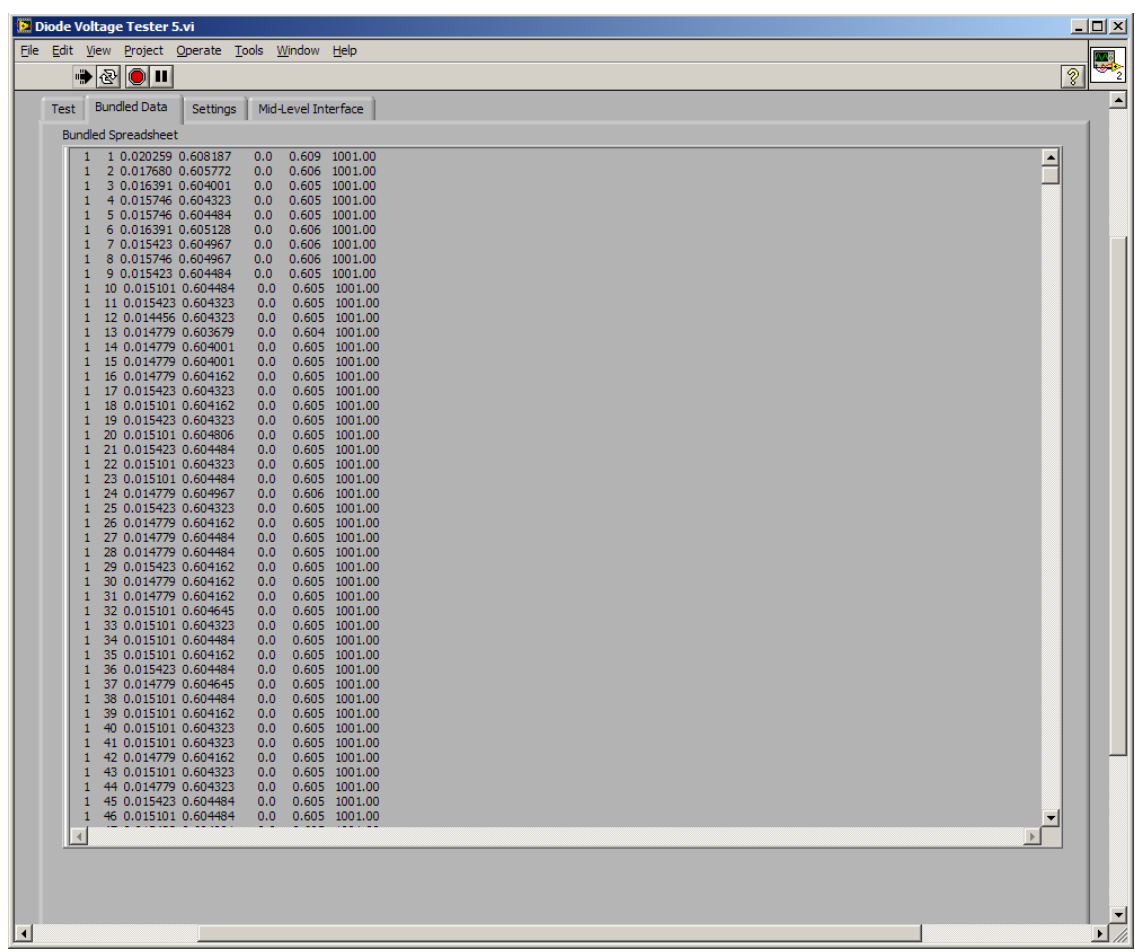

Screen shot of the "Bundled Data" tab. Each time the "Next Data Group" button is pressed, the collected data is added to the Bundled Data table as a set of 6 columns next to the one shown above.

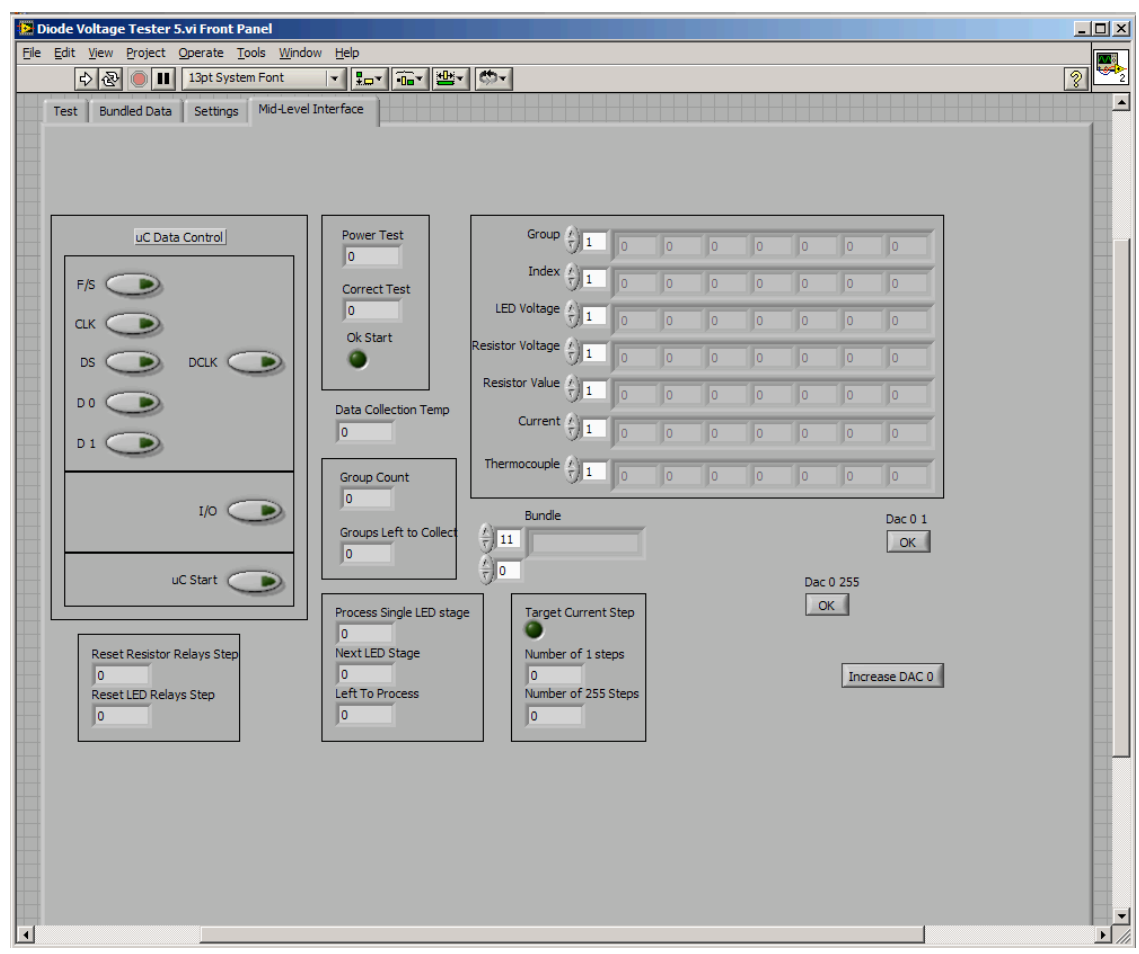

This is the mid-level interface tab. This tab shows the primary tools used in the main user interface on the test tab. 


\section{A.5 Bill of Materials}

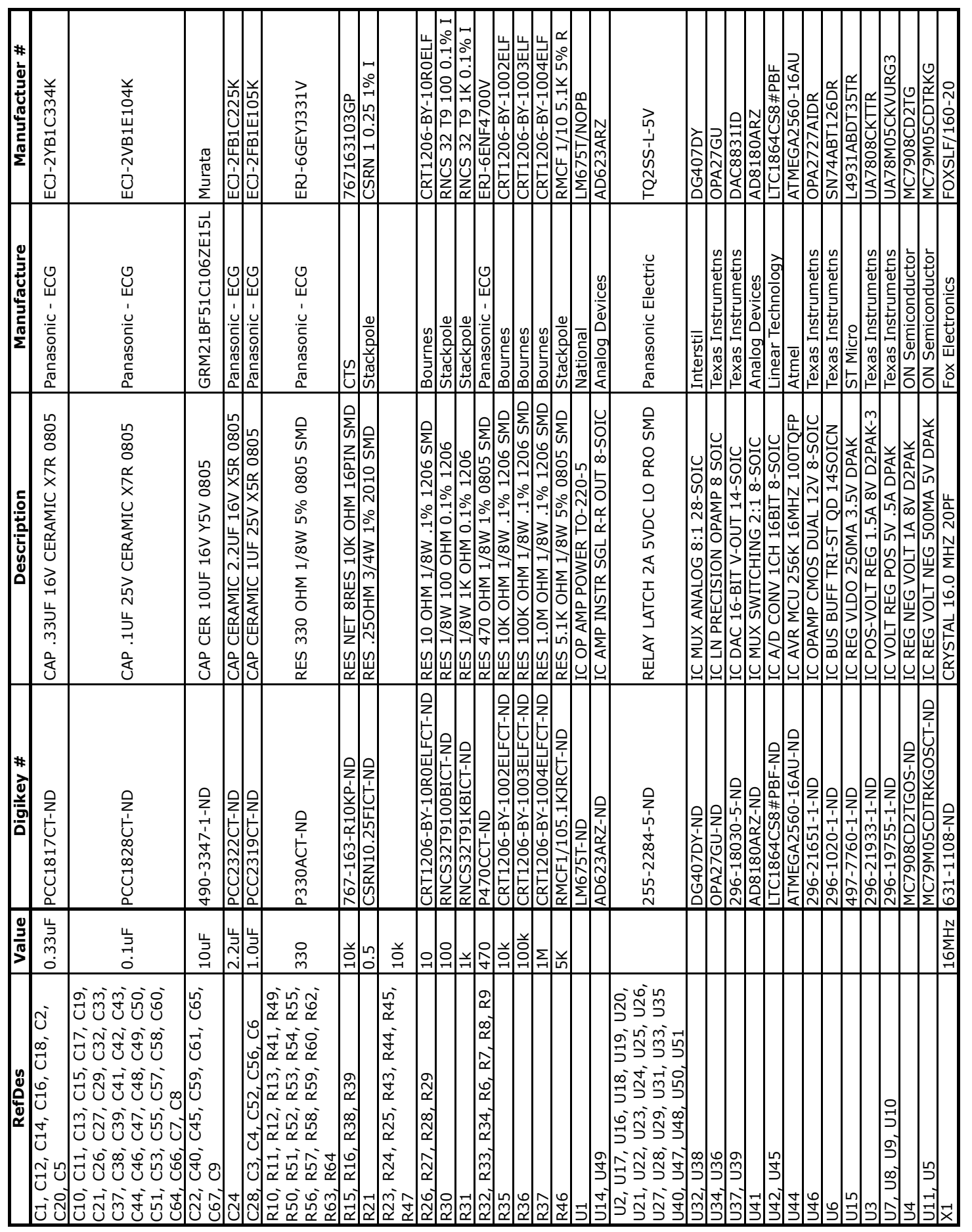




\section{A.6 Chassis Design}

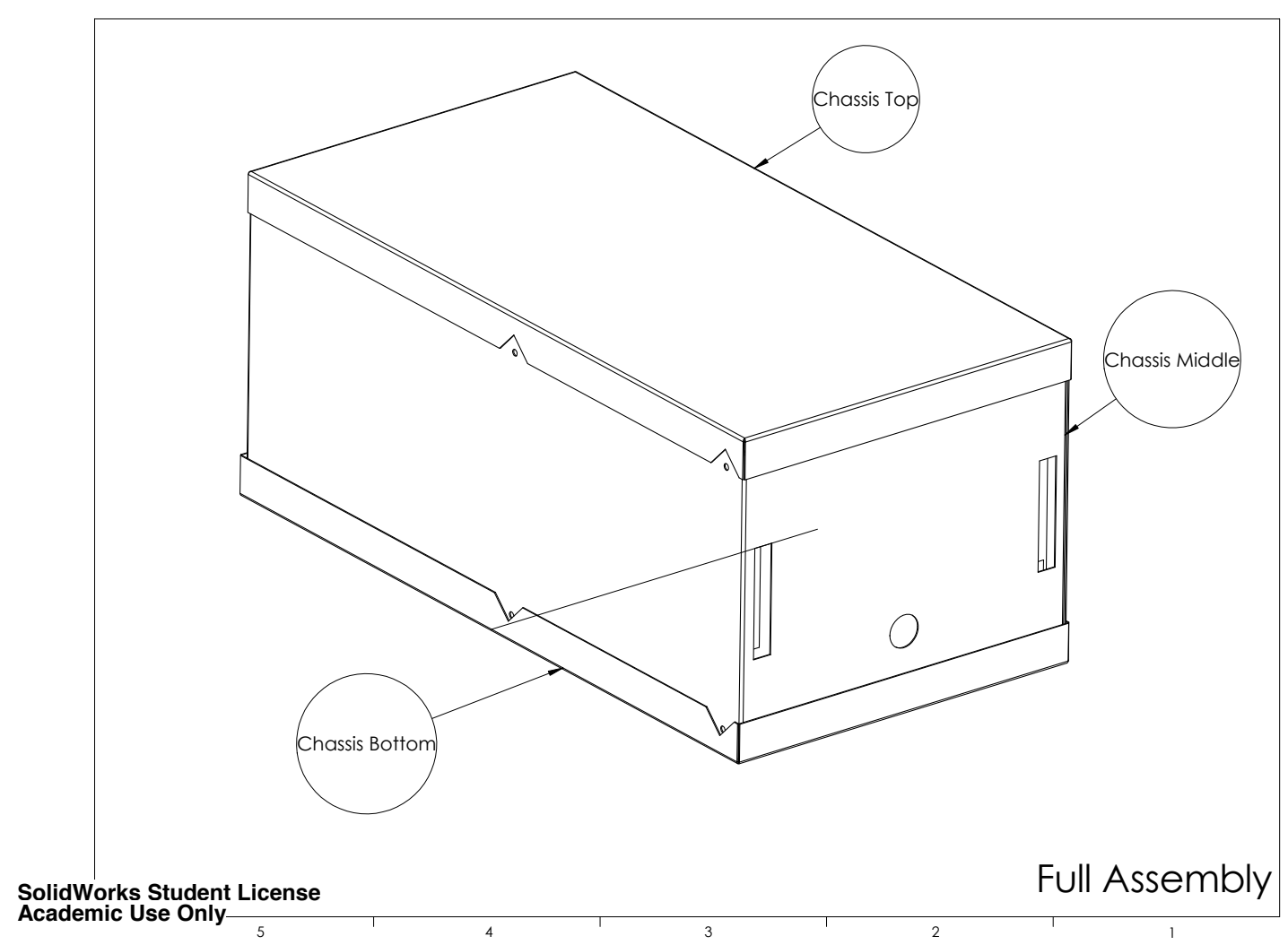



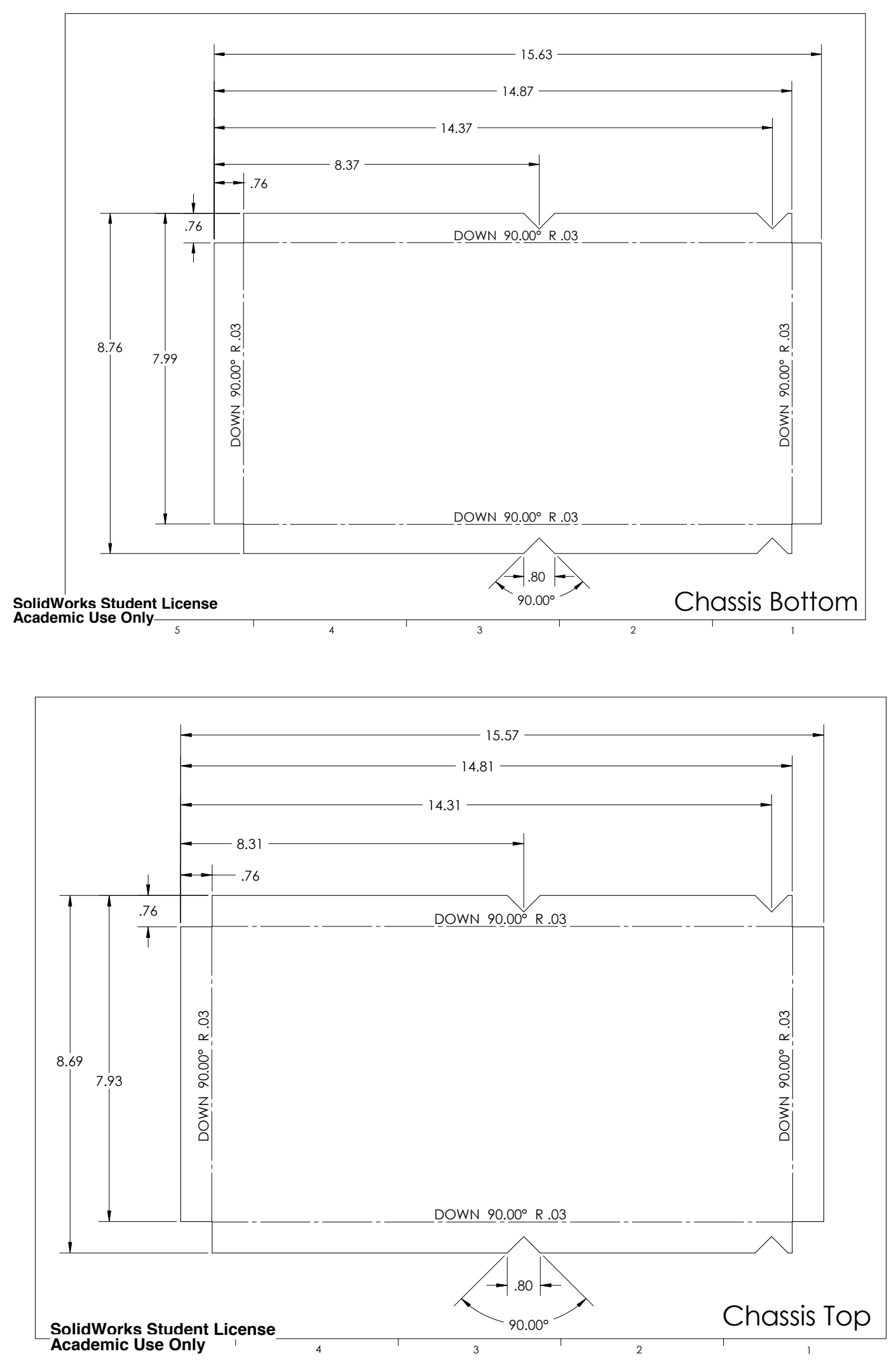

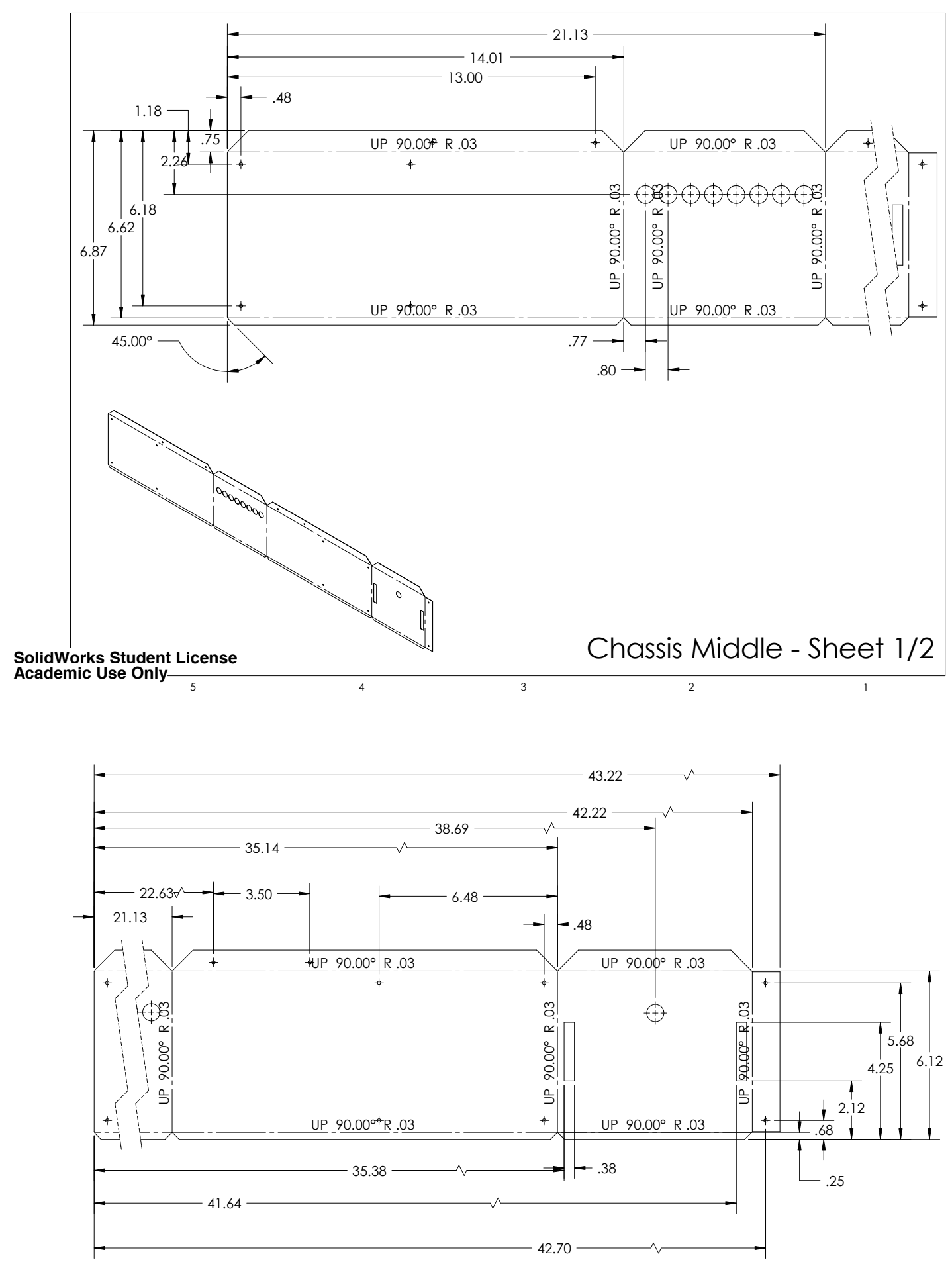


\section{Appendix B - Test Environment}

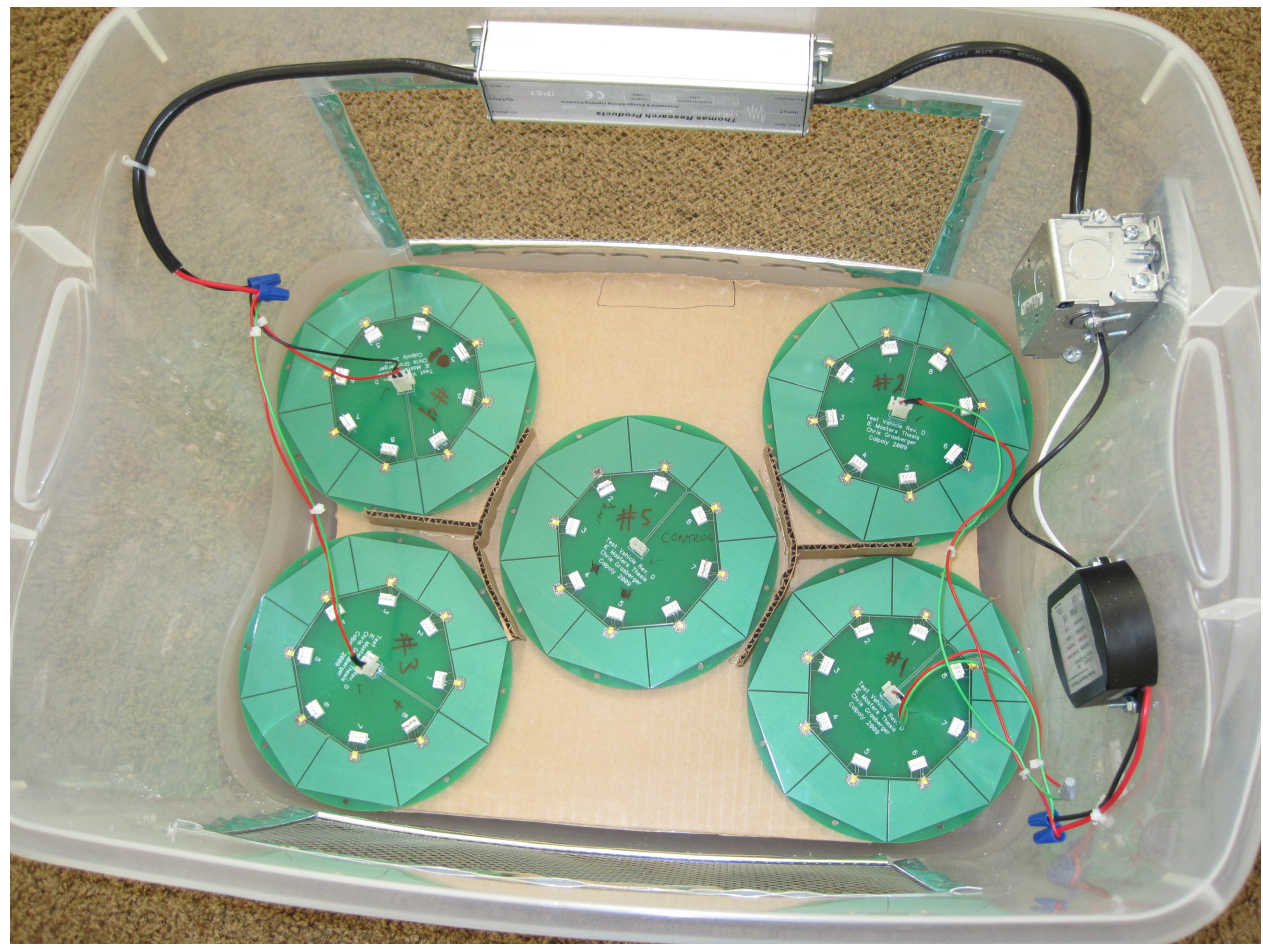

Box built to protect LEDs during aging

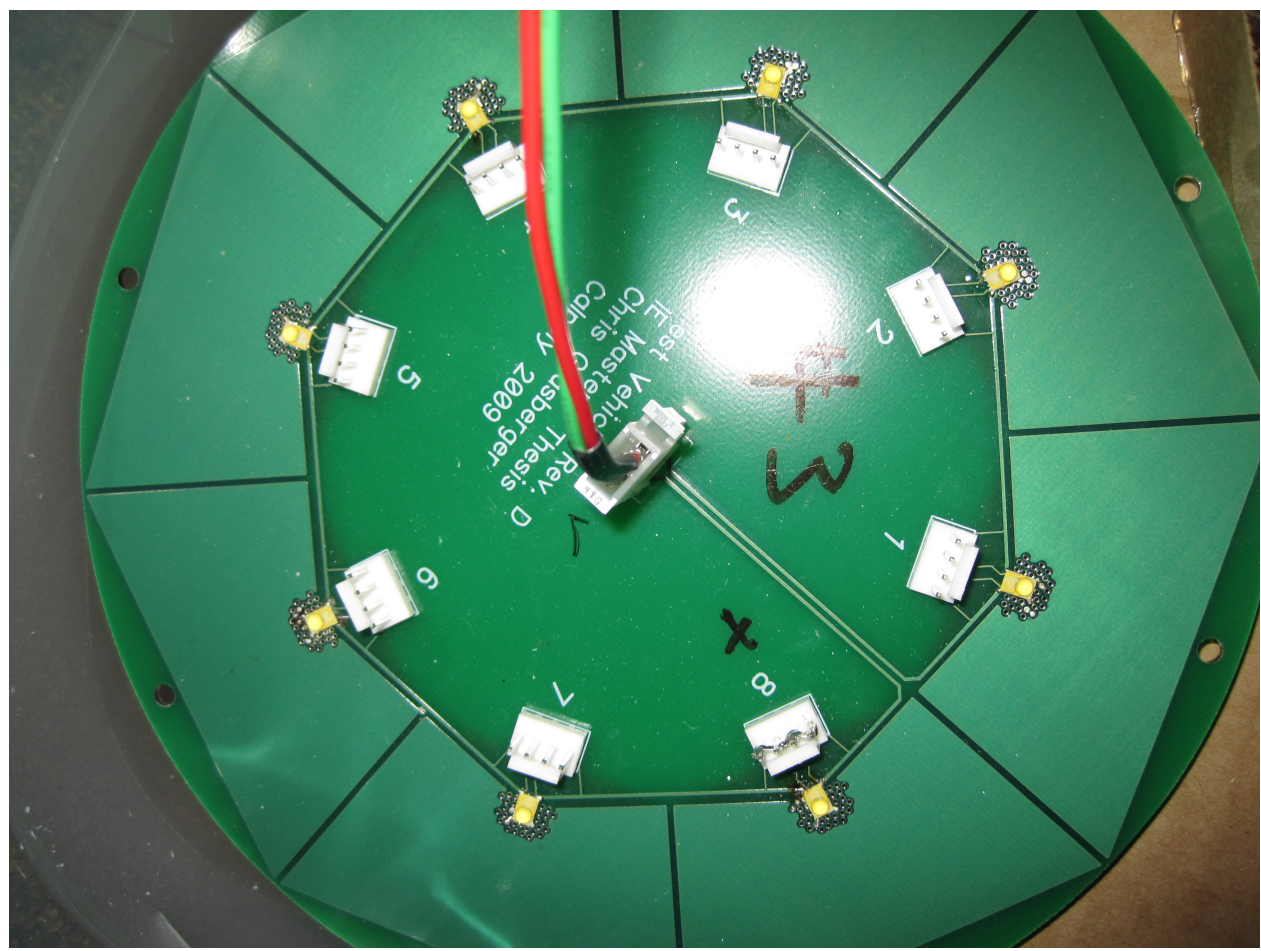

Close up of a test vehicle with 8 LEDs 


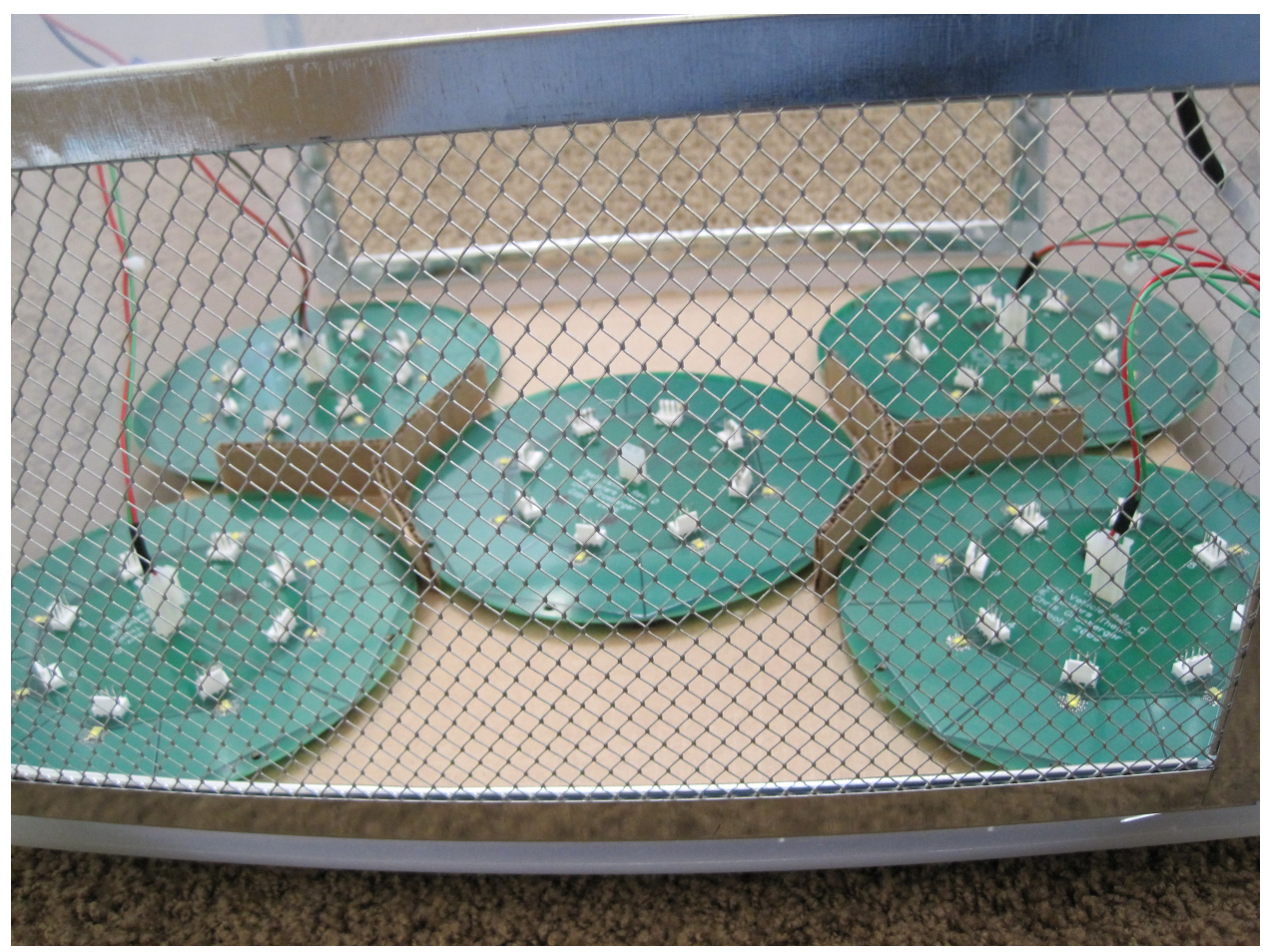

Air vent in test box to circulate air

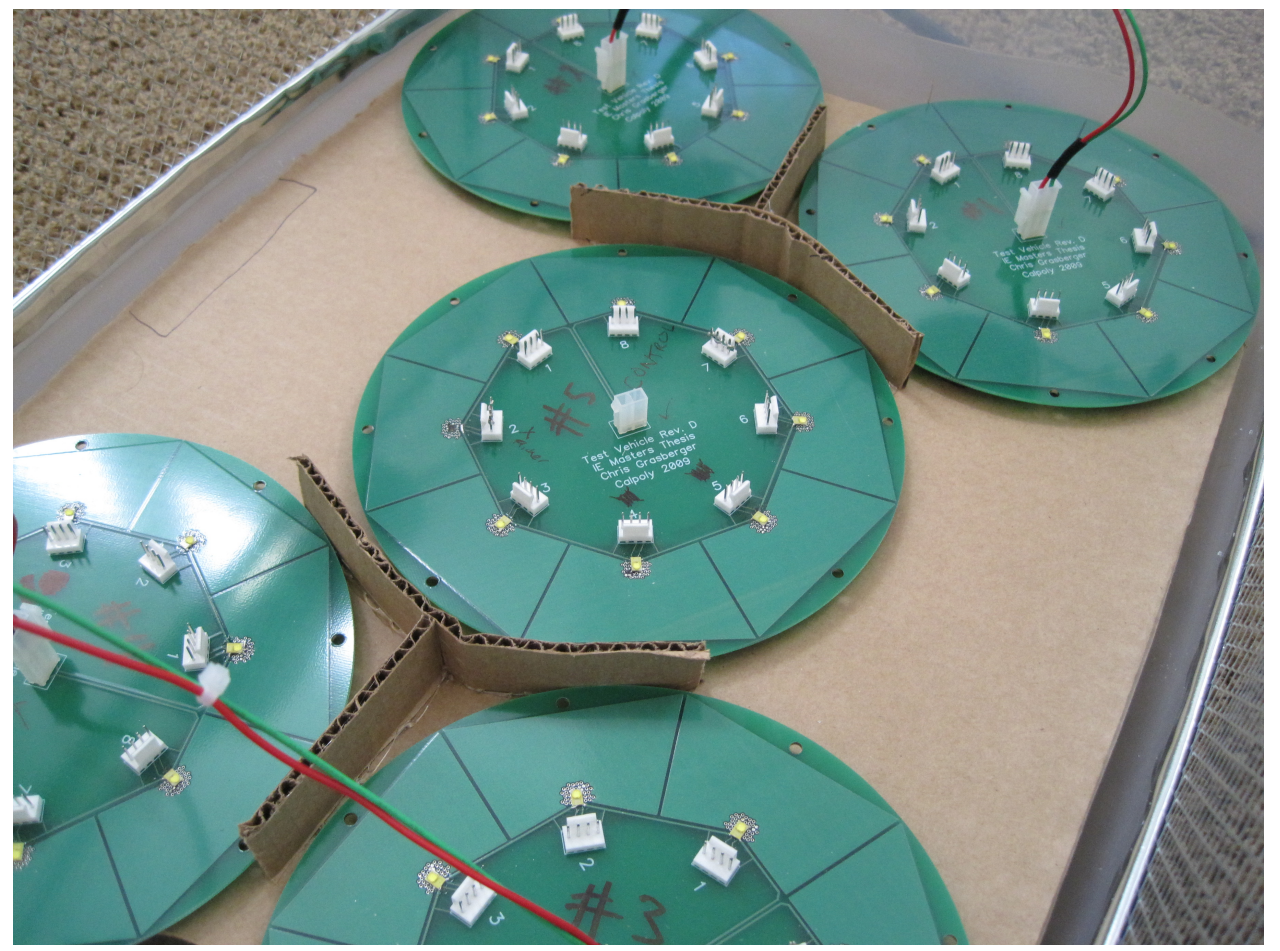

Test groups at both ends of the box with the control in the center 